\title{
A Systematic Literature Review of Blockchain Technology for Smart Villages
}

\author{
Parminder Kaur ${ }^{1} \cdot$ Anshu Parashar ${ }^{1}$ (D)
}

Received: 13 May 2021 / Accepted: 1 October 2021 / Published online: 27 October 2021

(c) CIMNE, Barcelona, Spain 2021

\begin{abstract}
According to the United Nations, Sustainable Development Goals are framed for improving rural health, hunger, poverty issues, environmental conditions, and illiteracy globally. With the upcoming technology, there have been many advances in the lifestyle of people all around the world. Comparatively, more emphasis has been given to the development of urban areas than rural. The sustainable development of a country depends on the growth of its rural areas. Countless technological and theoretical models, projects, and frameworks have been proposed and implemented to help overcome sundry issues and challenges faced by rural people in quotidian life. New technological methods are deemed to be the future of livability, therefore; a technologically advanced solution for sustainable rural development is called for. Blockchain Technology is the next step for innovation and development and it has far many applications in sustainable rural development that are yet to be discovered. The objective of this paper is to explicitly review research conducted in rural development to fill the undone work in the future with better research ideas, to make rural areas a livable and advanced place while also maintaining their integrity leading to sustainable development. To conduct such a review, a systematic research methodology is applied following regulations in the conduction of standardized but explorative analysis. Within the timeline of 2010-2021, 112 papers are carefully selected to perform the systematic review. This review will provide a comprehensible as well as concise research compendium for all applications proposed, implemented, and possible in the future to realize the concept of smart villages for the development of rural areas using blockchain technology.
\end{abstract}

Anshu Parashar

aparashar@thapar.edu

Parminder Kaur

pmakode_me19@thapar.edu

1 Thapar Institute of Engineering and Technology, Patiala,

Punjab, India 


\section{Graphic Abstract}

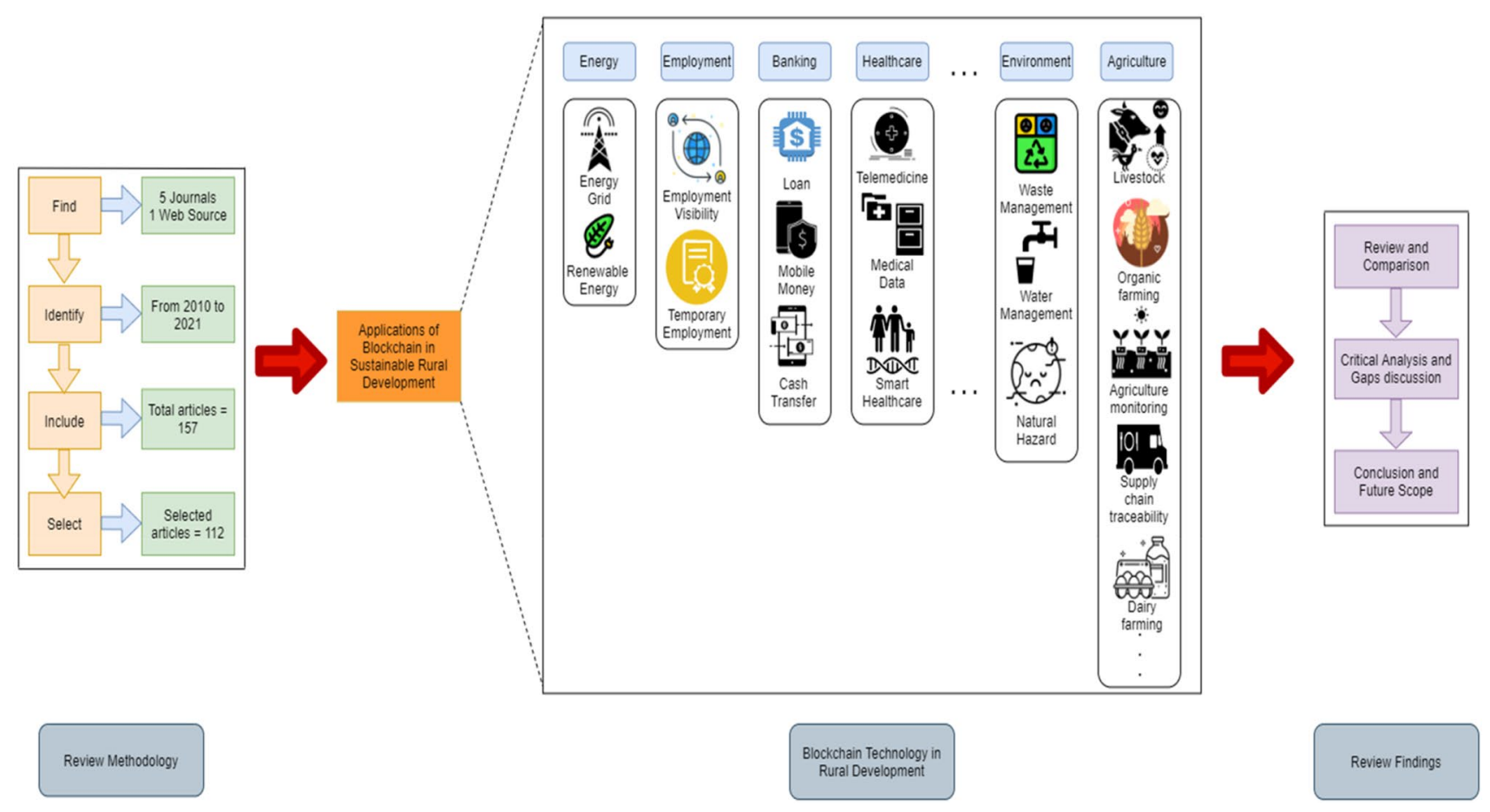

\section{Introduction}

The development of a country partly depends on how well connected are its rural areas to the global chain and how technologically advanced they are. Rural areas as we know of are geographical locations sited outside town or cities with fewer populations. Essentially, we also know it as a place unprivileged of vital necessities, stricken by poverty [1], and unemployment. For many years, rural areas have been developing consecutively in Technology, Education, Housing, Governance, Human rights. Accordingly, the world's rural population has dropped from 66.389 percent in 1960-44.286 [2] percent in 2019 due to various transformations. Years ago, people in rural areas were deprived of necessities such as water, electricity, and education. Even getting a reliable source of electricity was a strenuous effort. Moreover, female rights, reliable healthcare and subsequently securing a job were more of a dream. According to the United Nations, there can be seen a steady drop in the percentage of people residing in rural areas from 1960 to 2019 [3]. What was the core reason behind it? A general example of the reason can be migration, rural decline, demographic qualities, natural disasters, and infrastructure: transportation or socio-economic. These can further be exploited into many explanations as to what leads to those choices.
Rural-Urban migration itself directs catastrophic changes in the environment and economy. Rural Decline is another consequence of migration that drains the area of services, businesses, and social capital forcing the development of the

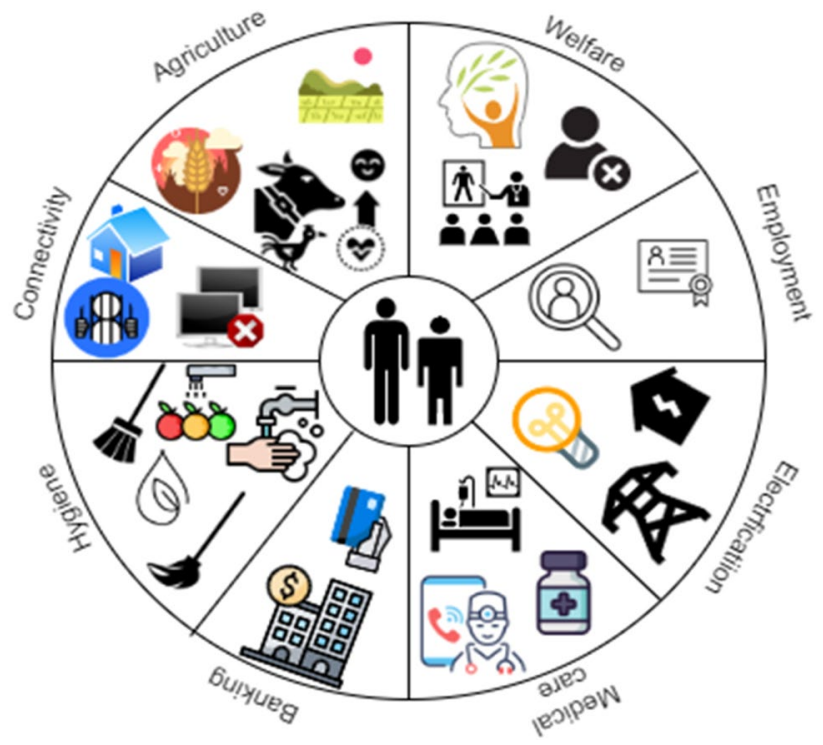

Fig. 1 Issues in rural areas 
rural area to halt or probably diminish [4]. Even then, almost half of the world's population comes under rural areas and it consists of many more issues than resolvable.

\subsection{Background}

This section explores the interdependent backdrops of the rural area and a feasible solution through the concept of smart villages. Sustainable development goals with respect to Blockchain Technology are discussed in sub-Sect. 1.1.2 and a brief introduction on Blockchain Technology and development techniques are mentioned in sub-Sect. 1.1.3.

\subsubsection{Rural Development}

Sustainable Development Goals (SDGs) were framed for improving rural health, hunger, poverty issues, environmental conditions, and illiteracy globally. The present situation of rural areas brings us to a list of issues (Fig. 1) that can further promote the eradication of rural areas from the global chain if not technologically. Beginning with poverty which has been an issue unresolved regardless of the various monetary schemes provided by the government drives the young generation out of the community to find jobs to sustain daily needs. Many of them fail to finish even high school, which leads to securing menial jobs in urban regions. This brings us to the second issue in the rural community, illiteracy [5]. Education that plays a vital role in the overall development of humans, as well as the community, is often disregarded to fulfill contemporary requirements such as money. In many cases, the parents exploit their children into working on the farm or small family businesses.

Typical issues in a rural school can be enumerated as teacher's absenteeism, unhygienic school premises, and distant schools, technologically backward, absence of school records, inexperienced teachers, and teachers with false degrees. Those who get themselves educated, consider it better to get a job in urban areas because of job opportunities and better pay which is at times difficult since most villages lack communication between employees and job availability [6]. Basic hygiene and pollution are other issues in rural areas that deplete life expectancy and give birth to numerous diseases. Many rural communities do not have proper sanitation facilities, dumping grounds, or recycling plants. Not having the basic facilities drives people into a lack of personal hygiene such as bathing, washing, and cleanliness [7]. Pollution of land and soil is prevalent due to unhealthy sanitary practices. Hundreds of people still live without washing their hands leading to diarrhea, cholera, and the death of children [8]. Acknowledging the fact that medical practitioners, physicians are scarce on top of that reaching a nearby multispecialty hospital takes a lot of time [9]. The primary activity of rural people is said to be agriculture. It is considered to be the basic source of income for the dwellers. Farmers in many areas remain uninformed about the recent advancements in agro-technologies. The core reason for this incomprehension is the lack of broadband connection and incentives. Even though the Government provides various monetary as well as agricultural schemes, more than half of the farmers fail to enroll in one [10]. In addition to that from the consumer's point, there is a whole heap of issues relating to the certification of quality produce, improper monitoring of crops, traceability of farm produce, and unsustainable agro-activities. Besides, the involvement of middlemen leaves the farmers with the minimal price of agricultural produce [11]. Further, given the aspects of daily needs, approximately 940 million [12] people around the world live without access to electricity, most of which belong to rural areas. In a generation where electricity is the basic need in every household, industry, medical center without which the whole institution of Earth would come to a halt, there are still people who do their daily activities without it [8,9]. About 1.7 billion [13] people in the world are still unbanked. The banking facility is essential for financial assistance especially much needed to financially excluded dwellers of the rural community. However, due to unreachable banking locations, time-consuming Banking processes, and in many cases lacking identity proof constrains the adults from applying for a bank account further reducing the chances of obtaining a loan or funding from government schemes [14].

The concept of a smart village [15] is to develop a rural area using technology as a medium. The biggest problems in rural areas are financial exclusion, poverty, hygiene, and education [16]. All the issues are interconnected and codependent, such as due to poverty, children in rural areas fail to get an education [17]. Due to illiteracy, the villagers do not come to know about various financial schemes. People seem to care very less about hygiene. Not only the waste is disposed of incorrectly, but it is also burnt giving rise to environmental pollution. Most of the time people do not find encouragement to learn how to properly discard waste material, to get educated, or find a solution to their financial problems [18].

\subsubsection{Sustainable Development and Blockchain}

The development of an economically backward area without jeopardizing the natural assets or future necessities is termed sustainable development. According to the United Nations, Sustainable Development Goals (SDG) [19] were adopted in 2015 for improving rural health, hunger, poverty issues, environmental conditions, and illiteracy globally (Fig. 2). The sustainable development goals that balance the socioeconomic and environmental factors are: 
Fig. 2 Sustainable development goals

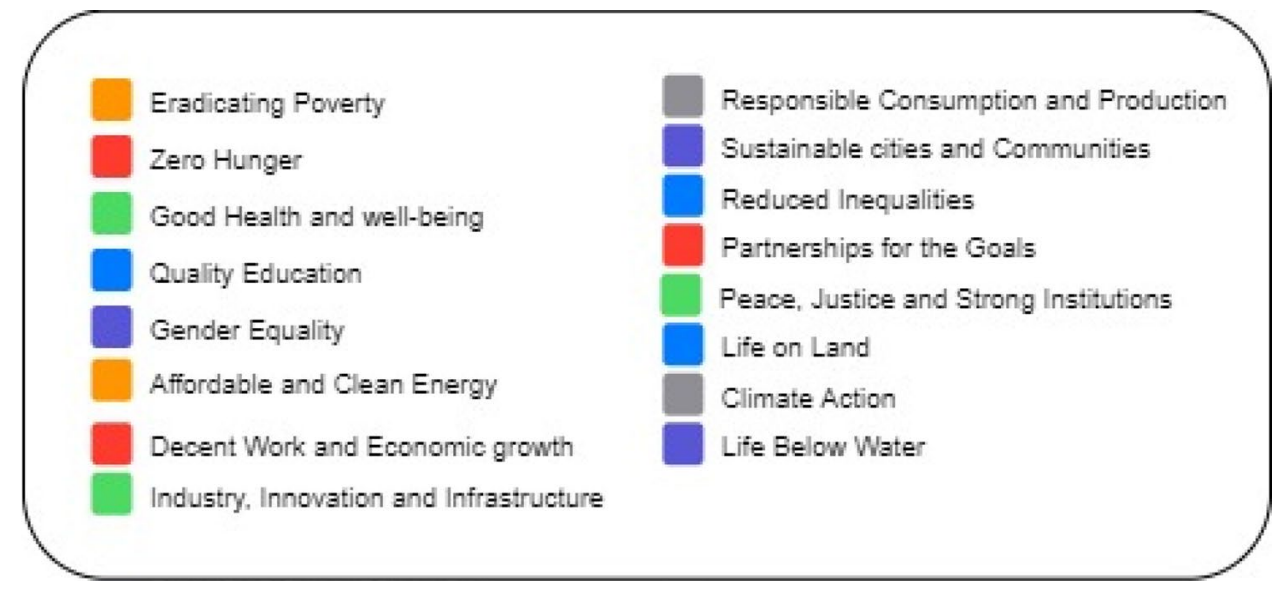

For rural development, World Bank has provided programs in public administration, agricultural markets, commercialization, and agriculture business, agricultural extension, research, and many other support activities along with social protection and transportation programs for rural communities [2]. IFAD projects for eliminating poverty and hunger, activism against gender-based violence, boosting development, investing in rural people in Papua, Food and nutrition security in Latin America boosting millet value chain, income security, and nutritional security in East Africa, Climate Risk Analysis in East and Southern Africa, Climate finance gap examination for small-scale agriculture, etcetera [20]. The IEEE smart village is an approach to empowering underserved communities, providing the power, education, entrepreneur opportunities. Following are the project initiatives by IEEE Smart Village Initiative: Mural Net(MNAZ)- Broadband to underserved on tribal lands, Regis University(RGU)measurement and evaluation Praxis Course scholarships, Sirona Cares Foundation (SCF)- SunBlazer deployment in Haiti, Village Help for South Sudan(VHSS)- South Sudan rural electrification, Lichi community solutions (LCS)sustainable energy kiosk for rural development, Green village electricity (GVE)- Electricity project expansion in Nigeria, Global Himalayan Expedition (GHE)- Electrification of remote Himalayan villages, Seva-Bharati India (SBI)- Sustainable development of community villages, Shakti Empowerment Solutions(SES)- sustainable energy distribution for rural consumers in eastern Uttar Pradesh, India [21].

Challenges of achieving Sustainable Development Goals (SG's) in rural areas can be elucidated in terms of different regions. As per the research [22], in Ukraine, control over the large businesses and their impact over the agribusiness structures in addition to shrinking the number of farms, jeopardizing rural population, poverty, and fewer efforts in social cohesion improvements or remote development are the principal challenges of achieving SDG.
Similarly, as per the methodology applied by the author in [23], the major challenges faced by Romania over achieving SDG are the Socio economic discrepancy among the rural dwellers' lives as well as the Environmental incongruity.

A few of the Sustainable Development challenges faced by the Iranian Rural communities as per the authors [24] are economic setbacks, improper management, and underplanned developments, environmental factors, social concerns, and infrastructural challenges were determined. Overall implications of the studies provide us with a concise picture of significant challenges of achieving sustainable development goals in rural areas.

Sustainability and blockchain both are the call for the future to reduce cost, increase productivity, improving health, better environmental state, and availability of food, water, and sanitation. Blockchain holds the ability for longterm and inclusive progress in sustainable development and to achieve SDGs.

\subsubsection{Blockchain Technology}

In 2008 when Satoshi Nakamoto [25] (pseudonym) proposed Bitcoin, its expansion was doubted. The rise of Blockchain was such unforeseen that some enthusiasts asserted it as the biggest invention since the Internet [26]. Although W Scott Stornetta and Stuart Haber described the first cryptographically secured chain of blocks in 1991, it wasn't until 2009 that Blockchain was implemented as the public ledger for bitcoin transactions by Nakamoto. For a substantial amount of time, Blockchain technology was only preferred for a cryptocurrency (Fig. 3). However, after the introduction of scripting language into the blocks by Ethereum Blockchain to work as bonds, which are now known as Smart Contracts the inventory of applications widely opened. In his paper Nakamoto proposed to create a peer-to-peer form of electronic cash that did not require a financial institution as an intermediary and would be transferred directly between one party and another. He improved the double-spending 
Fig. 3 Centralized and decentralized systems
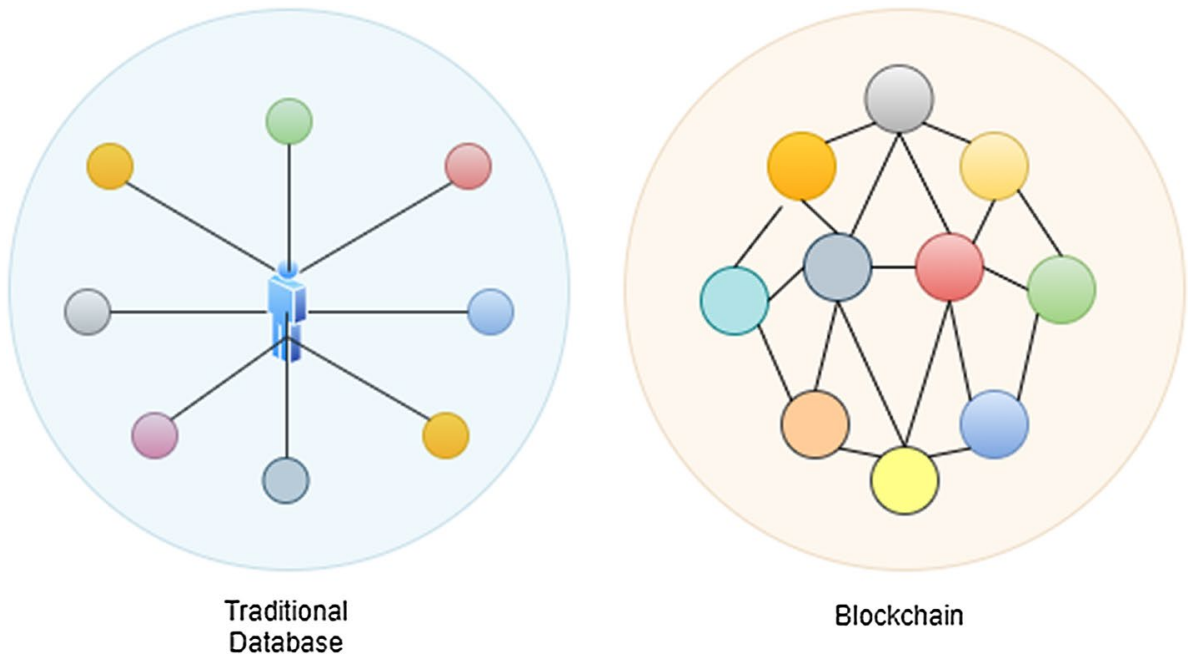

problem in Digital Signatures by implementing timestamps on the transaction and hashing them onto the ongoing chain of hash-based proof-of-work which changed the proof-ofwork if tampered with hence forming an immutable record.

Blockchain, even though it uses pseudonyms as account identifiers, has four key trust characteristics that eliminate the need for third-party authenticators. Firstly, a ledger in which after successful verification and authentication the transaction details are stored. Secondly, it is Secure since its transactions are time-stamped and hashed to the previous blocks; it makes the blockchain cryptographically secure (Fig. 4). Thirdly, the shared characteristic of involving multiple users provides transparency amongst all participants in the distributed ledger. Lastly, its property of being distributed eliminates operational inefficiencies, provides more security as the more the number of nodes the more resilient it is towards attacks [27].

The complexity of the working of blockchain can be simplified by exploring the components that make up its architecture [28]. The main components can be enumerated as Node, Cryptographic hash functions, Transactions, Asymmetric-key cryptography, Ledgers, Blocks, Miners, and Consensus (Fig. 5).

Node: A device possibly a computer forming the structure of a blockchain. A node is where the blockchain exists. Copies, as well as original records of the blockchain, are stored in a node. Classified as Full node and Light nodes, where Full node is a server in a decentralized network that contains the Block chain's block history, and Light nodes are used for simple payment verification such as a wallet that queries the current status of a block.

Ledgers: A decentralized blockchain uses a ledger for record-keeping. As it is decentralized, it keeps many copies of the transaction including providing a copy to each user of their transaction.
Blocks: A block resembles a page in a record book (ledger). The first block is called the generic block. A block comprises a block header and block data where the block header consists of the history of the blockchain (previous hash value, timestamp, size of the block, and nonce) and miners perform hashing to validate the block, and block data keeps the record of recent transactions that are yet to enter the blocks.

Cryptographic hash functions: A digest or an algorithm that takes up an arbitrary amount of data and produces a hash value or hash which is an output of fixed size. It eliminates the use of a password, instead uses enciphered text that provides more security from attackers.

Transactions: A transaction is what the components work about. When two parties interact in blockchain, a transaction takes place. Authorization is required to approve a transaction between two parties. In a public blockchain, the transaction is inserted by consensus which happens when the majority of nodes validate the transaction.

Asymmetric-key cryptography: It is public-key cryptography that is used to enable certitude between the transacting parties who are unsure about each other's integrity. Asymmetric-key cryptography uses mathematically related keys to ensure safety as well as the secrecy of data. The public key and Private key, even though relative is used for decryption and encryption, respectively.

Miners: When two users create a transaction, the miners validate that transaction in the block data before putting it on the ledger. The average time it takes for a miner to mine a block is $10 \mathrm{~min}$. Since miners use their energy and hardware to solve a block, they also require an incentive for their work which is mostly paid in cryptocurrency.

Consensus: A consensus can be identified as a decisionmaking criterion. It makes sure that all the nodes validate a block and no such duplicity exists in the ledger that hasn't been agreed upon. The discussion involved in consensus is 


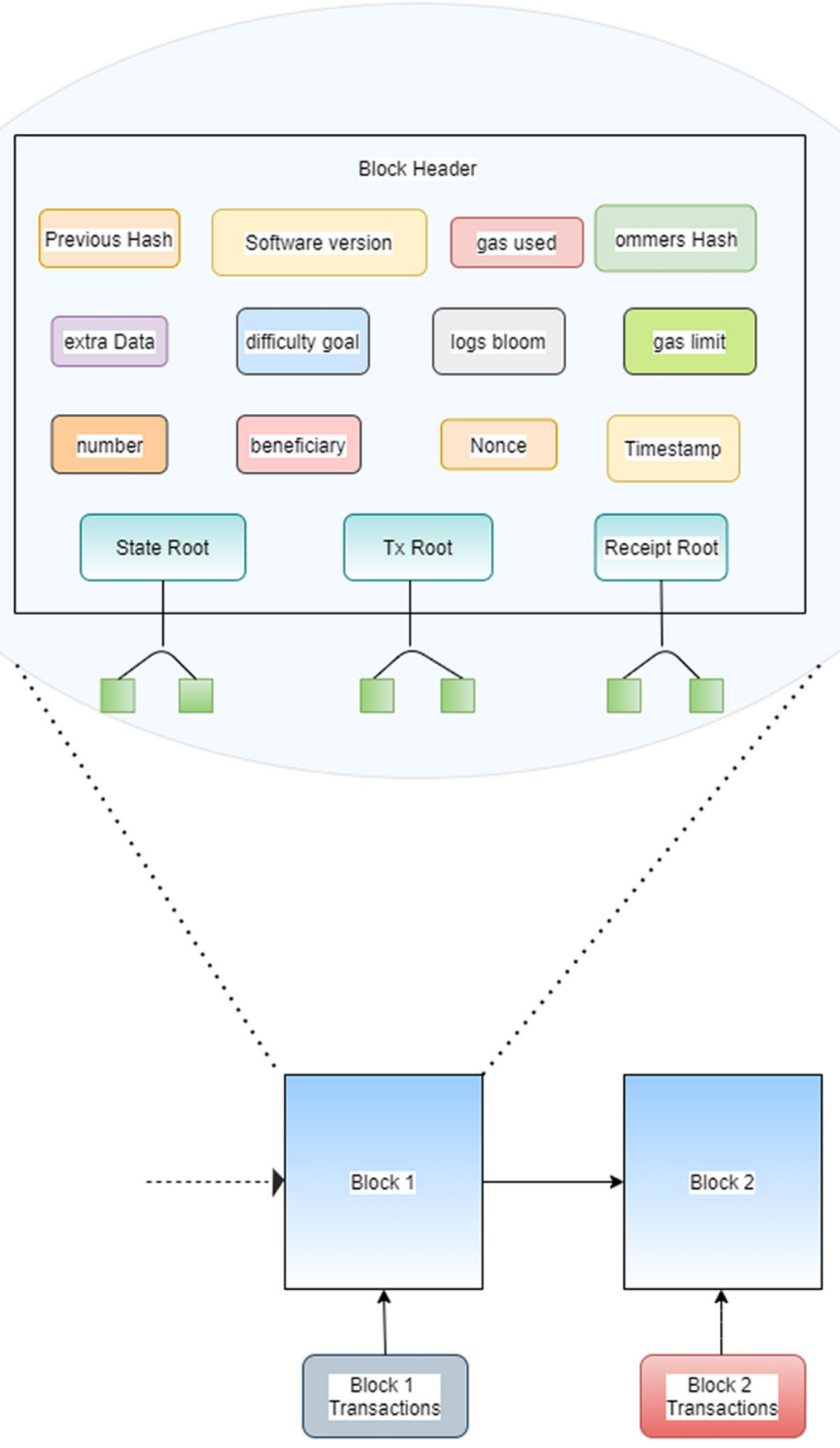

Fig. 4 Blockchain technology diagram

used to solve identity-issue, clarify altercations, and establish a similar viewpoint between the participants by applying a set of rules.

Ethereum: introduced by Vitalik Buterin [29] addressed various limitations of the scripting language in the blockchain. The platform is used to build and publish distributed applications by using a programming language. It is said to be an improvement over the blockchain structure. It provides data-friendly services to all and sundry no matter their location or background. Ethereum consists of full nodes that run the Ethereum Virtual machine to deploy distributed programs such as smart contracts. Application development in blockchain can be done through Ethereum which can also call multiple other blockchain, protocols, and cryptocurrencies [30]. Ethereum uses the chain of global computers to operate and runs smart contracts that are free of intermediaries or third-party censorships. Ethereum uses an incentive mechanism [31] to encourage programmers who run the 
Ethereum functions to compensate for hardware and energy used in running decentralized digital applications (dapps). These incentives are called Ether which is a cryptocurrency in the Ethereum protocol.

\subsubsection{Blockchain Development Platforms and Tools}

To simplify the blockchain processes and to ease the development various tools and programming languages have been introduced.

1.1.4.1 Ethereum Virtual Machine (EVM) The executing code and the Executing machine consist of an abstraction which is referred to as virtual machines, and Ethereum virtual machines increase the intended code execution chances, and the consensus is maintained on it [32].

1.1.4.2 Remix IDE Remix Integrated Development Environment is open-source software for web or desktop development. An intuitive and appealing interface remix allows smart contract development and Ethereum interaction [33]. Remix IDE has multiple plugin options such as Web3 integration, embedded Web3, and Javascript for running the contract locally. Solidity smart contract programming language is used for development in Remix IDE.

1.1.4.3 Smart Contracts Simple programs stored on the blockchain comprise some predefined conditions [34]. Upon meeting the conditions the contract is self-executed giving the edge of non-intermediary processes as well as time efficiency. Multiple programming languages are used

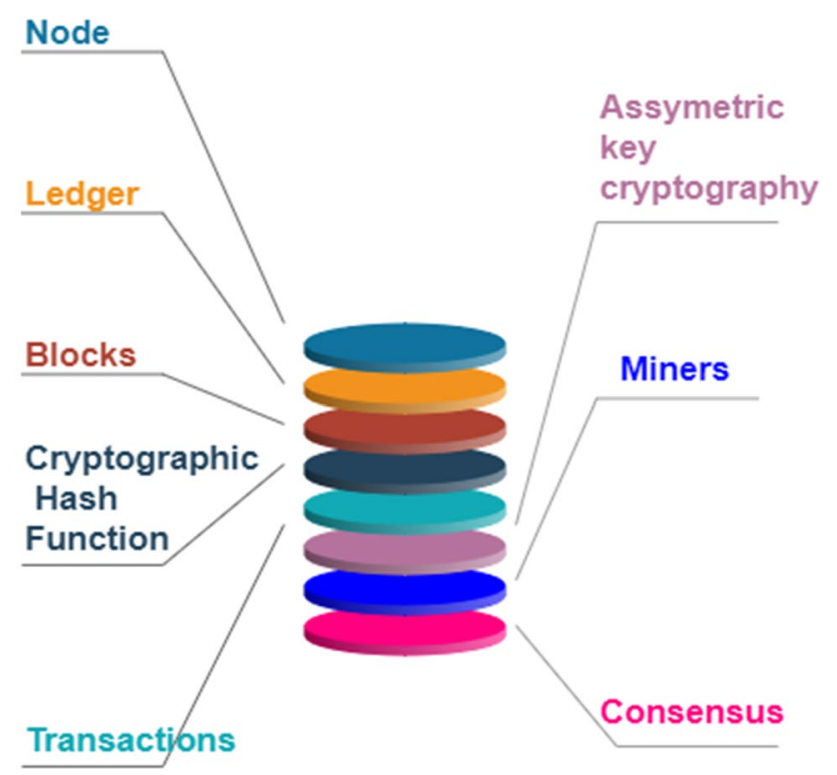

Fig. 5 Blockchain components to develop smart contracts for blockchain; a few of them have been discussed below:

- Solidity [35]: A highly preferred object-oriented designbased, high-level language conveniently made for developing smart contracts. Most of the solidity syntax inspiration came from $\mathrm{C}++$, Javascript, and Python programming languages. Solidity, along with being the top smart contract language focusing on EVM in certain also supports inheritance and user-defined types.

- Vyper [36]: Highly influenced by python and the second-best after Solidity, vyper is based on three important principles namely auditability to ensure the readability and understandability of the code for the user, Security to ensure secure smart contracts, and Simplicity of the language and the implementation.

- Yul [37]: An intermediate smart contract development language that includes the bytecode compilation according to different backend needs. The main focuses of Yul are simplicity in bytecode translation, understandability, and readability of the scripted programs. Yul supports stack machines and is specifically tailored for them, whole-program optimization, and static type reference and value nature.

1.1.4.4 Hyperledger A Linux framework for blockchain development that provides standards and tools for opensource blockchain applications [38]. Hyperledger enterprise helps build permissioned blockchain solutions for businesses and services. Under the Hyperledger Framework, multiple projects have been introduced:

- Hyperledger Fabric: A modular permissioned and private framework for blockchain technology used for developing solutions for businesses and private enterprises. Fabric has a well updated smart contract interaction, faster transactions, and efficient data sharing.

- Hyperledger Explorer: Explorer is a user-friendly blockchain development web application tool. The interface provides detailed information about the blocks, transactions, network nodes, and the state of the blocks. Hyperledger Explorer uses visualization tools for representing the blockchain data in a user-friendly and readable manner.

- Hyperledger Sawtooth: By separating the core system, that is, specifying the business rules without interacting with the application domain is the main task of hyperledger sawtooth. It supports the Practical Byzantine Fault Tolerance (PBFT) as well as the Proof of Elapsed Time (POET). The smart contracts can be developed and run on the platform without actually knowing the core system's design. 
- Hyperledger Caliper: A blockchain benchmark tool, the caliper used pre-defined uses cases to test the blockchain solutions along with a test result of its performance. Caliper has a very proficient success rate for testing the successful and failed transactions, provides the maximum, minimum, and average latency of transaction and read data for the test cycle.

Limitations of Blockchain are limited but cannot be disregarded [39]. From the creation of the node to the validation by miners, Blockchain consumes a lot of energy. Splitting of the chain is another problem where a node does not accept the transactions in a new chain if it is operating to the old software. The computing requirements increase as the blockchain grows. Since all the nodes cannot provide the necessary capacity, the node breaks, and the immutability and transparency of the blockchain cease to exist.

\subsubsection{Blockchain for Smart Village Applications}

The scenario in a typical village is such, in terms of the infrastructure most of it is inadequately built, there exists schools and colleges but poorly maintained, poorly built houses with no constraints for disaster management. In terms of necessities, normal villages lack stable electricity supplies, or a secure income to support electricity bills, and non-purified water. People in villages are often neglected and most of the dwellers don't have any personal or national identity. The healthcare system in villages is simple and inefficient which does not help during major problems. Normal villages lack any technological advancement and people there live in history because of the lacking development.

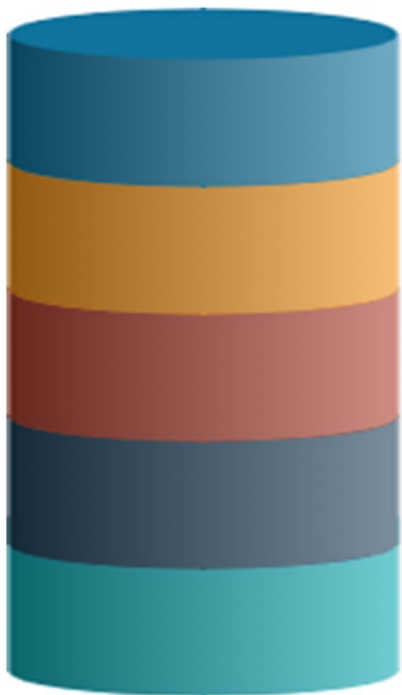

Cryptocurrency

Security

Recordkeeping

Smart Contracts

Transparency
Sustainable development with the concept of smart villages can give a secure and feasible future to the villages.

Beyond the conventional use of blockchain in finance using cryptocurrency, numerous applications can change the way we perceive digitization. According to Kandaswamy [40], blockchain can have four types of initiatives: blockchain disruptor, digital asset, efficiency play, and recordkeeper (Fig. 6). With similar inventiveness some of the blockchain applications with the concept of a smart village can be enumerated as:

Healthcare: Blockchain with its record-keeping characteristics and smart contract with its privacy and security has greatly assisted the medical area by providing a solution for publicly or semi-private sharing of the medical data of patients. This can help the researchers and students to elicit a new solution or use it for clinical trials [41]. The solution for missing health documents or previous clinic visit records can be improved through blockchain. The potential of Blockchain to store patient's record on the ledger make it possible to get treatment across the globe. Furthermore, the problem of counterfeit drugs in the market can be resolved through the traceability solution from blockchain through which fake medicines can be traced and removed from the supply chain.

International payments and insurance: Accelerated payment to international locations is possible through blockchain technology. Several Bitcoin-operated services make it easier to transfer money cross-border. The process includes converting the payer's local currency into Bitcoin bypassing the existing banking infrastructure and then converting that Bitcoin into the receiver's local currency. This saves the trade cost and speeds up the transaction. Apart from that, the insurance industry can also be benefitted from blockchain technology [42]. Blockchain can provide a transparent and trustworthy system to overcome the challenges of the insurance industry. Fraudulent claims, intermediary payment transactions, and big data handling are some of the many issues faced by insurance companies. Blockchain can resolve the issues through its security and transparency provided by the distributed ledger which also furnishes the authenticity of the participants. Besides, its characteristic of recordkeeping comes in handy with the huge amount of customer data that is immutable in the blockchain ledger. Additionally, by using the smart contracts real-time data of the claims, reimbursements or payments can be fetched from multiple systems in no time.

Personal Identity Record-keeping: Identity is an integral part of society that provides a unique character and sense of acceptability in a country. However, physical forms of national identity are not accessible to many people around the world. The absence of identity makes it difficult for people to participate in voting, banking, employment and limits the chances of access to the financial system. Here blockchain steps in by providing identity solutions through

Fig. 6 Blockchain elements 
digital identity. Additionally, self-sovereign identity arranges options to store one's identity on devices accessible across the world [43].

Supply chain and logistics: Blockchain can bring great usability to supply chain management. Procurement, traceability, digital payments, and logistics are some areas that have benefitted from blockchain technology. The distributed ledger can reduce the sharing of operational data by providing a full view of the sale/purchase data, accessible from any device. Fraud in the food supply chain is prevalent in many countries. Counterfeit products selling in the market prove hazardous to the consumer. The Block chain's QR tracking system along with digitized physical products can be used to track products from production to delivery [44]. This technology has started benefiting the agricultural sector to develop food safety and smart farming increasing the income of small farms and food producers.

Education: Keeping physical records and transcripts can be a hassle. This blockchain provides a solution for digitizing student records, transcripts, and payment receipts [45]. Digital record-keeping can benefit a student as it will be acceptable by universities across the globe, free of manipulation, and handy. Blockchain can also be used to incentivize students through a course credit system. The credit can be translated to cryptocurrency, which can be further used as fee payment.

Blockchain with the Internet of Things (IoT): Powerful union of two futuristic technologies makes machine-tomachine transactions easier. The decentralized authority of blockchain combined with the smart devices run by IoT allows a function to autonomously execute without a central authority [46]. Smart IoT run devices can be implemented on edge devices, reducing data transfer costs, and security issues with the blockchain collaboration [47]. Blockchain integration with IoT can highly change the agricultural sector. Supply chain traceability could benefit the farmers in eliminating the intermediaries through traceability and RFID tag-based applications. Water, soil, climate, and other sensory-type IoT devices can help in monitoring the agricultural activities and gathering the farm data and activities such as cultivation and livestock data in the blockchain ledger. IoT with blockchain will certainly revolutionize and transform many rural and urban sectors.

\subsection{Motivation and Major Contributions}

Sustainable Rural development starts with the participation of rural people in improving their lifestyle. Without the people working for their development, any implementation or help is incomplete. Economic and technological sector links are important for rural areas to develop. Along with that, a healthy agricultural sector improves the dweller's linkage to the global supply sector. By managing the social, economic, environmental, and health objectives the development can be fast-forwarded. There is a considerable amount of potential in rural people which can be applied to employment issues, social disparities, E-governance, women's rights etcetera. Developing rural areas can benefit nationally, economically, and financially. This systematic literature review aims to provide extensive literature related to blockchain's application in rural development and sustainable living. A plethora of blockchain review papers available does not provide a collective literature review of blockchain applications divided into different areas directed towards rural and sustainable development. Therefore, clear and concise information can be gained about blockchain's work in improving rural development providing scope for future research in this direction. The primary contributions are mentioned below:

- A systematic review of relevant literature for research trends, key applications, and areas of implementing Blockchain Technology for smart villages for sustainable rural development.

- Identification of major issues in rural development and how they can be addressed using Blockchain Technology.

- Exploration of the existing software, platforms, and tools for the implementation of Blockchain in Rural Development.

- Identifications of the research gaps and future research directions for applying Blockchain Technology to Rural Development.

To conduct a fair and precise literature review, the studies have been selectively chosen after processing through the query string, and inclusion and exclusion criteria. The relevant set of research questions are formulated as depicted in Table 3 and also addressed in their relevant sections. The complete review methodology process is elucidated in Sect. 2.

The remaining paper is organized as follows: Sect. 2 presents the details and process of the review methodology adopted to include relevant studies for literature review. Section 3 presents an extensively reviewed literature study of the papers selected through review methodology. Section 4, presents the critical analysis and discussion of the reviewed papers for a clear perspective on the existing work in Blockchain Technology pertaining to rural development and for future research directions. In Sect. 5, the limitation of this work is mentioned. Section 6, finally, presents the conclusion and future scope. 
Table 1 Search criteria

Sources

Few keywords

Search strings
ACM Digital library, IEEE, Elsevier, Science Direct, Springer, Google Scholar

Blockchain, rural, rural development, rural healthcare, rural banking, rural education, rural incentivization, rural environment, rural energy, agriculture, traceability, supply chain, farming, livestock, developing countries, and smart village

("Blockchain" AND ("rural incentivization" OR "rural" OR "agriculture" OR "e-agriculture" OR "traceability" OR "farm monitoring" OR "supply chains" OR "smart management" OR "rural waste" OR "waste management" OR "recycling" OR "rural electrification" OR "rural banking" OR "village" OR "smart village" OR "rural development" OR "rural healthcare" OR "e-health" OR "telemedicine" OR "rural banking" OR "rural review" OR "financial exclusion" OR "developing countries" OR "SDG" OR "sustainable development goals" OR "agrarian development" OR "sustainable development" OR "labor" OR "sustainability" OR "rural employment" OR "incentive mechanism" OR "rural rewards" OR rural education" OR "livestocks" OR "farming" OR "IOT" OR "Internet of things"))

Table 2 Inclusion or exclusion criteria

Inclusion criteria

Articles published in peer-reviewed journals, conference proceedings, and articles published in reputed journals

Articles that are written in English in notable journals

Published between 2010 and 2021 as most of the blockchain applications w.r.t rural development articles were published after 2010

Articles focusing on the applications of blockchain in rural development were elected

\section{Exclusion criteria}

Poster, prefaces, summaries, book reviews, editorials, readers' letters, panels, and conferences

Studies that not provided evidence. Duplicate Studies Not relevant to our targeted area/theme

Articles in other than the English language
Fig. 7 Systematic review process

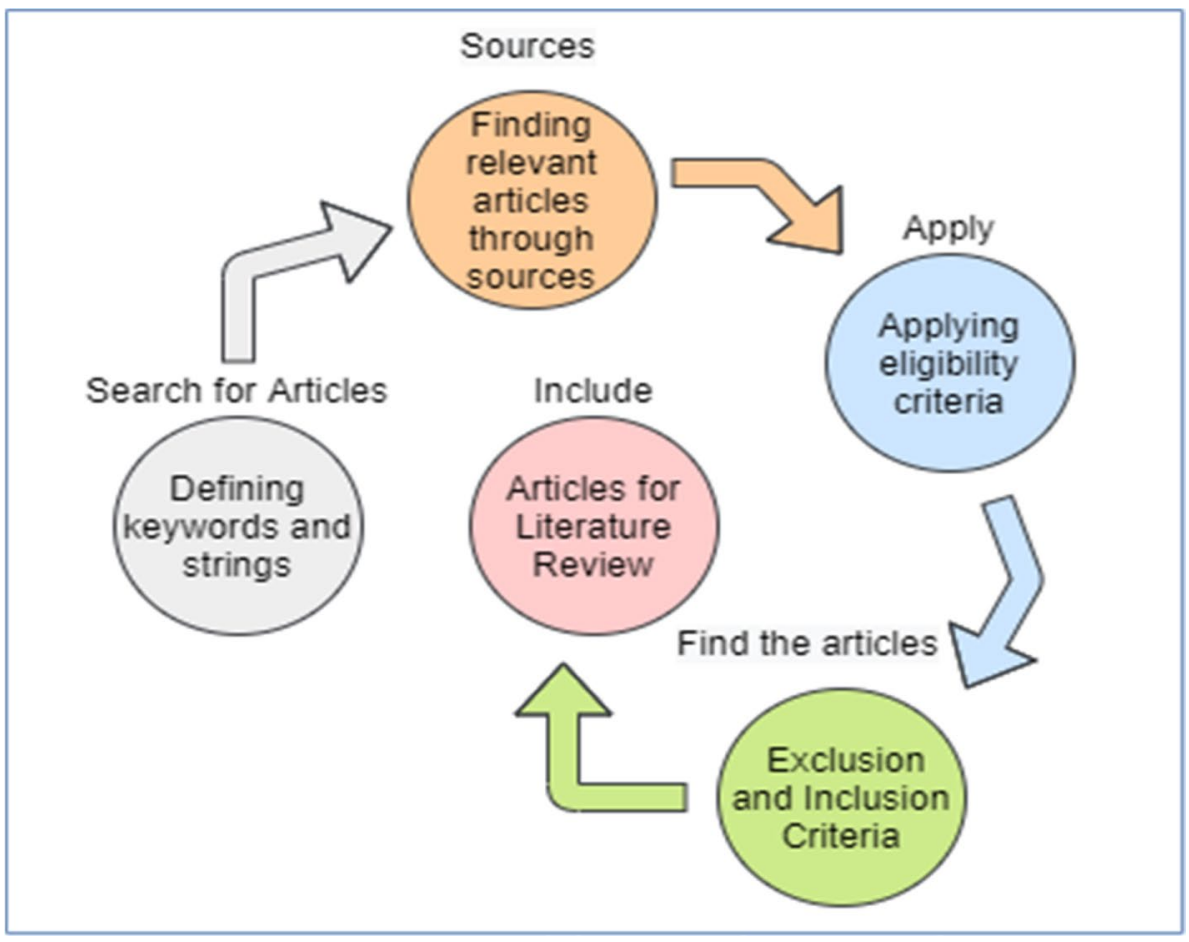


Table 3 Research questions

\begin{tabular}{|c|c|c|}
\hline S. no. & Research Questions (RQ) & Description \\
\hline RQ1 & $\begin{array}{l}\text { What are the main applications and areas of implementing Block- } \\
\text { chain Technology in Rural Development? }\end{array}$ & $\begin{array}{l}\text { The revealing question demonstrating Blockchain's application in } \\
\text { rural development for the betterment of the undeserved along } \\
\text { with the comparison of literature proposed by various authors and } \\
\text { understanding the key differences between each proposed article, } \\
\text { and contrasting approaches for implementing the same problem, } \\
\text { with improved performance }\end{array}$ \\
\hline RQ2 & $\begin{array}{l}\text { What are the major issues in Rural Development and how they can } \\
\text { be addressed using Blockchain Technology? }\end{array}$ & $\begin{array}{l}\text { Primary and unending issues in rural development and its solution } \\
\text { using the latest technology }\end{array}$ \\
\hline RQ3 & $\begin{array}{l}\text { What are the targeted software, platforms, and tools for the imple- } \\
\text { mentation of Blockchain in Rural Development? }\end{array}$ & $\begin{array}{l}\text { To get a comprehensive overview of mostly used technology(s), } \\
\text { software, platforms, and tools in implementing the state-of-the- } \\
\text { art research applications, and explore infrequent approaches of } \\
\text { implementation }\end{array}$ \\
\hline RQ4 & $\begin{array}{l}\text { What are the research gaps and future research directions for } \\
\text { applying Blockchain Technology to Rural Development? }\end{array}$ & $\begin{array}{l}\text { To help researchers and practitioners in understanding the future } \\
\text { of technology for implementing new research in the area, and } \\
\text { finding the relevant areas of direction to get a clear picture of } \\
\text { applications at large }\end{array}$ \\
\hline
\end{tabular}

\section{Review Methodology}

The systematic review was conducted with relevant articles on blockchain technology in rural development. To perform a systematic review, Kitchenham's and other related guidelines were followed [48-50]. To provide a transparent, systematic, understandable review of papers multiple sites and journals were visited, segregating articles into the various application of blockchain technology. The main objective of a systematic review is to write a planned article to relay a comprehensible, clearly stated literature after repeated analysis to define a problem, be replicated, or identify research gaps. To find a relevant article miscellaneous Journals, digital libraries, and web sources were delved into.

\subsection{Search Strings}

To find a relevant article, the following sources were considered: ACM Digital Library, IEEE, Science Direct, Elsevier, and Springer. Along with that Google Scholar was used as a web source where a broad search for scholarly articles is possible. The keywords and strings are listed in Table 1.

\subsection{Selection Criteria}

To search for articles best suited for the review, the following (Table 2) selection criteria were applied.

\subsection{Process Flow}

The process of forming a literature review consisted of selecting relevant papers, applying inclusion or exclusion criteria on them, and reviewing them (Fig. 7). In the process, a total of 157 articles were considered out of which 112 papers were reviewed pertaining to the keywords specified in Table 1.

\section{Research Questions}

To identify the scope of the systematic literature review, few research questions have been formed. The research questions along with the explanation on the depiction of the answers are shown in Table 3.
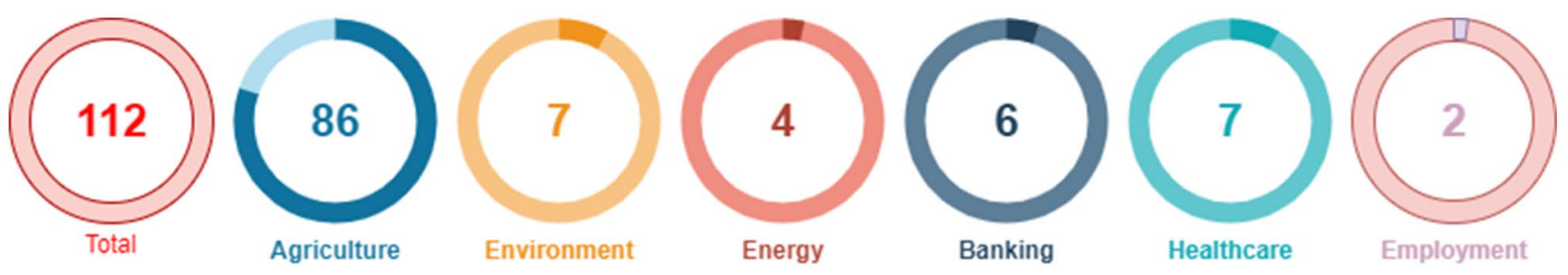

Fig. 8 Distribution of Blockchain applications in rural development 
Table 4 Relevant literature: blockchain application for sustainable rural development

\begin{tabular}{|c|c|c|}
\hline References & Application areas & Description \\
\hline$[51-96]$ & Supply chain traceability & Tracking the Provenance and journey of the product \\
\hline$[101,104]$ & Organic farming & Natural cultivation of crops and animal rearing using biological materials \\
\hline$[100,105-110]$ & Smart agriculture & $\begin{array}{l}\text { Using modern Information and Communication Technologies (ICT) to manage farms and ameliorate } \\
\text { the quality and quantity of products }\end{array}$ \\
\hline$[111,112]$ & Dairy farming & $\begin{array}{l}\text { Using advanced sensing and analyzing technologies to improve animal health, environmental condi- } \\
\text { tions, and satisfy dairy demands }\end{array}$ \\
\hline$[113-115,147]$ & Livestock & Management of livestock using advanced technologies to monitor health and potency \\
\hline$[116,117]$ & E-Agriculture & $\begin{array}{l}\text { Sharing informative use of ICT in agriculture, ideas, and resources for rural development and sus- } \\
\text { tainability }\end{array}$ \\
\hline$[99,118,119]$ & Agriculture monitoring & $\begin{array}{l}\text { Use of smart sensors and monitors to observe crop health, environmental factors, and prompt steps } \\
\text { during disasters }\end{array}$ \\
\hline$[120-122]$ & Farmers & Using ICT's to facilitate farmers and protect their data \\
\hline$[123-132,148]$ & Incentivization & Using Incentives to motivate actors to perform better \\
\hline [134] & Natural hazard & Smart agricultural disaster management and recovery \\
\hline$[128,133,148]$ & Waste management & Using smart technologies to promote cleanliness \\
\hline [135-139] & Water management & Managing and monitoring water usage in agriculture using ICT's \\
\hline$[142,143]$ & Renewable energy & Facilitating energy in areas from renewable resources \\
\hline$[140,144]$ & Energy grid & Providing Electricity to unreachable areas with transparency \\
\hline$[151,152]$ & Loan & Dispense loan solutions to underserve \\
\hline$[149,150]$ & Mobile banking & Using ICT's to provide banking solutions in remote areas \\
\hline$[153,154]$ & Cash transfer & Ease of money transfer with reliable and trustable platforms in ICT \\
\hline$[157,158]$ & Medical data & Sharing medical data with privacy and to selected actors \\
\hline$[159-161]$ & Telemedicine & Using modern technologies to provide medical care in remote places \\
\hline$[155,156]$ & Smart healthcare system & Using ICT's to monitor, connect, share, and manage patients and their data \\
\hline$[163,164]$ & Employment & $\begin{array}{l}\text { Facilitating Temporary employment solutions and employment visibility with reliable employers } \\
\text { using ICT's }\end{array}$ \\
\hline
\end{tabular}

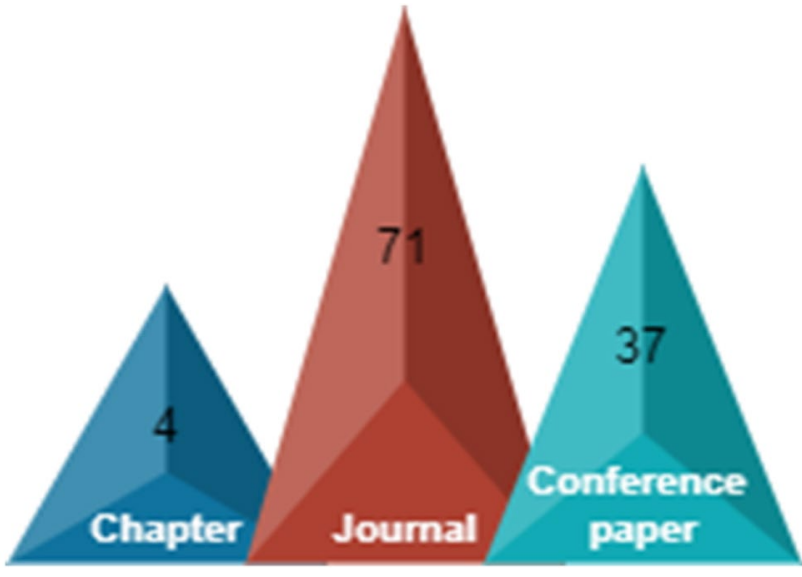

Fig. 9 Publication distribution

\subsection{Relevant Literature Trend}

From all the papers reviewed consisting of applications of blockchain in rural development, the following applications were recognized: Agriculture, Banking, healthcare, energy,
Environment, and Employment. Additionally, the articles consisting of incentive mechanisms were segregated (Fig. 8). From each of the applications, different areas were identified concerning each application (Fig. 11). Table 4 is a detailed table with application areas and its definition concerning Blockchain in rural development.

\subsection{Publication Distribution}

To provide a simplified view of the literature review for better understanding the articles are distributed according to the peer-reviewed journals, conference papers, and chapters as shown in Fig. 9.

The articles are further distributed according to the applications type while also displaying the number of articles and their publication year in Fig. 10.

For further classification, the geographic distribution of papers was performed with 112 papers (Fig. 11), distributed in 37 countries as shown in Fig. 12 with India, China, and the USA is the largest publishing countries followed by Italy, Spain, and Pakistan for blockchain applications in rural development. 


\section{Articles and Publication Years}

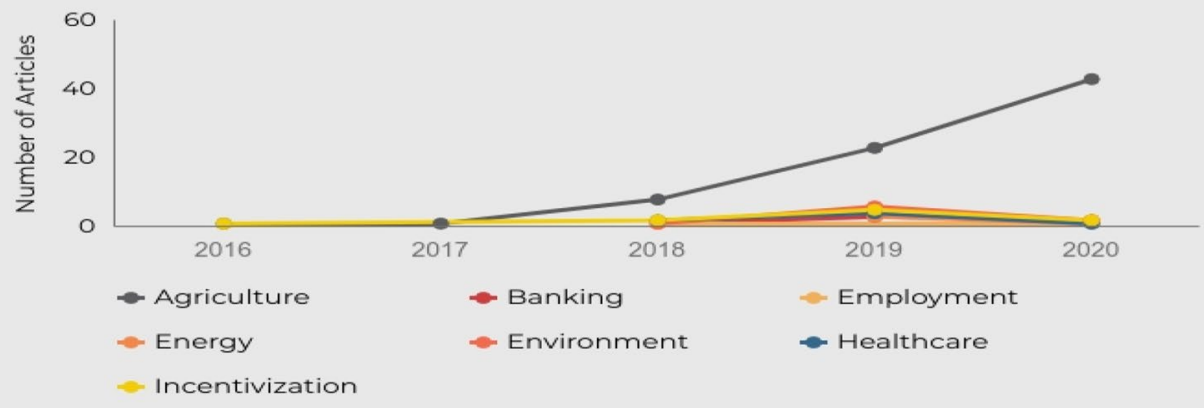

Fig. 10 Number of articles and their area of publications (2016-2020)

\subsection{Publication Type}

The distribution of the articles according to different publication types was found (Fig. 13) with the largest number of publications (61) in The Institute of Electrical and Electronics Engineers (IEEE), followed by (27) in Springer, (16) in Elsevier, (3), and (5) in ACM digital library and Science direct respectively.

\section{Literature Review on Blockchain Technology for Sustainable Rural Development}

The literature review consists of the collective work of blockchain in rural development. A total of 6 areas of application were identified after careful extraction of data and transformation globally namely: Agriculture, Banking, Environment, Energy, Employment, and Healthcare. A detailed discussion on the related work is discussed in the subsections.

\subsection{Agriculture}

In the agriculture sector, most of the application areas included supply chain traceability, facilitation of smart agriculture, and incentivization of services (Fig. 14). A detailed summary is given in Tables 5, 6, and 7 .

\subsubsection{Supply Chain Traceability}

The author F. Tian, [51] studied the integration of RFID (Radio-frequency Identification) and blockchain technology in building the agri-food supply chain traceability system.
With the help of blockchain technology, the information shared and traceability is guaranteed. Apart from the supply chain, it also regulates food safety and quality supervision. This system can enhance the credibility and reliability of agri-food safety information. With the depletion of an application cost, this system can effectively change the current supply chain to be more quality-enhanced and safe. Similarly, Hua et al. proposed an agriculture [65] provenance system based on blockchain featured by decentralization, collective maintenance, consensus trust, and reliable data to solve the trust crisis in the product supply chain. The system's Target is to record information related to the production supply chain: production, processing, storage, transportation, and distribution of agricultural products. It also facilitates Recordkeeping from basic planting information to provenance records. The proposed work solved the issue of the credibility of data and the difficulty of integrating the subsystem of each company.

The paper by Casado-Vara et al., [58] addressed the issues of the current supply chain such as communication gaps between vendors or the opacity of the origin of the product. The author has proposed a new model of the supply chain via blockchain where all the members of the supply chain save all their transactions in the blockchain to ensure higher security. This model also enables a circular economy that is a make-use-recycle model. With this model, all products can be traced from their origin to their sale and subsequent recycling.

Further, Caro et al., [70] presented AgriBlockIoT which is a fully decentralized blockchain-based traceability solution for agricultural food supply chain management. The proposed architecture based on API includes a controller to convert high-level function calls to corresponding for the blockchain layer and blockchain itself which is the main 


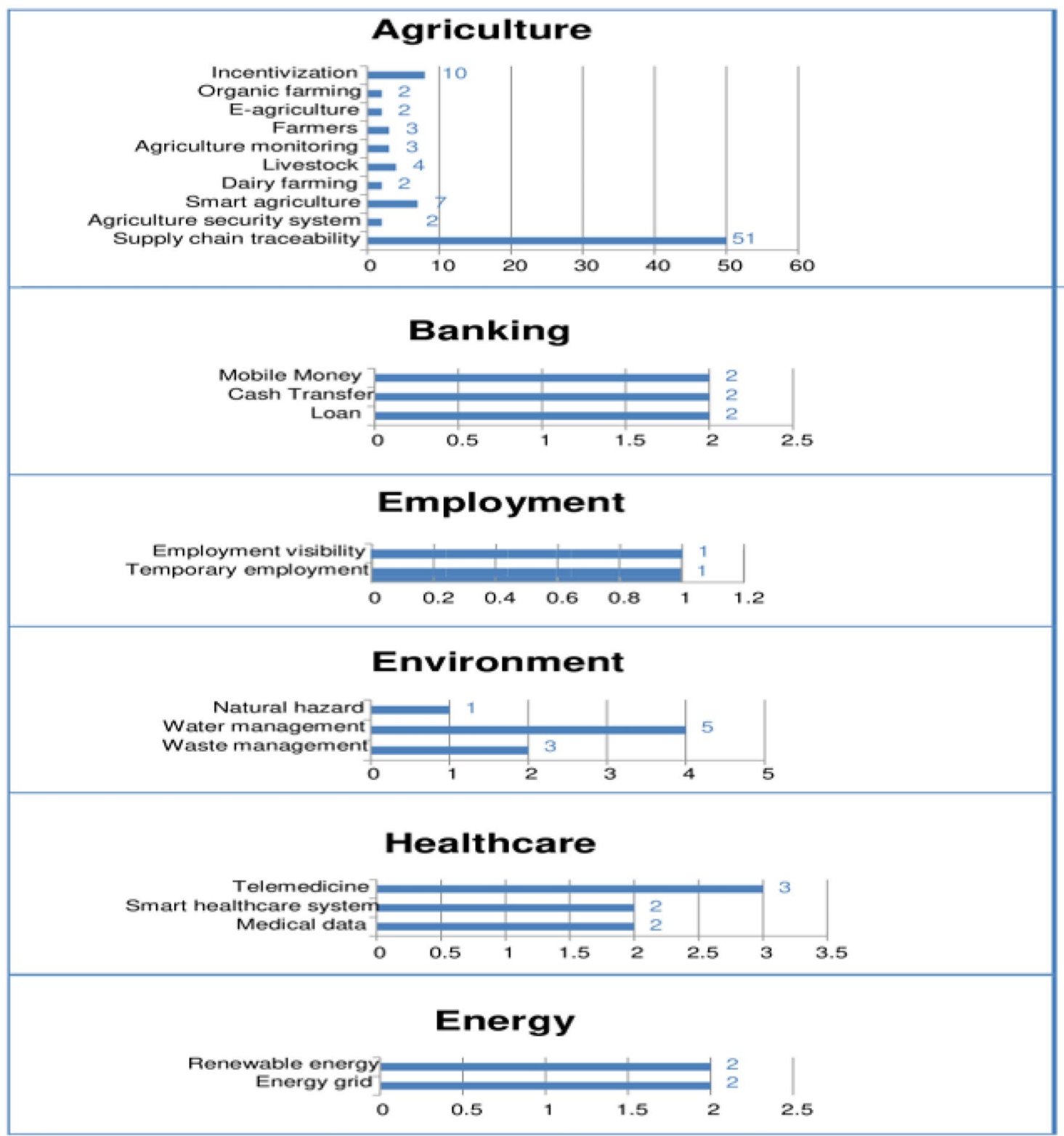

\section{Number of Articles}

Fig. 11 Areas of blockchain application in rural development

component of the system. The collaboration of IoT and blockchain can create transparent, fault-tolerant, immutable, and auditable agri-food traceability records. The authors $\mathrm{Li}$ and Wang, [85] characterized the research applications of blockchain in food supply traceability. With the help of blockchain technology and various radiofrequency devices can be integrated to collect data from farms, deploy sensors, and create intelligent contracts to implement server logic. The new system can change the traditional food supply system by making it more convenient, efficient, and trustable. Kim et al., [54] presented a theoretical, end-to-end, vis a vie "farm-to-fork", food traceability application named Harvest Network with the integration of Blockchain technology and Internet-of-things. The process includes tracing the products from processing, grading, transportation, temperature, and contractual payment all with blockchain, IoT, and smart contracts. This can help consumers gain field-level insight into the products. Lin et al., [63] proposed an IoT and blockchain integrated self-organized, open, and ecological food traceability system. The proposed model consisted of trade, logistics, delivery, and warehousing information as well as data from IoT devices such as soil humidity, soil $\mathrm{pH}$, and soil 


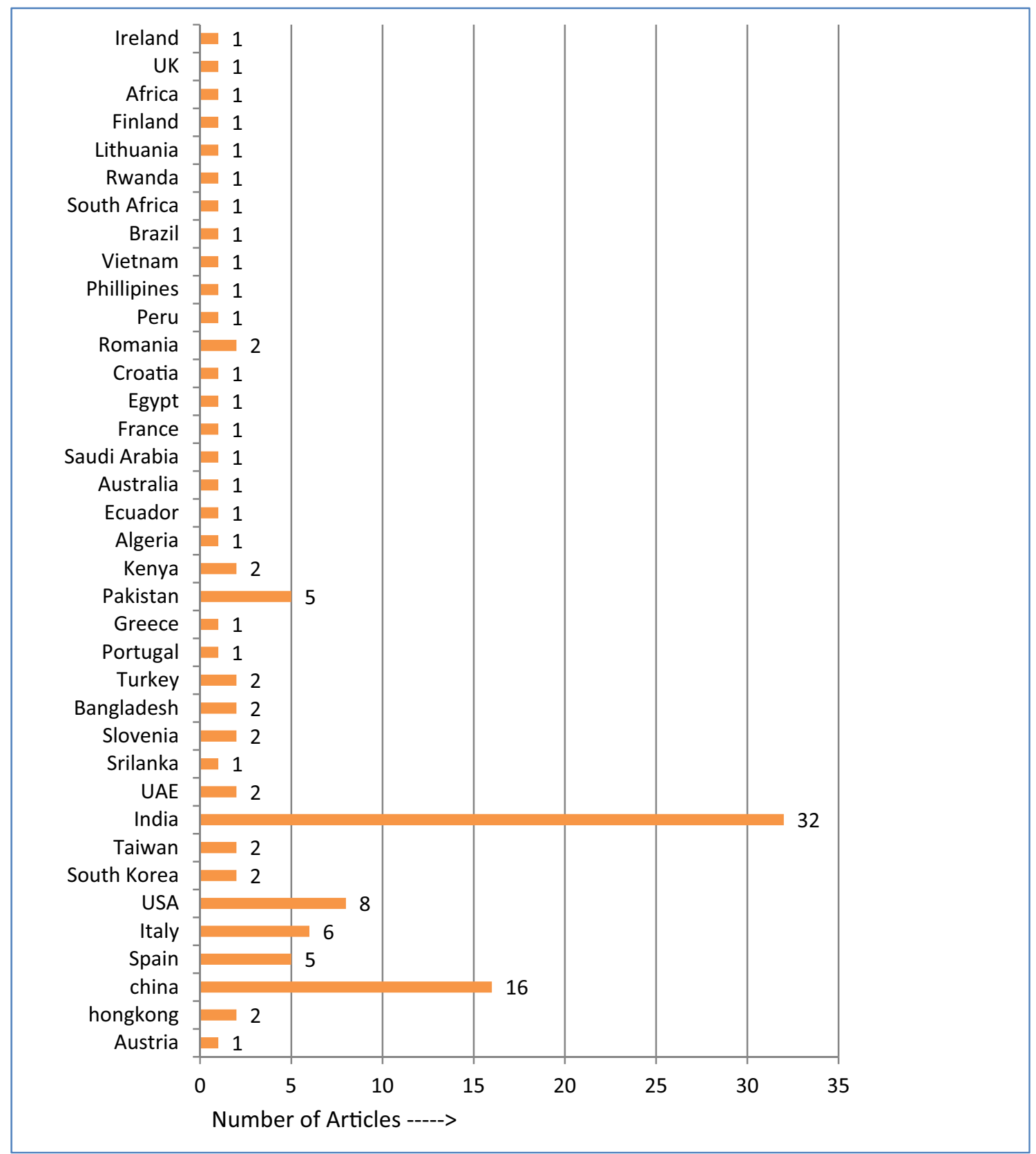

Fig. 12 Geographical distribution of articles

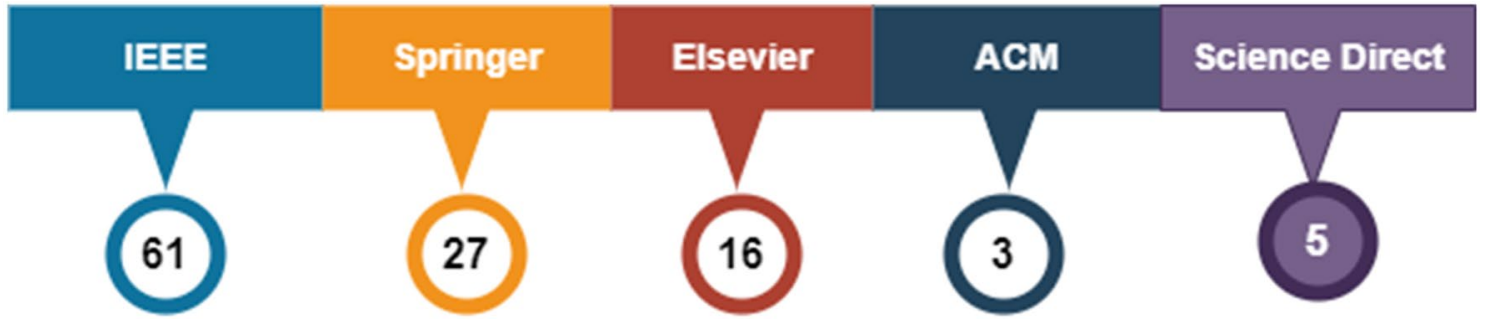

Fig. 13 Distribution of articles by journal type 


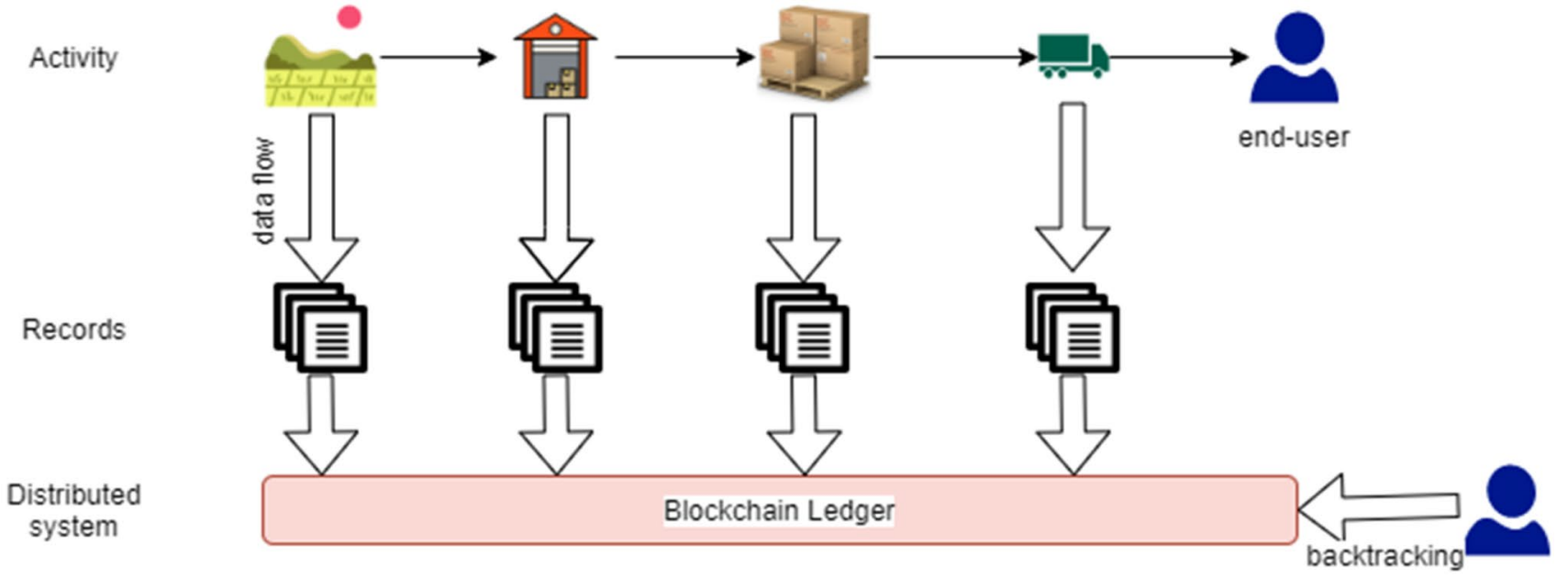

Fig. 14 Agriculture supply chain traceability diagram

nutrition. The concept was to enable a user to get detailed information about the product they buy with the help of a trusted, self-organized smart agriculture ecosystem.

Galvez et al., [78] review the potential of blockchain technology in guaranteeing traceability and authenticity in the food supply chain. The review included blockchain solutions to traceability problems. It explained the use of a chronological distributed database to coordinate individual activities. By using a probabilistic approach to enable transparency and verifiability without a central authority, enabling consensus on a transaction to secure legitimate transactions, and time-stamped blocks providing immutable records to preserve records the traceability issues were solved. The paper also discussed the Block chain's concept on the food supply chain which provides transparency, efficiency, security, and safety to the food produce. According to Kamble et al., [55], the supply chain practitioners found a lack of efficiency and transparency which leads to constant threats to formers and consumers. The system deployed the ISM methodology to identify Blockchain technology enablers in the agriculture supply chain. The findings implied the acceptance of blockchain technology as an innovative tool to ensure an efficient agriculture supply chain by the practitioners. To achieve further traceability the farmers could capture relevant information about the agricultural events onto the blockchain to enable transparent and trusting sources of information for the farmers. Kamilaris et al., [60] explored how the food supply chain and agriculture were impacted by blockchain technology. The stages of the supply chain with blockchain technology has been identified as (1) the provider (2) producer, (3) processing, (4) distribution, (5) retailer, and (6) consumer where a web application or device can be used to scan the item's QR code to view its detailed information. Along with this, the author explored various challenges and benefits of the agricultural supply chain and Blockchain's collaboration. Salah et al., [66] proposed a solution of eliminating the third parties and centralized authorities in the food supply chain along with a security system for food traceability, transparent records, and governance of interactions and transactions between the users. The model entities are related to providing secure tracking of the product and payment with Ethereum smart contracts. Thus, the presented model for traceability can be used to trace and track the soybean supply chain. S. Missineo, [75] proposed a model to secure storage origin provenance for food data. The proposed system aims to certify the production and the supply chain concerning food local products by using Blockchain Technology and Smart Contracts. The author aimed to ensure the authenticity of typical Sardinian products and to sell them online or offline. The platform ensured the consumer to check the authenticity of the product before the purchase giving details on both the production chain and supply chain. Jaiswal et al., [86] proposed multiple smart contracts deployed on the Ethereum blockchain for decentralized trading of food grains. The framework included Peer-to-peer trading, the security of food grain data, transparency, user anonymity, trust, and incentives as key features. The design of the framework consisted of four contracts namely food grain supply, bidding, trading, and utilization for the supply chain management. Dong et al., [56] proposed a collaborative model of blockchain and IoT in the agriculture sector. The data collection and transmission can be distinguished through a unique identity card given to each agricultural product. All the environmental aspects of the agricultural process can be gathered at the source. Along with that crop growth information, circulation of the product using an RFID tag and distribution process can also be recorded and stored on the distributed ledger. A QR code attached to the product can be scanned by the consumer to view product information in details. 


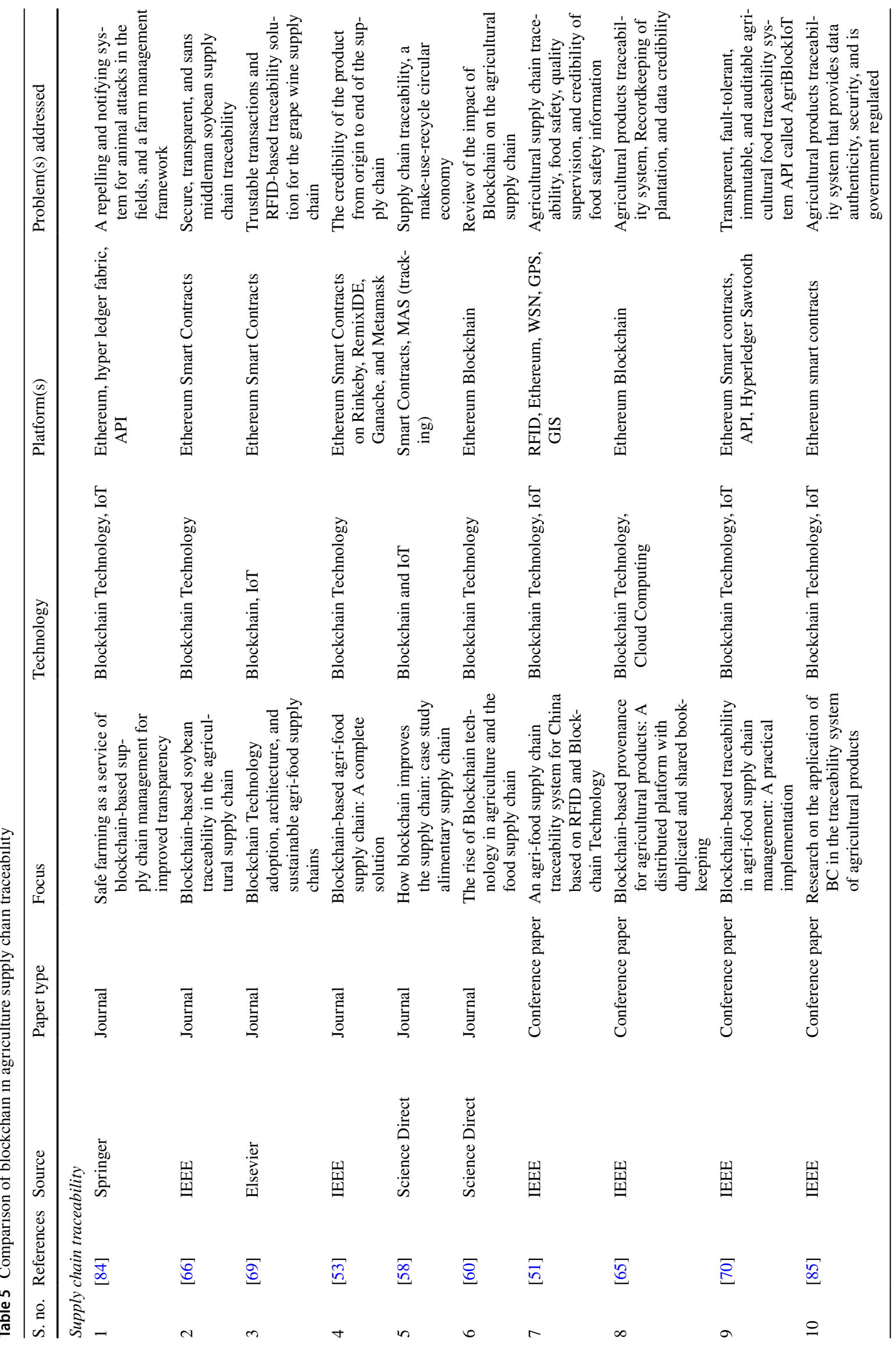




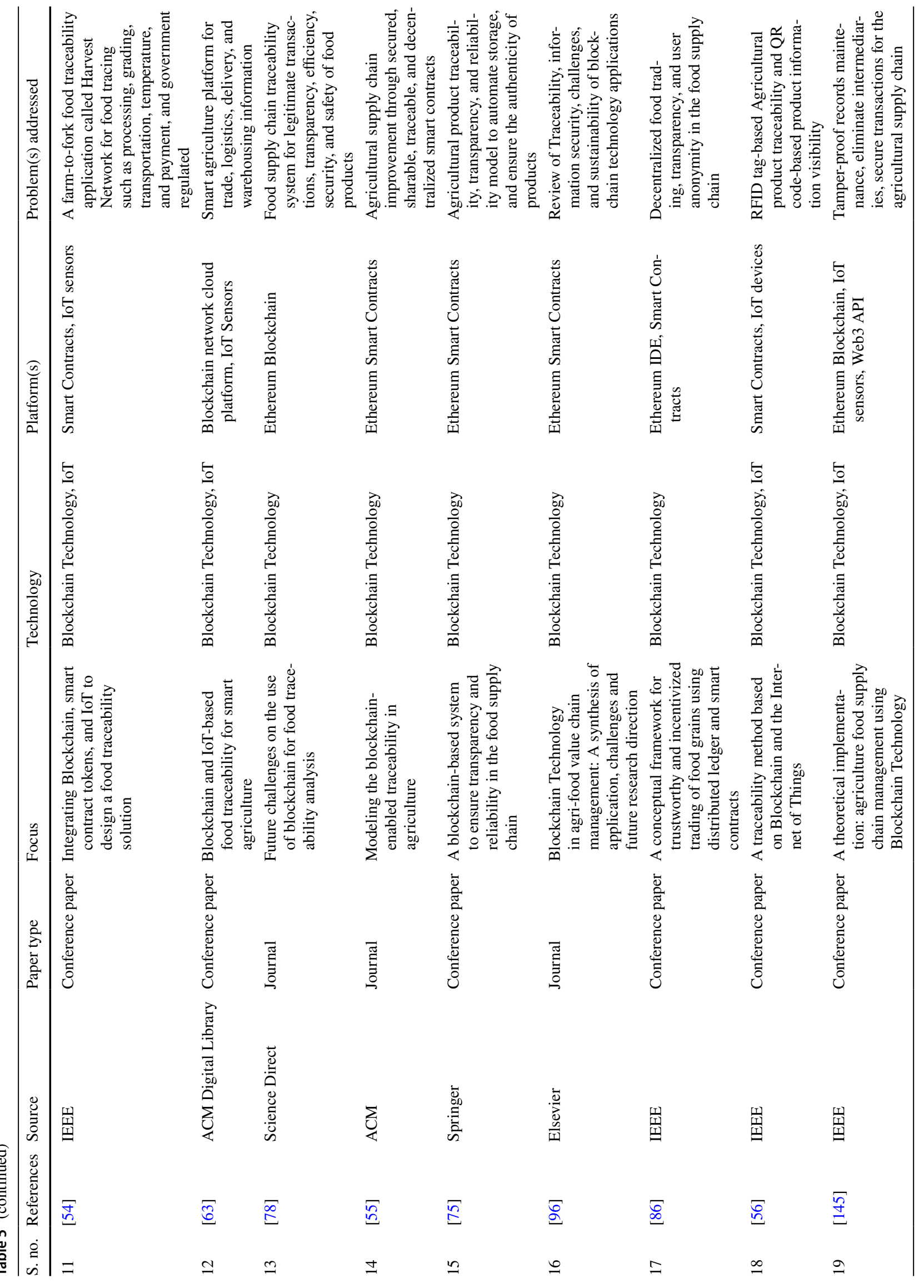




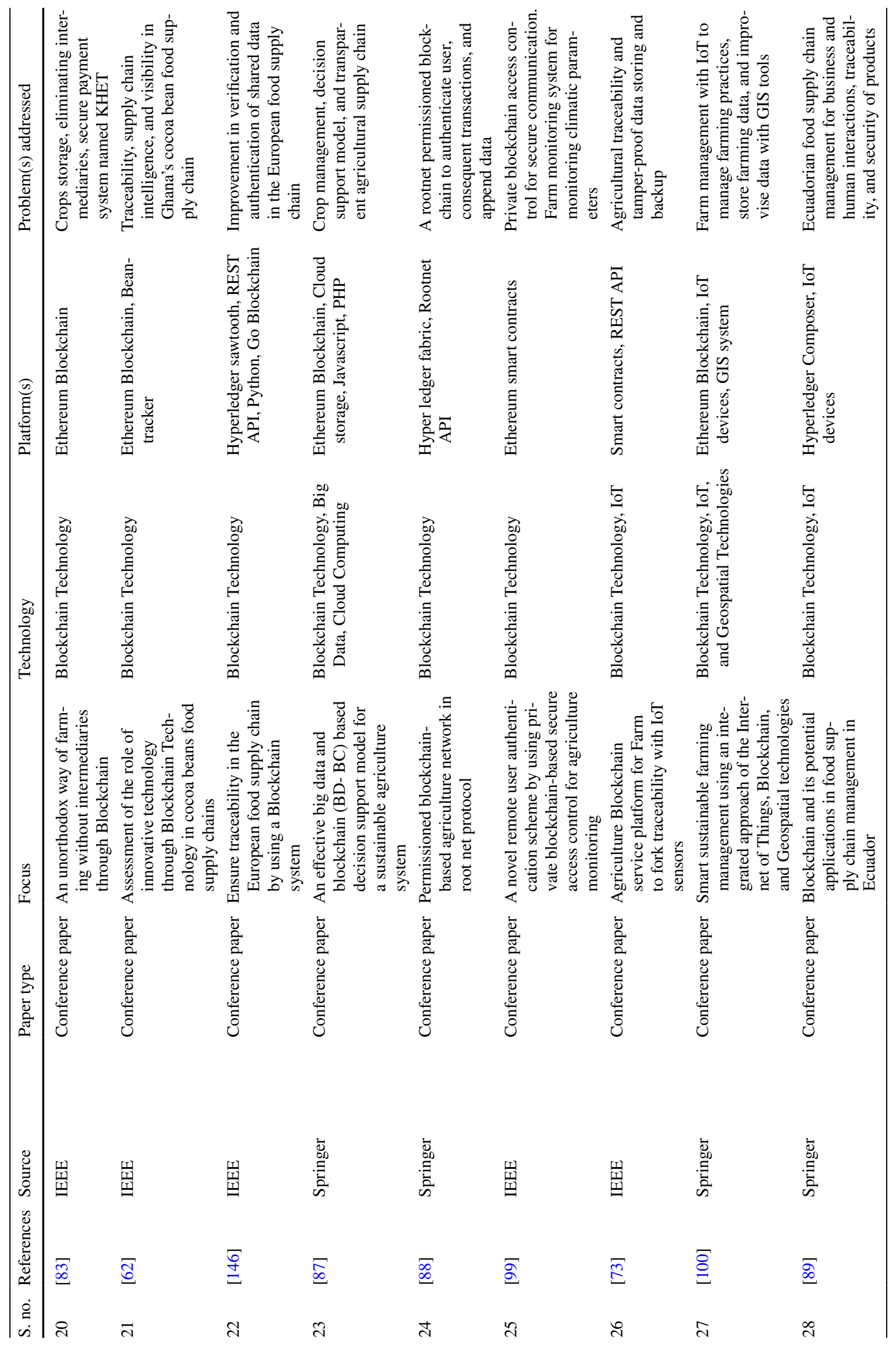




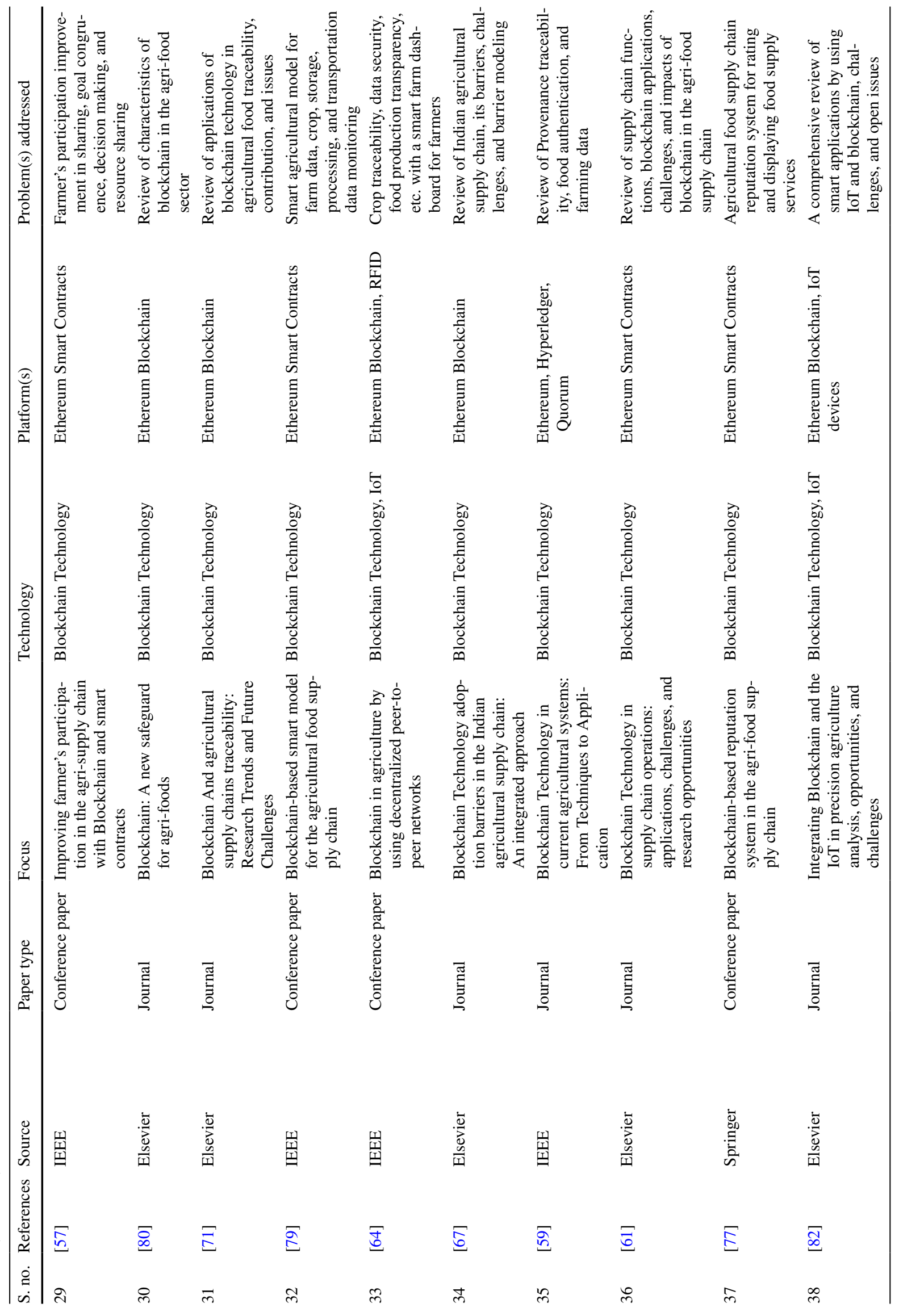




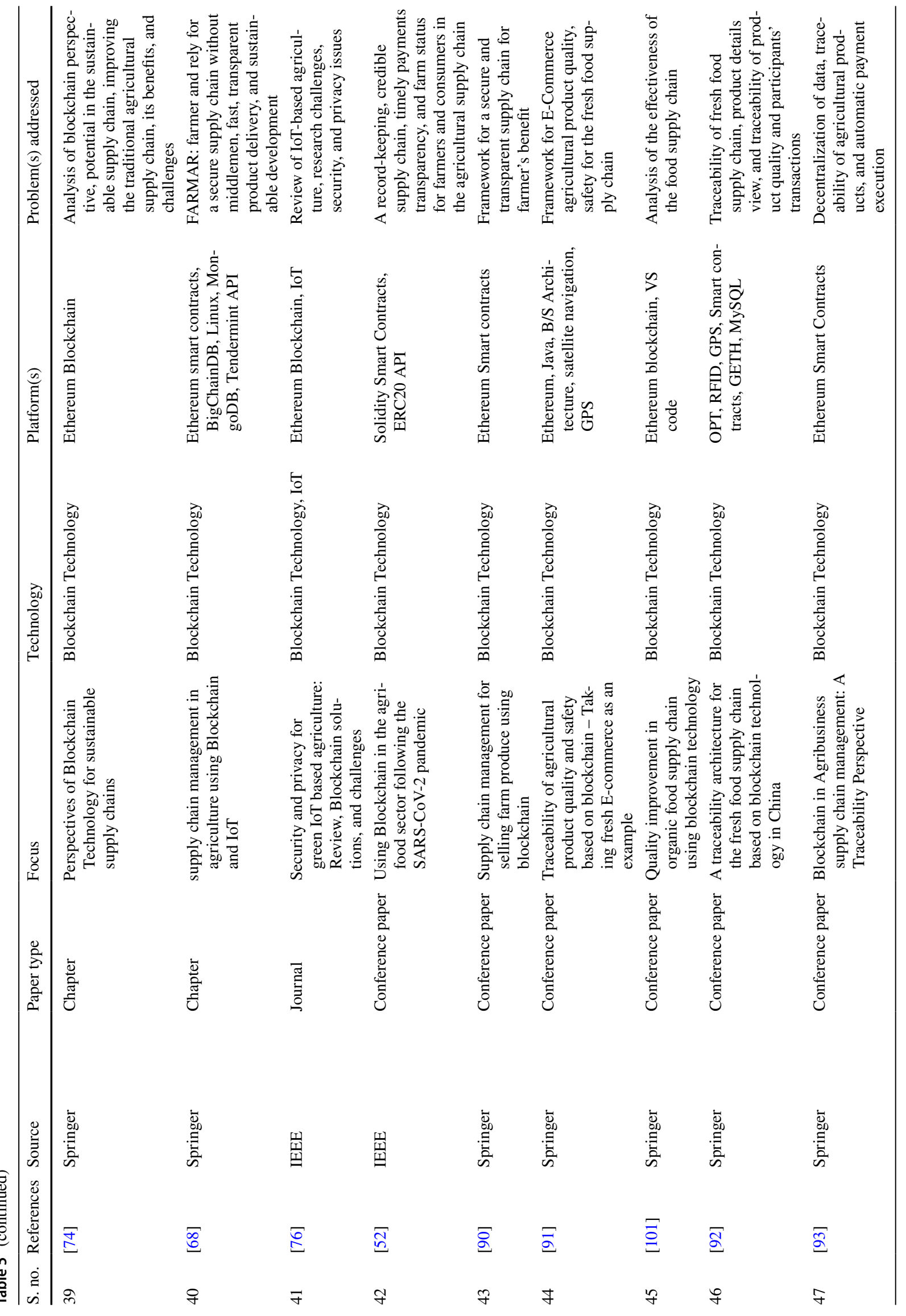




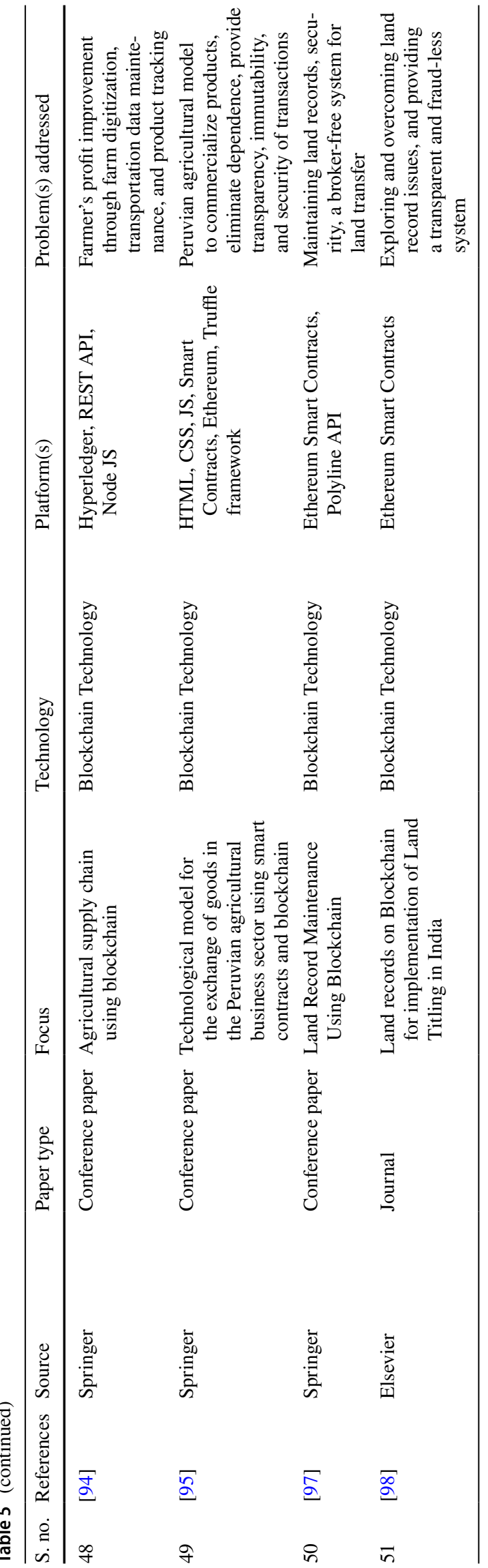

Withal, Madumidha et al., [145] proposed the use of blockchain technology to maintain tamper-proof records, avoid intermediaries and provide security to the transactions which in turn reduces transaction costs and improves the quality of the products. The food products are labeled with RFID tags to maintain the supply chain. The author explained the revolutionary changes blockchain technology can bring to the supply chains and how it can increase the economic conditions of a country by reducing corruption rates and increasing the satisfaction of producers and consumers. Paul et al., [83] proposed a way to eliminate intermediaries between farmers and consumers to provide the right amount for the farm produce. The proposed system consists of blockchain nodes namely Supply companies, landowners, markets, and farmers. The farmer node sets the amount after the agreement period, the market node collects and stores crops and stops intermediaries from manipulating the prices, the landlord node collects the money from the land on lease, and the supply company node sells extra agricultural products to the farmers. This platform named KHET where all the nodes are interconnected through Ethereum blockchain is beneficial for farmers, landlords, and markets.

Musah et al., [62] main objective in proposing the role of blockchain in Ghana's cocoa beans food supply chain was to evaluate the contributions made by applications of blockchain technology in the supply chain. The system provides a global traceability platform, supply chain intelligence and visibility, Africa cocoa village; impact the investing for smallholder farmer and uses Bean tracker. The author carefully studied the tools and platforms benefiting the cocoa bean production and supply chain processes.

Additionally, Baralla et al., [146] proposed a blockchainbased generic agri-food supply chain traceability system for implementing the farm-to-fork model. In this system, a QR code scan can allow the consumer to reconstruct the product history to verify product health and quality. The main contribution of this article was the authentication and verification of shared data's integrity in supply chain management. With the help of this system, the involved operators could identify any new participants along with the supply chain which increased the degree of trust between organizations and individuals. Dakshayini et al., [87] proposed an integrated model based on Blockchain, big data, and cloud to efficiently manage crops that achieve effective demandbased decision support, simplified, transparent, and secure agricultural supply chain. The proposed model has a higher percentile of achieving demand and supply of crops which avoids the farmer's loss, catering to consumer's needs, provides sustainable agricultural practices, reducing middlemen involvement, and reducing price inflation problems. Saji et al., [88] proposed a model to enhance the supply chain performance by using a blockchain network. The proposed model provides security food safety, traceability, and opens 


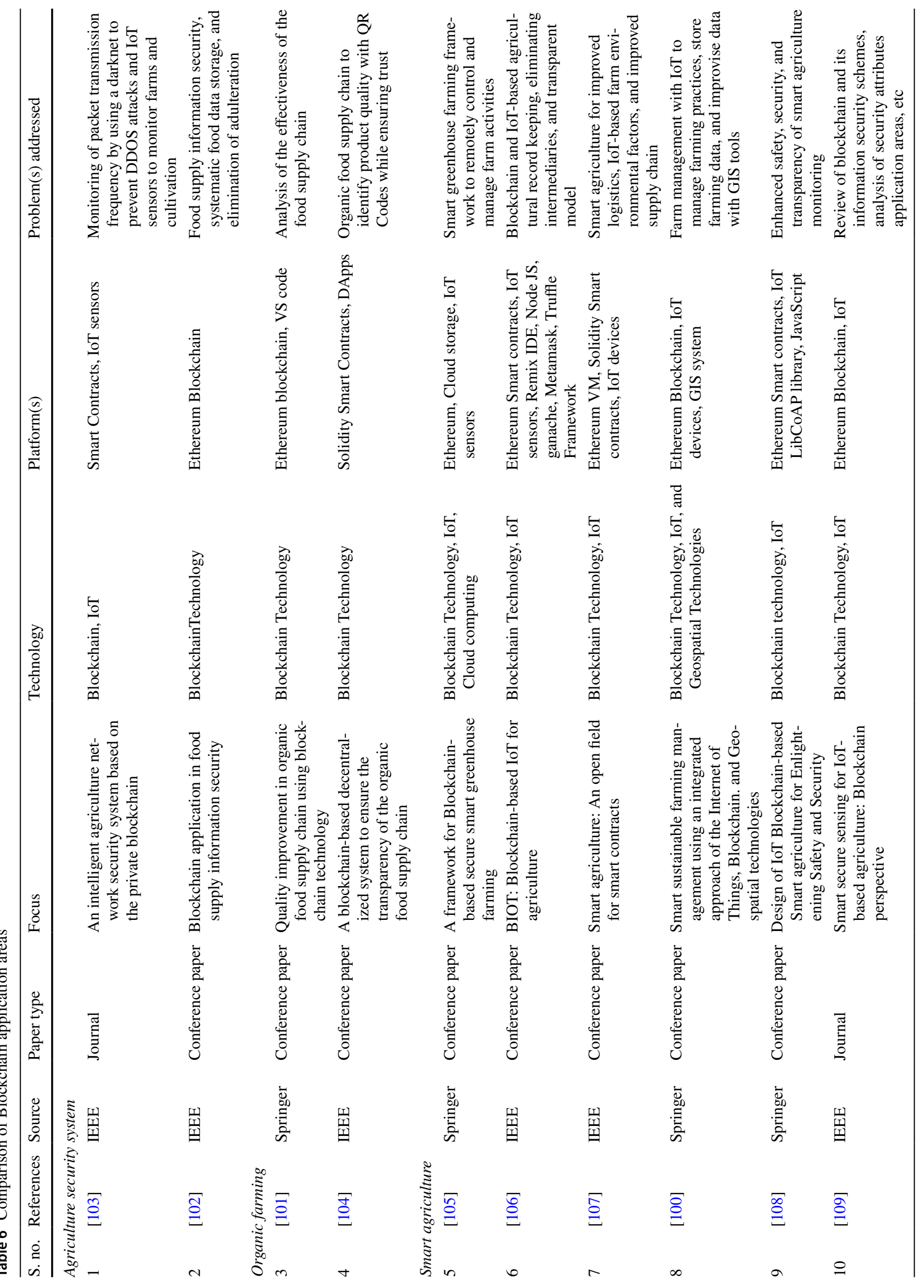




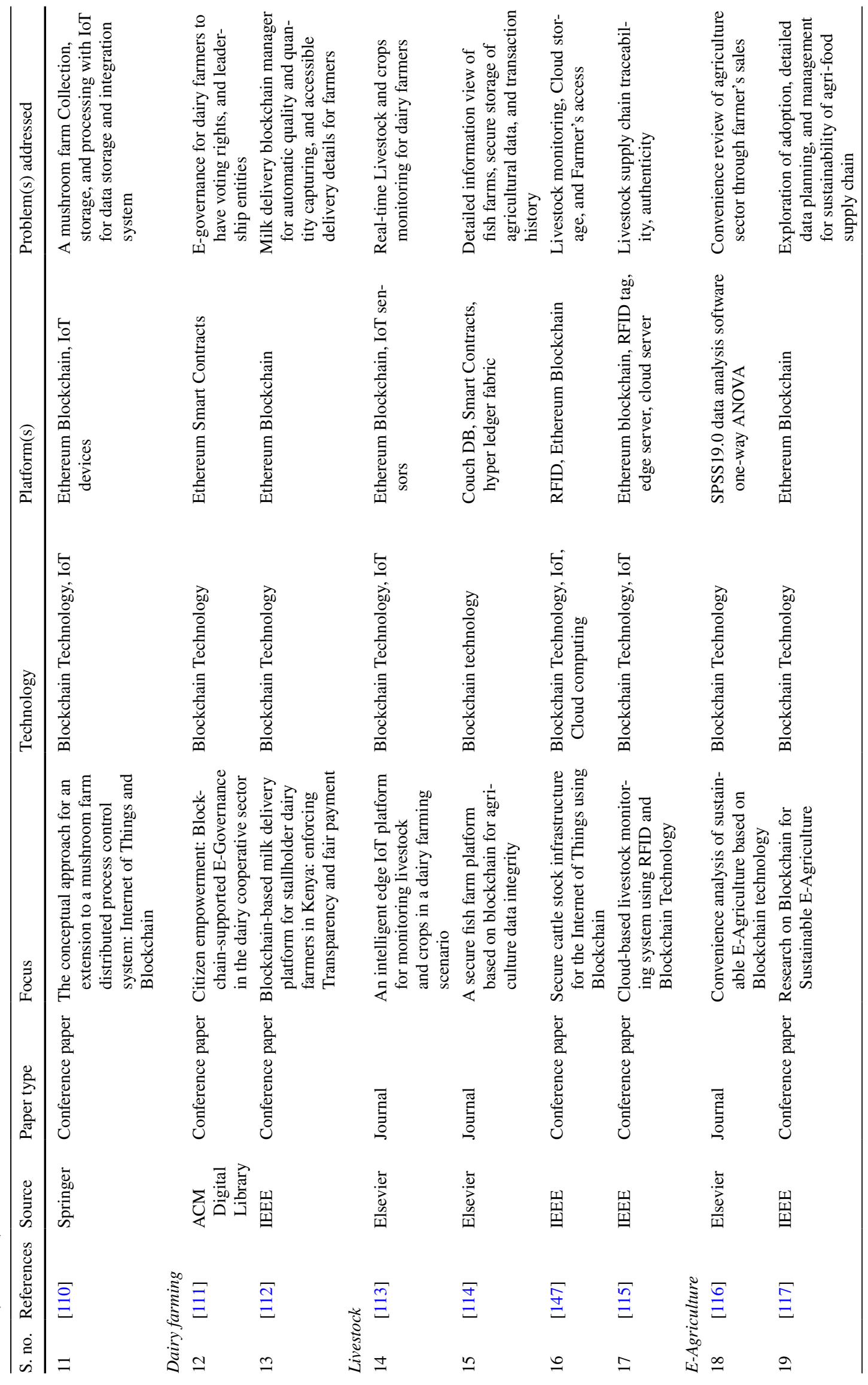




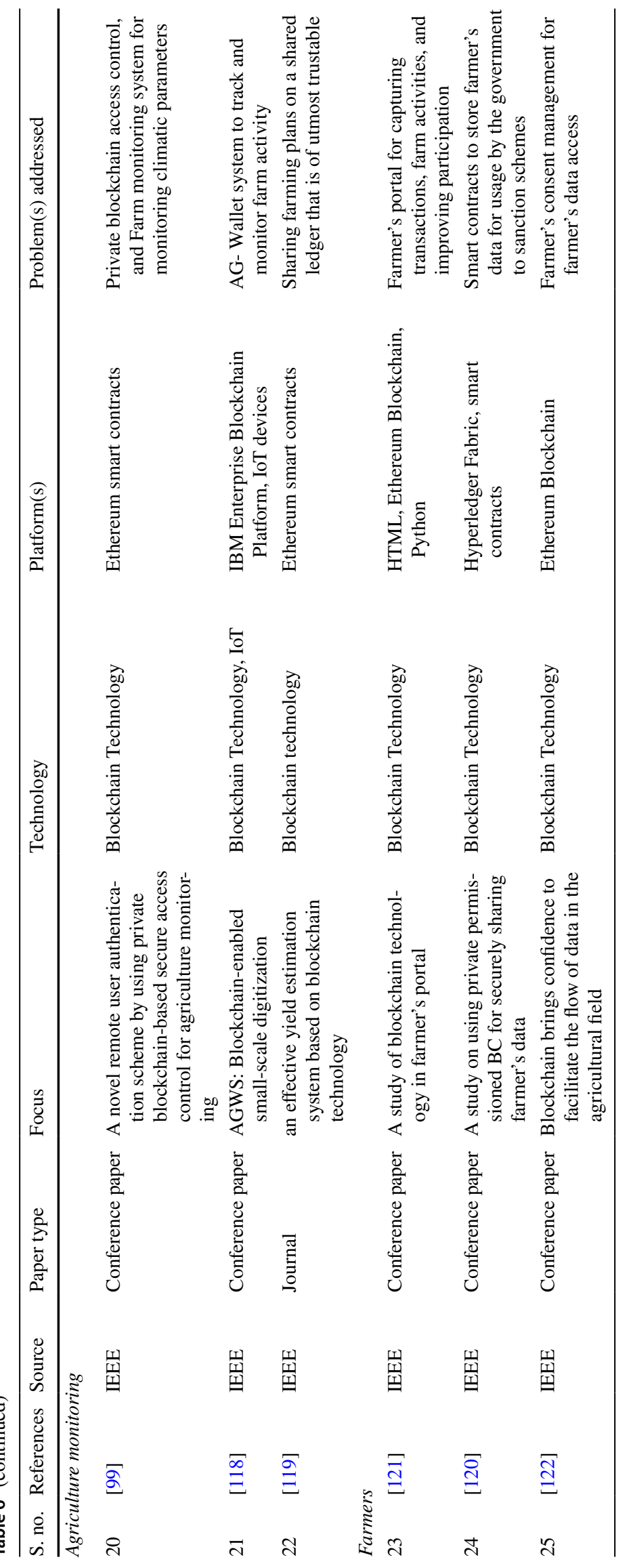




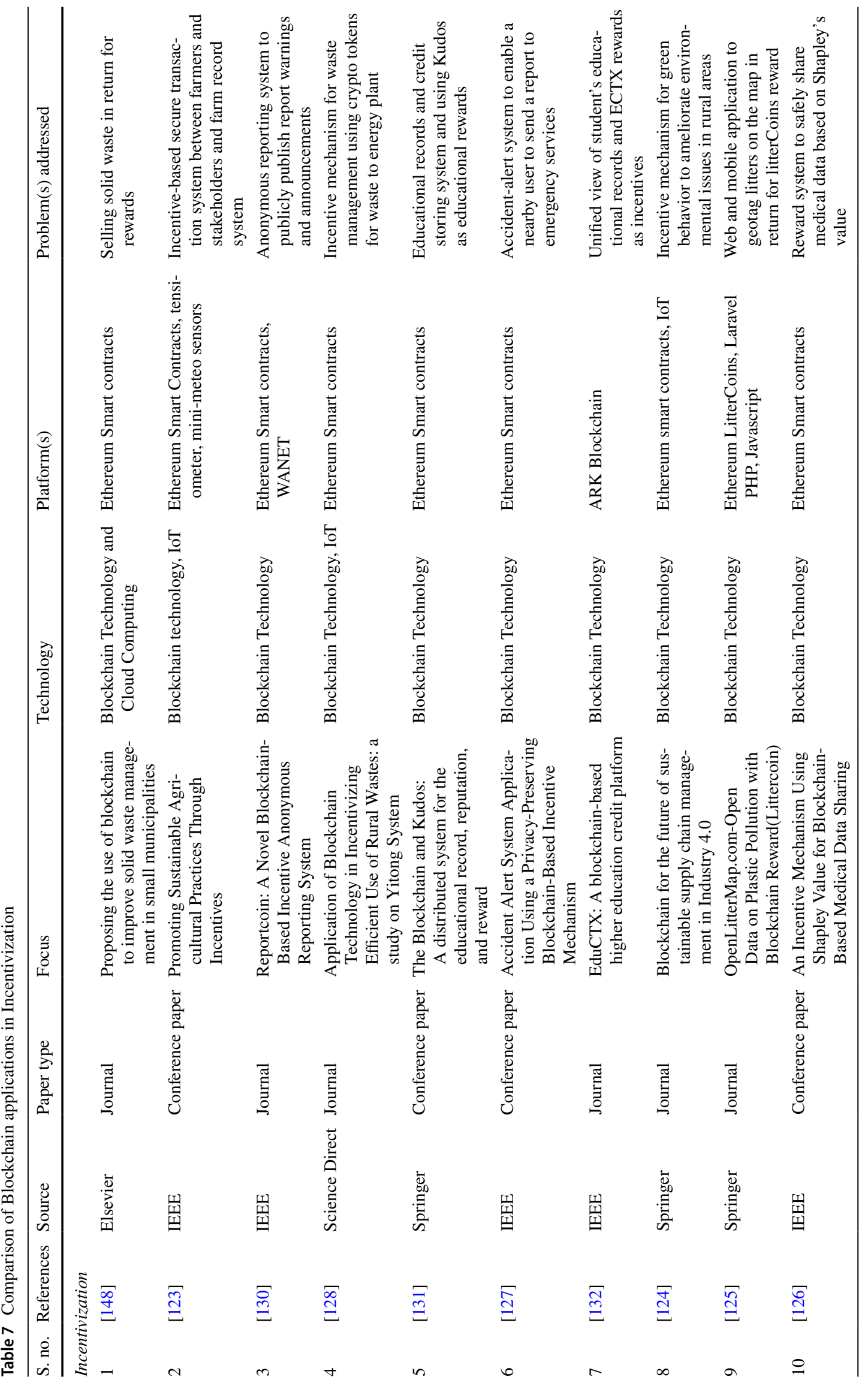


new markets. The system improved farming profitability and endorsed the financial stability of cultivators. It also provided health benefits, reduced food wastage, eliminated manipulation, and adulteration, and supports the supply chain of agro-products. Saurabh and Dey, [69] identified the potential divers of blockchain concerning the grape wine supply chain. The smart contract-based module was constructed to ensure trust between participants during transactions. The proposed model enhanced the customization, competitiveness, and usability of the supply chain.

Iqbal and Butt, [84] proposed a model to save the farmer's crops from animals at night. A repelling and notifying system (RNS) is installed in the field that receives signals during an animal attack. Human-safe ultrasonic waves are produced by this RNS which drives the animals away. This proposal also consists of a farm management system that receives the report regarding the hazards caused in the fields. This system enabled timely data delivery, efficient multi-hop communication, dependable data transmission, and low-cost technology. Chun-Ting et al., [73] proposed a blockchainbased agricultural traceability service platform for tamperproof data storing and backup. The system design consists of Data collecting layer where IoT sensors collect environmental data, the blockchain layer takes data from the formal layer and sends them to blockchain nodes and later to blocks, and the application layer handles the requests to access transaction data based on the transaction hash. Hegde et al., [81] presented different ways of implementing blockchain with the agricultural supply chain. With the use of blockchain, the producers can get data and income security, and keep track of environmental changes that affect the crops. The traceability option provides clarity in any damage that occurred to the product and an overall increase in efficiency can be achieved by producing only required products hence reducing wastage. Peña et al., [89] presented a systematic review on blockchain in food supply chain management in Ecuador. According to the review, most of the work was done in Hyperledger composer, models for business interactions and human interactions, Traceability, Security, and Blockchain Information.

Additionally, M. Kumarathunga, [57] after reviewing presented the way to reduce transaction costs and improve farmer's involvement in agricultural supply chains. To reduce transaction costs farmers can participate in Information sharing, goal congruence, decision synchronization, incentive alignment, resource sharing, collaborative communication, joint knowledge creation. Xu et al., [80] reviewed the working principle of blockchain technology in the agrifood sector. Blockchain technology provided data transparency, data traceability, food safety, and quality monitoring, and agriculture finance. Additionally, food safety and quality can be secured by digitizing products. According to the review, blockchain revealed a better approach to the future of the agri-food supply chain which is safer, healthier, sustainable, and reliable. Mirabelli and Solina, [71] collected and analyzed the applications of blockchain technology and its contribution to agricultural food traceability issues. The review showed that the usability of blockchain technology in the agricultural sector was still in the early stage. The review highlighted three main aspects namely starting problem, area of interest, and contribution. Blockchain can be a valid way to minimize fraud and errors in agricultural supply chains by increasing the quality and safety of food products. Shahid et al., [53] have proposed a complete solution to the blockchain-based agricultural and food supply chain. The paper aimed to provide an end-to-end solution to the growing blockchain-based agri-food supply chains. Further, it achieved the following properties: accountability, credibility, auditability, autonomy, and authenticity. The system also acted as a better alternative to the existing supply chain system by enabling a scalable and auditable system. Awan et al., [79] proposed a smart agricultural model as a transformation to the traditional agricultural supply chain. The system consists of Seed seller, Farmer, Crop buyer, Processor, Crop storage, Distributor, Retailer, Customer. To improve the food supply chain's productivity and reliability the smart model was proposed. The model allowed farmers to enter and monitor the data in the plant. The main objective of this model was to provide equal opportunities to the participants of the agricultural food supply chain. Thejaswini and Ranjitha, [64] proposed a model that explores the problems faced by people in agriculture production and its solutions based on blockchain technology. Blockchain solutions for traceability of crops, disclosure of data, clarity in food production, and authentic agricultural products was proposed by the author. This proposed model ensured food safety, benefitted farmers, and stakeholders.

Yadav et al., [67] reviewed the blockchain adoption barriers in the Indian agricultural supply chain. The barriers can be enumerated as Lack of proper government regulation and regularity uncertainty, Huge resource, and initial capital requirement, security and privacy concerns, lack of interoperability and standardization, etc. Further, the barriers were modeled using an integrated ISM-DEMATEL approach which provided limited interpretative logic. W. Lin, [59] provided a survey to study the techniques and applications of blockchain technology. The application categories of blockchain in agriculture are Provenance traceability and food authentication, smart farming data management, trade finance in the supply chain management, and other information management systems. The paper also indicated possible future developments and applications of blockchain. Dutta et al., [61] reviewed articles related to blockchain technology's integration with various supply chain operations. The benefits of Blockchain in supply chains can be enumerated as Data management, Improvement in transparency, 
Improvement in response time smart contract management, Operational efficiency, and Disintermediation, Immutability, and Intellectual Property management. According to the review, the main supply chain functions were identified as supply chain provenance, supply chain resilience, supply chain re-engineering, security enhancement, business process management, and product management. The work also examined various challenges and impacts of blockchain in the supply chain. Shahid et al., [77] proposed a solution for a blockchain-based reputation system in the agriculture and food supply chain. The system model consisted of invoking smart contracts to provide reviews based on the services to the providers. The reviews are requested by buyers and the sellers' review the transactions and perform other transactions based on that. The system was proposed to maintain the immutability and integrity of the registered review. Torky and Hassanein, [82] presented a comprehensive survey on IoT and blockchain and their importance in developing smart applications. According to the review, crops overseeing, livestock grazing, and food supply chain are a few subsectors in precision agriculture managed by blockchain platforms. Apart from that, a novel blockchain model was also proposed to use as an important solution for major challenges in IoT-based precision agricultural systems. The objectives of Skender and Zaninović, [74] in their paper were to analyze blockchain technology's overall perspective, investigate its potential in a sustainable supply chain to replace the shortcomings in the traditional supply chain. The traceability and transparency in the agricultural supply chain can be improved with blockchain.

To better understand the benefits and challenges and the perspective for sustainable blockchain, the author provided a conceptual framework. Borah et al., [68] proposed a novel blockchain-based Farmer and Rely called FARMAR. The system could provide fair prices and reduce duping by middlemen. The assets can be traced from farmers to consumers, reducing the artificial inflation of prices. Ferrag et al., (2020) [76] reviewed the research challenges on IoT-based agriculture and its security and privacy issues. The rest of the paper identified threat models against green IoT-based agriculture analyzed the privacy-oriented blockchain-based solutions and consensus algorithms for green IoT-based agriculture. Enescu and Ionescu, [52] proposed a model for farmers in the agri-food sector using blockchain. This system ensures a credible supply chain for producers and consumers, guaranteed timely payments between the participants. The authors proposed this system to provide transparency, security, and trust in the trading process. Chaudhari et al., [90] proposed a framework for a secure and transparent supply chain with the help of blockchain technology. With the help of this system, the farmers can get a fair price for their products. This transparent and tamper-proof supply chain system generates a bill at the end including the commissioning price as well as the total price after sold product hence benefiting the farmers in knowing the selling and market price. Xie et al., [91] proposed to construct a traceability framework For fresh E-commerce agricultural product quality and safety based on blockchain technology. To access the key control points the author used the FMECA (failure model effect and key analysis) to analyze the failure mode, impact, and hazards in the traceability chain. This system can promote agricultural development through decentralization, consensus trust, maintenance, and reliable database features.

Furthermore, Li et al., [92] proposed a blockchain-based Traceability of the fresh food supply chain With the help of business process reengineering (BPR). The overall traceability architecture is based on key links' product quality data and participants' transactions. The objective of this traceability system was to ensure data integrity. Flores et al., [93] proposed a model for decentralization of data and provide traceability of agricultural products with blockchain technology. Using this method could guarantee transparency of the supply chain and other operations as well as the transactions involved. Fernandez et al., [94] proposed a Blockchainbased model to improve farmer's profits. The author aimed to improve the output primitives of the supply chain. Farmerto-consumer product tracking and cost were the main factors in improving traceability in the supply chain. Cortez-Zaga et al., [95] proposed a model used in the Peruvian agricultural sector using blockchain. When using blockchain it can eliminate dependence on a central entity, provides integrity of the process, transactions become irrevocable, secure, and private, and provides transparency and immutability. G. Zhao, [96] presented a systematic literature review that explored the advances in the agri-food supply chain. The paper also pointed out the challenge of the applications of blockchain technology enumerated as storage capacity and scalability, privacy leakage, high-cost problem, regulation problem, throughput and latency issues, and lack of skills.

Land record maintenance using blockchain was also proposed by Bhorshetti et al., for easy maintenance of land records in real-time. The database proved to be a non-failure system and the work provided intermediary-less land title transfer and processing between owners. This system provided security, transparency, and a broker-free land management system [97]. The paper by Thakur et al. presented the issues related to land records maintenance, registration, settlements, and banks. The system ensured better land management, lesser fraudulent transactions while strengthening the sustainable development goals (SDG) and increasing the GDP of the country [98].

\subsubsection{Agriculture Security System}

Tse et al., [102] proposed food supply information security based on blockchain technology. The use of blockchain in 
this system can regain the people's trust in the food market, the government can collect statistics on various kinds of food, and adulterated and fake food in the market can be eliminated. This type of technology can benefit the customer, manufacturers, and supervision departments of the food supply chain. Wu and Tsai, [103] proposed an intelligent agriculture network security system by applying dark web technology to monitor packet transmission frequency in order to prevent DDOS attacks. The system applied a darknet mechanism to identify anyone who attempts to access blockchain data. It also incorporated IoT sensors to gather data regarding temperature, humidity, and soil. This model was proposed to keep track of the farms and cultivation factors related to an environment and to establish network security for IoT networks.

\subsubsection{Organic Farming}

Reddy and Kumar, [101] presented the article based on the sustainability of the food supply chain. The author's objective was to achieve Fair Trading and a circular economy with the help of blockchain technology. With this framework, the following results but achieved: Automatic hashing for less electricity consumption, product malfunctioning and add alteration, the involvement of middlemen, availability of farming jobs, and facilitating development and unity among farmers. According to Basnayake and Rajapakse, [104], the purpose of the research was to implement a Blockchainbased solution to verify food quality. The process included Farmers issuing a product contract to control the quality of each product. For each deployment of the product contract, it would return an address that was used to generate the QR code to identify the physical product. Lastly, Consumers were also eligible to rate the product quality to ensure trust.

\subsubsection{Smart Agriculture}

To overcome remote monitoring challenges and provide security and privacy in agriculture, Patil et al., [105] proposed a lightweight architecture for smart greenhouse farming. The model consisted of four groups showing the integration of blockchain with IoT namely (1) smart greenhouse, (2) overlay network, (3) Cloud storage, and (4) End-user. This model can be used to successfully monitor the secure transmission of greenhouse data. Umamaheshwari et al., [106] proposed a model for Buying and selling crops and land. The model used Ethers as a cryptocurrency. According to the paper, the recordkeeping of crops grown in the land was useful to know the history of plantations in the land. With the help of this model, users were able to access real-time data about crops, eliminate the need for middlemen, and establish a transparent and efficient system. Voutos et al., [107] proposed the integration of IoT and smart contracts to develop smart agriculture to deliver higher quality agricultural products. It also focuses on improving the associated supply chain and logistics benefiting the participants involved. The author discussed the factors of smart agriculture as soil factors, climate, sensors, research, supply chain, storage, analytics, and smart contracts. Miloudi et al., [100] proposed IoT, Blockchain, and Geospatial technologybased Smart farming to manage the farming practices more smartly and sustainably. The system proposed smart farming management in 4 stages namely (1) Integrated blockchain with IoT platform where various IoT sensors apply analytics and sends data to the blockchain, (2) Blockchain Working Methodology where data visibility is provided through smart contracts, (3) Integrating GIS with blockchain where the data sent from IoT sensors are improvised and accuracy is facilitated through GIS geospatial tools, and (4) certifying farmers in blockchain stage facilitates authorities and privileges to the farmers through smart contracts which could greatly benefit farmers and food production industry.

Furthermore, Devi Et al., [108] Proposed a design architecture by merging IoT and BC for smart agriculture. The nodes involved in the blockchain received the information from the sensors that were connected to the things involved in the Smart Agriculture monitoring process. The design architecture enhanced the security and data transparency performance of smart agriculture. Vangala et al., [109] reviewed blockchain technology and its information security schemes. The application areas covered by the authors were agriculture monitoring, controlled agriculture/smart greenhouses, food supply chain tracking, and precision farming/ smart farming. The review also presented a thorough analysis of the security attributes, application areas, advantages, drawbacks, and competing schemes' cost of computation and communication. Branco et al., [110] proposed a conceptual approach with the integration of IoT and blockchain for a mushroom farm distribution process control system. The proposed system allowed the collection of distributed data on the environmental factors contributing to mushroom production providing collection, storage, and processing of mushroom farm data to be scalable, immutable, transparent, auditable, and secure.

\subsubsection{Dairy Farming}

Misra and Das, [111] presented a conceptual framework using blockchain to bring feasibility and efficiency in E-governance. The architecture consisted of a serviceoriented architecture framework to store details of stakeholders involved in user services on demand, a blockchain architecture that would allow stakeholders to authenticate and perform transactions on the ledger, and digital identity architecture to act as a regulator in the architecture. With a dairy farmer as a user or participant in the architecture 
who would benefit from the transactions while having voting rights and leadership entities in the system the author conceptually explored the prototype of the dairy cooperative sector in India. Similarly, Rambim and Awuor, [112] proposed a model for dairy farmers in Kenya that explores the potential use of blockchain technology in milk delivery in rural areas. From the Naitiri Dairy farmers' cooperative (NADAFA) in Kenya, the author introduced a Milk Delivery Blockchain Manager (MDBM) which is a decentralized platform to automatically capture the quantity and quality of milk delivered by the farmers. The delivery data stored in the blockchain is immutable, cryptographically hashed, and digitally signed. The details of delivery are accessible to the farmers. The NADAFA facilitates the system and provides payment to the dairy farmers on time. The consortiumbased network provides leveraging blockchain solutions for farmers.

\subsubsection{Livestock}

Under Livestock monitoring, Alonso et al., [113] worked on important trends in the applications of IoT and edge computing paradigms in the smart farming field. This helps producers to optimize processes, provides the origin of the product, and guarantees the quality to its consumers. The state of dairy cattle and feed grain can be monitored in real-time by using artificial intelligence and blockchain technology. This is to ensure the traceability and sustainability of different processes of farming. The implementation of smart farming contributed to the reduction of data traffic and reliable communications between IoT-Edge layers and the Cloud. According to Hang et al., [114], the uncertain data quality of analysts' data can be solved through blockchain. The proposed structure brings scalability, off-chain storage, privacy, and high throughput as advancement to the previous version. Various IoT data is fetched from fish farms such as temperature, water level, oxygen, and $\mathrm{PH}$ data. The data storage can be a database or cloud and end-user can view the fish farm's detailed information through smart devices. Leme et al., [147] proposed a novel infrastructure based on the integration of cloud storage and blockchain technology to monitor the overall health of livestock. The components of the architecture can be named as (1) Administrator, (2) Users, (3) Cloud service, and (4) blockchain network. With the help of RFID tags attached to the cattle, various entities can be monitored to ensure that cattle go through necessary procedures. Yang et al., [115] proposed a novel method to ensure traceability and authenticity in the livestock supply chain using blockchain. The model uses RFID-sensor-based livestock monitoring in the food industry where the sensors augment the physical tracking and solved the RFID's inherent computational capacity limitation by using cloud services. The data is then made accessible to the end consumer through Block chain's transparent ledger.

\subsubsection{E-Agriculture}

The analysis proposed by $\mathrm{Li}$ et al., [116] Investigated the convenience of sustainable electronic agriculture based on Blockchain technology and analyzed the application likelihood and challenges of Blockchain in the agricultural field. The authors selected 5 villages with similar development rates in china and Blockchain technology was applied using data statistics to the sustainable e-agriculture for exploring its convenience. Results showed that sustainable electronic agriculture based on Blockchain Technology brought great convenience to the farmer's sales, increasing by $25 \%$ on average compared with traditional electronic agriculture. Song et al. [117], to improve the biased point of view, higher initial costs, and lack of transparency and trust proposed a system for providing sustainability in the current agri-food supply chain. The paper discussed blockchain adoption in rural areas and relative energy consumption from supply and demand perspectives.

\subsubsection{Agriculture Monitoring}

Arshad et al., [99] proposed a private blockchain-based secure access control for agriculture to monitor climatic parameters. Private Blockchain access control (PBAC) was used to guarantee secure communications where a user usually goes through initialization, authentication, and revocation. The farms monitoring system consists of the login phase, system setup phase, user/farm professional registration phase, password authentication and session key agreement phase, update or change phase, and addition of node phase. The whole system stores access records and lessen the computational and communication overhead. Forbye, N. Bore, [118] proposed a model to improve the shortcomings of existing digitized farming models through the AGWallet System (AGWS). The AGWS design consisted of (1) digitizing the far demand-supply, (2) The farm information pipeline was to ensure secure storage and validate events received from IoT, and (3) data analytic services that make the information visible to the participants. The system proposed by Osmanoglu et al., [119] uses a blockchain-based yield estimation solution. Farmers can share the farming plans for the upcoming harvesting season with other participants, or learn from other's plans to review their plans. Smart contracts can be employed by participants to share their yield commitments. The author improvised a censorship-resistant, tamper-proof, and immutable public ledger of time-stamped transactions. 


\subsubsection{Farmers}

Talreja et al., (2020) [121] proposed a farmer's portal with the help of blockchain technology and python to preserve the contract of trade between farmers and consumers. The farmer's portal is a way to access farm activities. The proposed work enhanced the degree of participation, reduced intermediary cost, simplified process, provided ease of selling crops, and greater efficiency. The immutability of blockchain technology fortified farmers for getting a fair price for their crops and reduced operational costs. Abraham and Kumar, [120] proposed a blockchain-based data security system to preserve farmer's data. The proposed work was based on a private-permissioned blockchain for controlled participation, hyper ledger fabric to support smart contracts, and system design to safely store farm data. The widened blockchain data helps farmer's data to be accessed by other participants which can allow the government to sanction schemes based on farmer's data. Topart et al., [122] proposed an interoperable ecosystem of farmer's consent management. The model used a permissioned blockchain to allow only a specific group of people to access the services. The immutability of consent allows the data to be non-manipulative, distributed, signed transactions, and transparent. The consent verification for each data allows only valid users to request data. The model was proposed to respect the privacy, security, transparency, and consent of the farmer's data.

\subsubsection{Incentivization}

Blockchain has been using incentive mechanisms since bitcoin to incentivize miners, but recently many authors have presented ways of promoting work for a reward. Incentives to promote sustainable agricultural practices by Giaffreda et al., [123]. Objectives include savings and increasing market value plus monitoring the use of water in the fields. Farmers have been relying on satellite data as it is a cheap source of agricultural services. With the use of LPWAN networks, accuracy in fields is increased along with a tensiometer-a sensing unit that is used to wirelessly communicate the data related to the humidity of the soil and a mini-meteo station that is used to measure temperature, air humidity, and air pressure. Smart contracts record the transactions from the calculated results in the cloud and release the incentives to the farmer according to their deal with the stakeholder. The proposal includes EnvCoins as the incentives, which can be further used to buy technologies for sustainable agricultural practices, for cash, or investment. Esmaeilian et al., [124] proposed an incentive mechanism for green behavior such as waste disposal, using re-furbished products, purchasing energy-efficient products, saving energy, recover, repair, and maintain. The tokens gained from sustainable behavior can be further used to access services on blockchain.
Incentivization can ameliorate some of the environmental issues in rural areas with the help of rural people by motivating them to clean the areas. OpenLitterMap by S. Lynch, [125] uses geospatial analysis to geotag various types of litter. It uses LitterCoins as an incentive mechanism for the proof of work. This is to motivate people to submit correct data. It also rewards for uploading litter images from a new location. Apart from plastic and other homogenous litter, a proposal to eliminate solid waste from small municipalities in return for a reward is given by França et al., [148]. The provision was to change the original system from attack risk, data loss, power outage, and other such problems. The new digitized system proves to be a handier as it is in the form of a mobile application. The reward for selling solid waste to the collecting agent is in Green Coins, a cryptocurrency sent to the seller's virtual wallet. This initiative led to computerization gains, information integrity, and the use of cryptocurrency. Additionally, in [128] D. Zhang, worked on a similar solution to efficiently use rural waste in incentivizing rural people. The process includes the installation of smart bins and when they are full, the collection trucks will swap the waste for a digital coupon which the farmer can use to either get agricultural products from the waste to the energy plant or cash them. Blockchain makes it an easier process to transfer and record data faster with maximum transparency. Other applications of incentives for waste include Recereum, SwachhCoin, Plastic Bank, 4New, and OILSC [129].

The motivational incentive mechanism can also transform the way medical data is shared for research and diagnosis. In the paper by Zhu et al., [126], the authors gave a solution to actuate people into sharing medical data by providing them rewards for doing so. The rewards system is based on the access provided by the owner of the medical file. Through Smart contracts, a trusted payment money flow can be devised between the third party and the owner. The Shapley value was considered for the revenue distribution of medical data sharing and to study the impact of consensus on the miner's income. Furthermore, an incentive mechanism for the accident alert system, proposed by Devi and Pamila, [127] is another blockchain-based medical application. According to the authors, most of the accidents occurs near rural places where medical help is unreachable on time. To eliminate the privacy issue of the nearby user who receives the accident report, a blockchain-based incentive method is implemented for the user who receives the accident alert to send the location of the victim to a close-by emergency service. Then the message initiator gets rewarded incentives for alerting about the accident. A similar report system mobile application for anonymous reporting is proposed by Zou et al., [130] in which reporting any incident can earn people rewards. The design goal of the author was to implement an anonymous report system, to provide privacy to the person who reports, without having to give their personal 
Fig.15 Blockchain applications in Environment

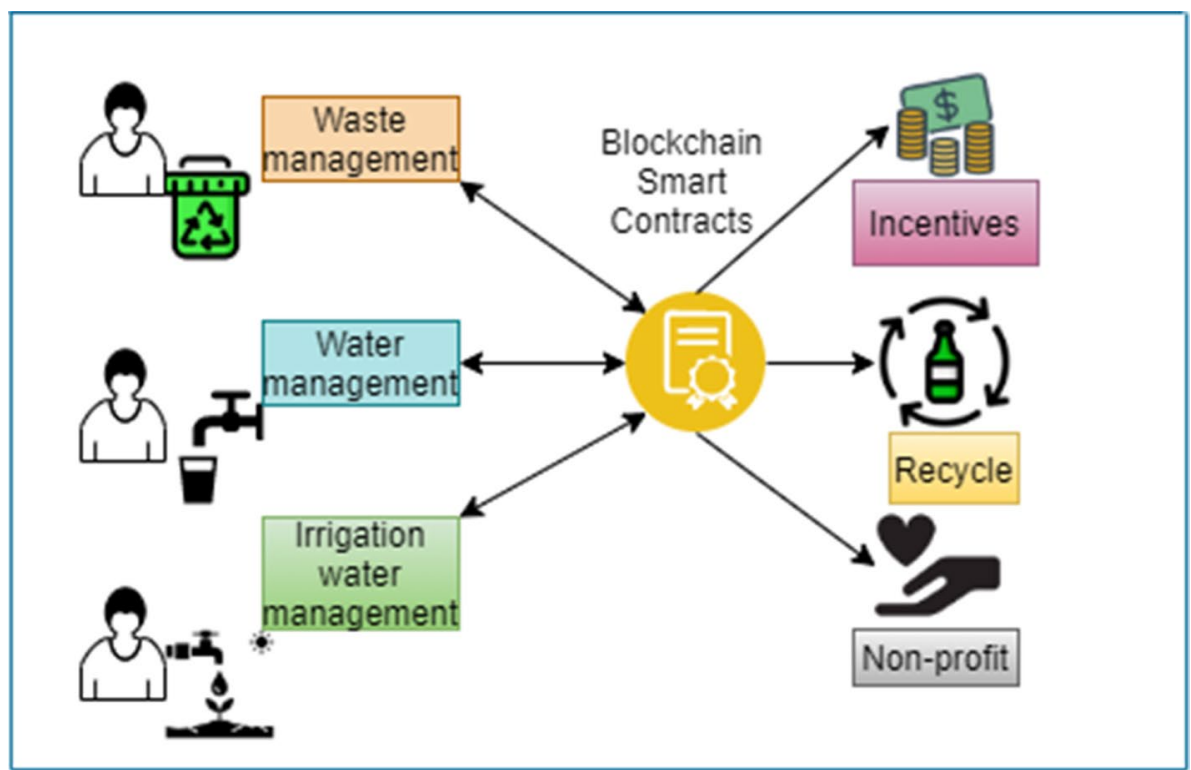

information to the system. This model induces incentive named Rcoins to whoever published the report information, the repliers, and the consenting miners. The Blockchain and Kudos by Sharples and Dominigue, [131], a reward-based permanent solution as the digital record-keeping model. The author proposed the use of blockchain to store digital certificates, achievements, and credits. Stored as a public record it can be accessed by the institutions or the student online. The model uses Kudos an educational reputation currency as a reward. The reward can be earned through uploading certificates on the blockchain, passing a test, or on course completion. Another application of blockchain-based incentive system is EduCTX by Turkanović et al., [132] which is proposed to globally enable the higher education credit platform. For potential stakeholders such as educational institutions, companies, and organizations a unified view of student's higher education credits and grading system is placed on the global ledger through blockchain. ECTX tokens will be credited based on the completion of courses which will act as proof of completed courses.

\subsection{Environment}

In the environment sector, the most emphasis was given on blockchain applications in Natural hazards, Water, and Waste management in rural areas (Fig. 15). A detailed summary is given in Table 8 .

\subsubsection{Waste Management}

From the articles proposed, in D. Zhang, [128] the author worked on a similar solution to efficiently use rural waste in incentivizing rural people. This framework is based on
China's Yitong system which is waste to energy plant for agricultural waste and the use of blockchain to provide digital coupons or cryptocurrency in return for waste. The author proposed the use of a web application to use a QR code scanner when the waste is collected from a smart bin, also encouraging segregation of agricultural waste and residential waste. The serves receive the weight of waste, lodges it on the global ledger, and the coupon is rewarded based on the weight. Apart from plastic and other homogenous litter, a proposal to eliminate solid waste from small municipalities in return for a reward is given by França et al., [148]. The provision was to change the original system from attack risk, data loss, power outage, and other such problems. The new digitized system proves to be a handier as it is in the form of a mobile application. The reward for selling solid waste to the collecting agent is in Green Coins, a cryptocurrency sent to the seller's virtual wallet. This initiative led to computerization gains, information integrity, and the use of crypto-currency.

Latif et al., [133] have addressed the smart waste management system with the integration of IoT and blockchain. The proposed model included identification of waste material, trace location, send to trash, categorize waste, transfer waste, recycling, and decision-making process. The sensor nodes in the model were used for waste identification, and adding new blocks and the admin and waste management offices were responsible for collecting, executing recycling, and delivering products. The recyclable wastes are transformed into useful products and share with the customers and send the non-recyclable wastes to the trash. 


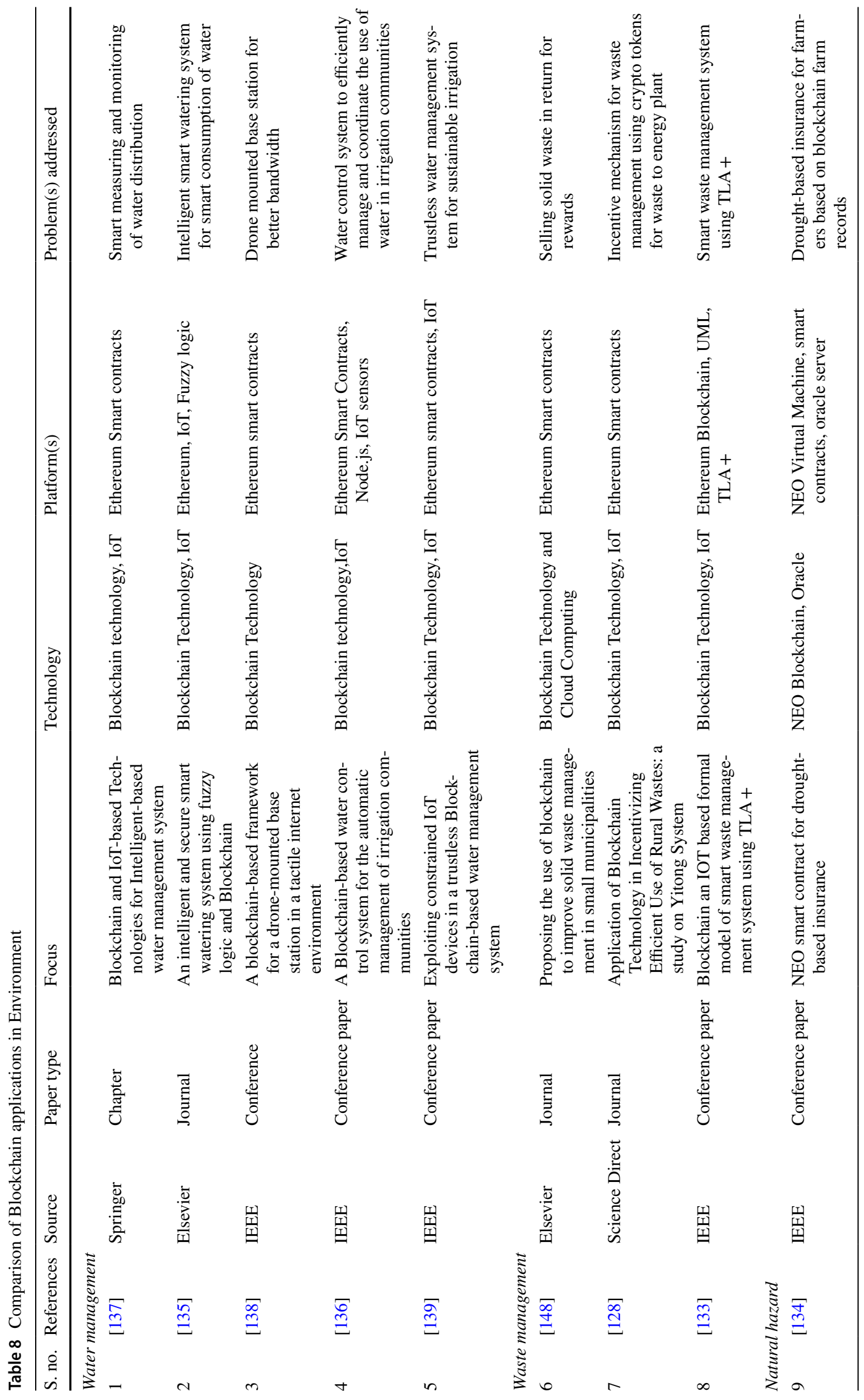




\subsubsection{Natural Hazard}

Additionally, Nguyen et al., [134] proposed a blockchainbased weather-based index framework based on smart contracts. In this system, a NEO smart contract with an oracle server was introduced. In the process of the farmer's request for an insurance enrolment, the insurance entity accepts the requests, the agreement is formed based on a policy scheme, Irrigation water companies release the water reports based on which the smart contracts execute the claims to the farmers. Deployment of the system can ensure water supply in rural areas and accessibility of insurance in case of droughts or floods.

\subsubsection{Water Management}

The intelligent smart watering system proposed by Munir et al., [135] is a blockchain-based system for the smart consumption of water. The system uses IoT for capturing real-time environment conditions such as soil moisture level, light intensity, air humidity, and air temperature. The main focus of the proposed system was to develop a healthy ecosystem while efficiently using water in plantations and gardening. Forbye, A water control system to efficiently manage and coordinate the use of water in irrigation communities is proposed by Bordel et al., [136]. The prosumer environment in the model is composed of a rule definition module where users can create irrigation recipes using ECA (Event-Condition-Action) rules. These rules are executable and easily transformed into other programming languages. Inputs are taken by a transformation engine, to create, compile, and deploy a set of Smart Contracts coding all the irrigation and management logic. Finally, irrigation recipes are executed by an execution engine, which invokes deployed Smart Contracts to interact with the infrastructure. From the perspective of Dogo et al., [137] proposed convergence of IoT and Blockchain. Objectives of smart water solutions include smart measuring and monitoring across the water distribution, enhanced security, better analysis of the generated data, and enhanced revenue and efficiency.

Similarly, Hassija et al., [138] proposed a drone-mounted base station in the tactile internet environment based on blockchain. The drone-mounted small cell station was based on a Permissioned peer-to-peer blockchain. To take strategic decisions, a game theory model was deployed. The decision was based on user association; transmit power level, drone speed, and altitude. Additionally, smart contracts can add parameters and conditions based on requirements. The model's results showed that the low network areas can experience better bandwidth with the proposed system.

Further, the proposed model by Pincheira et al., [139] presented a trustless water management system-based software architecture. The system proposed presented a decentralized water management system that could incentivize virtuous behavior in agricultural practices. Smart contracts were used for their intermediary-less characteristic. The authors also implemented a cross-platform software library to allow constrained devices to interact with blockchain directly. The
Fig. 16 Blockchain applications in Smart Energy

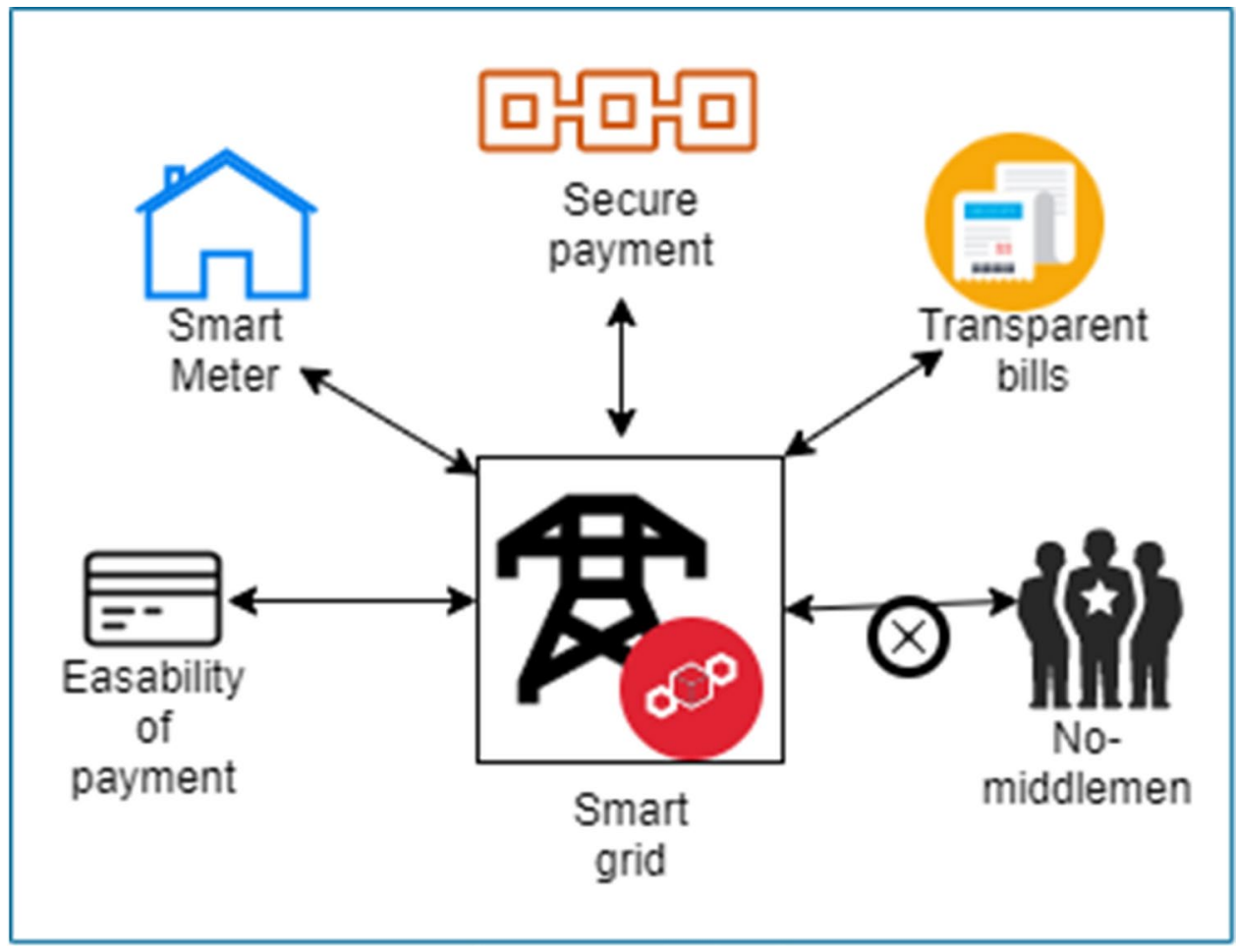


Table 9 Comparison of Blockchain applications in Energy

\begin{tabular}{|c|c|c|c|c|c|c|c|}
\hline S. no. & References & Source & Paper type & Focus & Technology & Platform(s) & Problem(s) addressed \\
\hline \multicolumn{8}{|c|}{ Renewable energy } \\
\hline 1 & [143] & Science Direct & Journal & $\begin{array}{l}\text { Biomass Blockchain } \\
\text { as a factor of ener- } \\
\text { getical sustainabil- } \\
\text { ity development }\end{array}$ & $\begin{array}{l}\text { Blockchain Tech- } \\
\text { nology }\end{array}$ & $\begin{array}{l}\text { Ethereum Smart } \\
\text { contracts }\end{array}$ & $\begin{array}{l}\text { Energy transfer } \\
\text { through smart grids } \\
\text { and real-time pay- } \\
\text { ment }\end{array}$ \\
\hline 2 & [142] & IEEE & Conference paper & $\begin{array}{l}\text { Blockchain } \\
\text { Technology and } \\
\text { renewable energy } \\
\text { access: A case } \\
\text { for sub- Saharan } \\
\text { Africa }\end{array}$ & $\begin{array}{l}\text { Blockchain Tech- } \\
\text { nology }\end{array}$ & - & $\begin{array}{l}\text { Sub-Saharan Africa } \\
\text { in the industrial } \\
\text { revolution, block- } \\
\text { chain adoption } \\
\text { challenges, and } \\
\text { modalities }\end{array}$ \\
\hline \multicolumn{8}{|c|}{ Energy grid } \\
\hline 3 & {$[144]$} & IEEE & Conference paper & $\begin{array}{l}\text { A blockchain-based } \\
\text { smart grid model } \\
\text { for rural electrifi- } \\
\text { cation in India }\end{array}$ & $\begin{array}{l}\text { Blockchain Tech- } \\
\text { nology }\end{array}$ & $\begin{array}{l}\text { Ethereum Smart } \\
\text { contracts }\end{array}$ & $\begin{array}{l}\text { Micro-grid energy } \\
\text { trading for rural } \\
\text { electrification }\end{array}$ \\
\hline 4 & {$[140]$} & IEEE & Conference paper & $\begin{array}{l}\text { Smart energy grid } \\
\text { in irrigation } \\
\text { systems using } \\
\text { the Blockchain } \\
\text { applications }\end{array}$ & $\begin{array}{l}\text { Blockchain Tech- } \\
\text { nology }\end{array}$ & $\begin{array}{l}\text { Ethereum block- } \\
\text { chain, Photovol- } \\
\text { taic panels }\end{array}$ & $\begin{array}{l}\text { Use of Photovoltaic } \\
\text { panels for solar } \\
\text { energy for farmers }\end{array}$ \\
\hline
\end{tabular}

Fig. 17 Blockchain applications in Banking

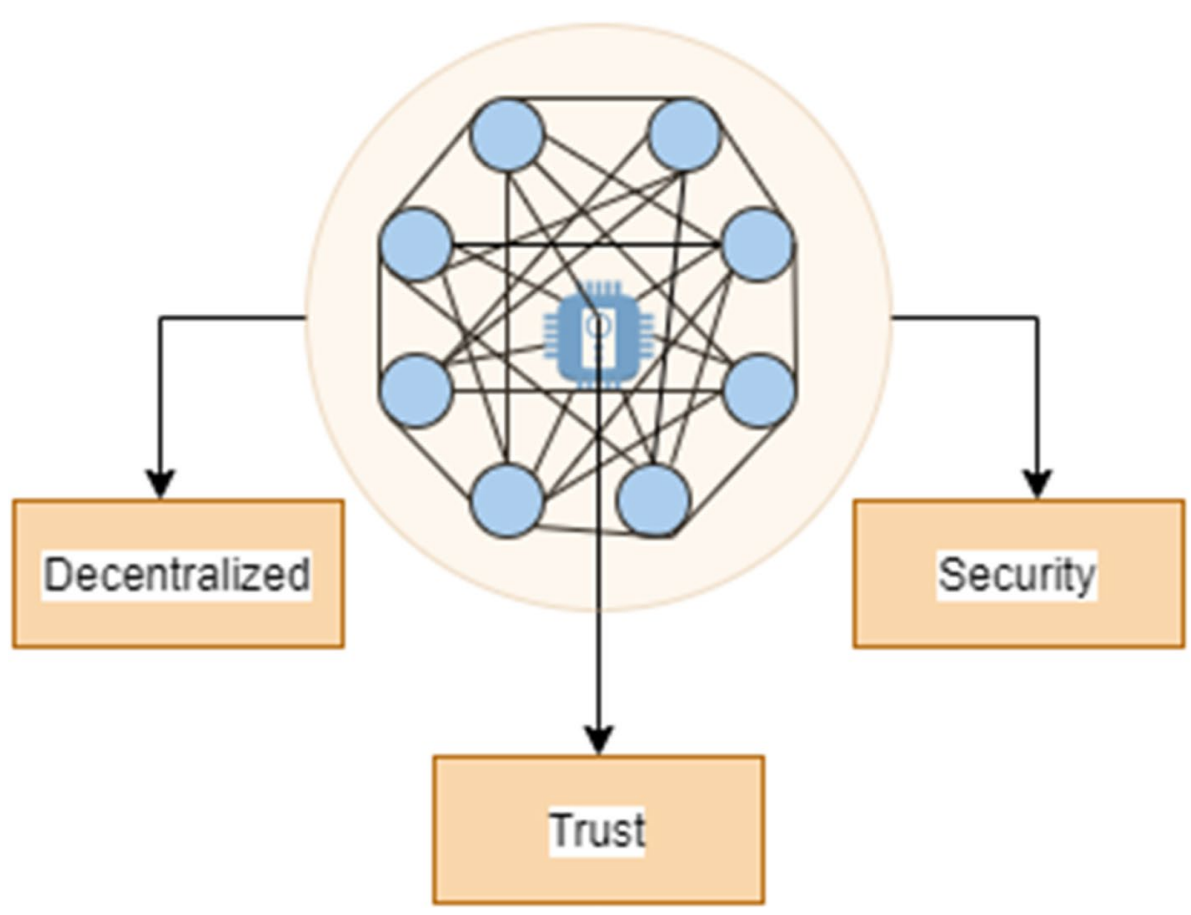

author's goal was to enable sustainable behavior between irrigation communities for reducing water consumption.

\subsection{Energy}

This section reviewed the application of blockchain in the electrification of rural areas (Fig. 16). A detailed summary is given in Table 9. 


\subsubsection{Energy Grid}

In the energy sector, rural electrification and the use of renewable energy were mainly focused on in the articles. Enescu et al., [140] proposed a study on the use of photovoltaic energy. The paper showed the use of photovoltaic panels to power a power plant for the improvement of abandoned land. According to the authors, photovoltaic panels can easily pump water and is a more appropriate use of solar energy. Blockchain can help reduce the intermediary distributors hence making the selling and buying of energy more profitable. Additionally, Kulkarni and Kulkarni, [141], considering the lack of electricity in rural India, proposed a model to solve rural electrification problems. The model introduces peer-to-peer energy trading through blockchain suitable for small and remote micro-grids. A reliable and profitable electricity supply can be obtained through micro-grids. Smart contract-based meters allow transparency in the daily usage of energy used hence encouraging rural people into investing in blockchain-based electrification.

\subsubsection{Renewable Energy}

Levi-Oguike et al., [142] have presented the challenges and modalities for the adoption of blockchain technologies and to ensure energy efficiency as an advancement to the subSaharan Africa environment. In the case study performed by the authors, the following factors affected its use to a large extent in sub-Saharan Africa: Employment and education, displacement and resettlement, financing the technology, regulatory provisions, operational modalities, and paranoia and wariness. The overall objective of the paper was to ensure that the sub-Saharan region was involved in the innovative and industrial revolution wave. From Krajnakova et al., [143] author's perspective following Scientific induction and deduction were made: The proposed Biomass blockchain structure is based on the use of traditional resources but the transactions are processed exclusively in a digital environment. The user can know the precise amount of energy and time when it is transferred to the consumer also ensuring real-time payment for the energy. According to the system Deal signed between biomass energy producer and consumer and transaction are based on cryptocurrency

Table 10 Comparison of blockchain applications in Banking

\begin{tabular}{|c|c|c|c|c|c|c|c|}
\hline S. no. & References & Source & Paper type & Focus & Technology & Platform(s) & Problem(s) addressed \\
\hline \multicolumn{8}{|c|}{ Mobile money } \\
\hline 1 & [149] & Springer & Chapter & $\begin{array}{l}\text { Secure, transparent, } \\
\text { and uniform mobile } \\
\text { money for internet- } \\
\text { undeserved areas }\end{array}$ & $\begin{array}{l}\text { Blockchain Technol- } \\
\text { ogy }\end{array}$ & $\begin{array}{l}\text { SIGMMA-Secure, } \\
\text { Interoperable } \\
\text { Mobile money in } \\
\text { sub-Saharan Africa, } \\
\text { API }\end{array}$ & $\begin{array}{l}\text { Semi-offline payments } \\
\text { through SIGMMA } \\
\text { without identity } \\
\text { proof }\end{array}$ \\
\hline 2 & {$[150]$} & IEEE & Journal & $\begin{array}{l}\text { A Delay tolerant pay- } \\
\text { ment scheme based } \\
\text { on the Ethereum } \\
\text { blockchain }\end{array}$ & $\begin{array}{l}\text { Blockchain Technol- } \\
\text { ogy }\end{array}$ & $\begin{array}{l}\text { Ethereum Smart } \\
\text { contracts }\end{array}$ & $\begin{array}{l}\text { Blockchain-based digi- } \\
\text { tal payment system }\end{array}$ \\
\hline \multicolumn{8}{|l|}{ Loan } \\
\hline 3 & [151] & IEEE & Conference paper & $\begin{array}{l}\text { LOC: Poverty } \\
\text { alleviation loan } \\
\text { management sys- } \\
\text { tem based on smart } \\
\text { contracts }\end{array}$ & $\begin{array}{l}\text { Blockchain Technol- } \\
\text { ogy }\end{array}$ & $\begin{array}{l}\text { Hyperledger Fabric, } \\
\text { smart contracts }\end{array}$ & $\begin{array}{l}\text { Poverty alleviation } \\
\text { loan management for } \\
\text { transfer of assets }\end{array}$ \\
\hline 4 & [152] & IEEE & Conference paper & $\begin{array}{l}\text { A blockchain-based } \\
\text { distributed network } \\
\text { for secure credit } \\
\text { scoring }\end{array}$ & $\begin{array}{l}\text { Blockchain Technol- } \\
\text { ogy }\end{array}$ & Ethereum Blockchain & $\begin{array}{l}\text { Bit-score: Credit scor- } \\
\text { ing system for rural } \\
\text { people }\end{array}$ \\
\hline \multicolumn{8}{|c|}{ Cash transfer } \\
\hline 5 & [153] & IEEE & Conference paper & $\begin{array}{l}\text { Blockchain-based } \\
\text { direct benefit } \\
\text { transfer system for } \\
\text { subsidy delivery }\end{array}$ & $\begin{array}{l}\text { Blockchain Technol- } \\
\text { ogy }\end{array}$ & $\begin{array}{l}\text { Angular JS, Node JS, } \\
\text { hyperledger fabric } \\
\text { and composer, } \\
\text { smart contract, } \\
\text { REST API }\end{array}$ & $\begin{array}{l}\text { Distributed system for } \\
\text { automatic subsidy } \\
\text { fund release }\end{array}$ \\
\hline 6 & [154] & IEEE & Conference paper & $\begin{array}{l}\text { Blockchain-based } \\
\text { chit fund system: a } \\
\text { financial inclusion } \\
\text { tool }\end{array}$ & $\begin{array}{l}\text { Blockchain Technol- } \\
\text { ogy }\end{array}$ & $\begin{array}{l}\text { Ethereum Smart } \\
\text { contracts }\end{array}$ & $\begin{array}{l}\text { Chit fund system to } \\
\text { provide credit to peo- } \\
\text { ple in rural areas }\end{array}$ \\
\hline
\end{tabular}


hence digitizing transaction accounting, payment and deposit mechanism, transaction security verification.

\subsection{Banking}

In the banking sector, most of the solutions were about issues in banking availability in rural areas, loan sanctions to under-documented people, and methods of transferring money (Fig. 17). A detailed summary is given in Table 10 .

\subsubsection{Loan}

Guo et al., [151] proposed a novel poverty alleviation loan management called the Loan On Blockchain (LoC). In the LoC, the participating roles can be named as the Financial department to check the identity and application information of the participants, bank to provide loan to the customer, Customer to provide identity and apply for loan, civil affairs department to audit the customer identity and loan applications, Regulator to monitor fund flow and inspect ledger. This digital account model was proposed for decentralized and centralized transfer of assets. Similarly, Jain et al., [152] presented a solution named Bit-score for credit scoring for underprivileged (rural) people with the help of blockchain. The authors' model used a self-sovereign model for identity, distributed ledger storage, credit score calculation without any extra charges, and non-financial factor for acquiring credit score. With bit-score being an improvisation over traditional credit scoring techniques it makes the transactions more transparent, decentralized, secure, and intermediary-free.

\subsubsection{Mobile Money}

Y. Hu, [150] proposed a blockchain-based digital payment system to deliver reliable services on unreliable network services in rural areas. The system management contract to record account types, user balances to avoid forks during disconnection with the help of smart contracts. True transparency can be obtained through digitization and economic growth can be boosted in poor countries. Ghatpande et al., [149] proposed a way of moving Secure, interoperable mobile money in sub-Saharan Africa (SIGMMA) to support semi-offline payments through blockchain. The model provides unreachable areas a monetary transaction solution without having to provide any identity proof while ensuring trust between parties along with not having to physically visit any bank.

\subsubsection{Cash Transfer}

Another proposal is to provide banking solutions to rural areas where a chit fund system has been designed by Kumar and Sangal, [154]. Chit fund being a traditional saving scheme in India is an easier way to have access to credit. The purpose of this system is to remove geographical barriers
Fig. 18 Blockchain applications in Healthcare

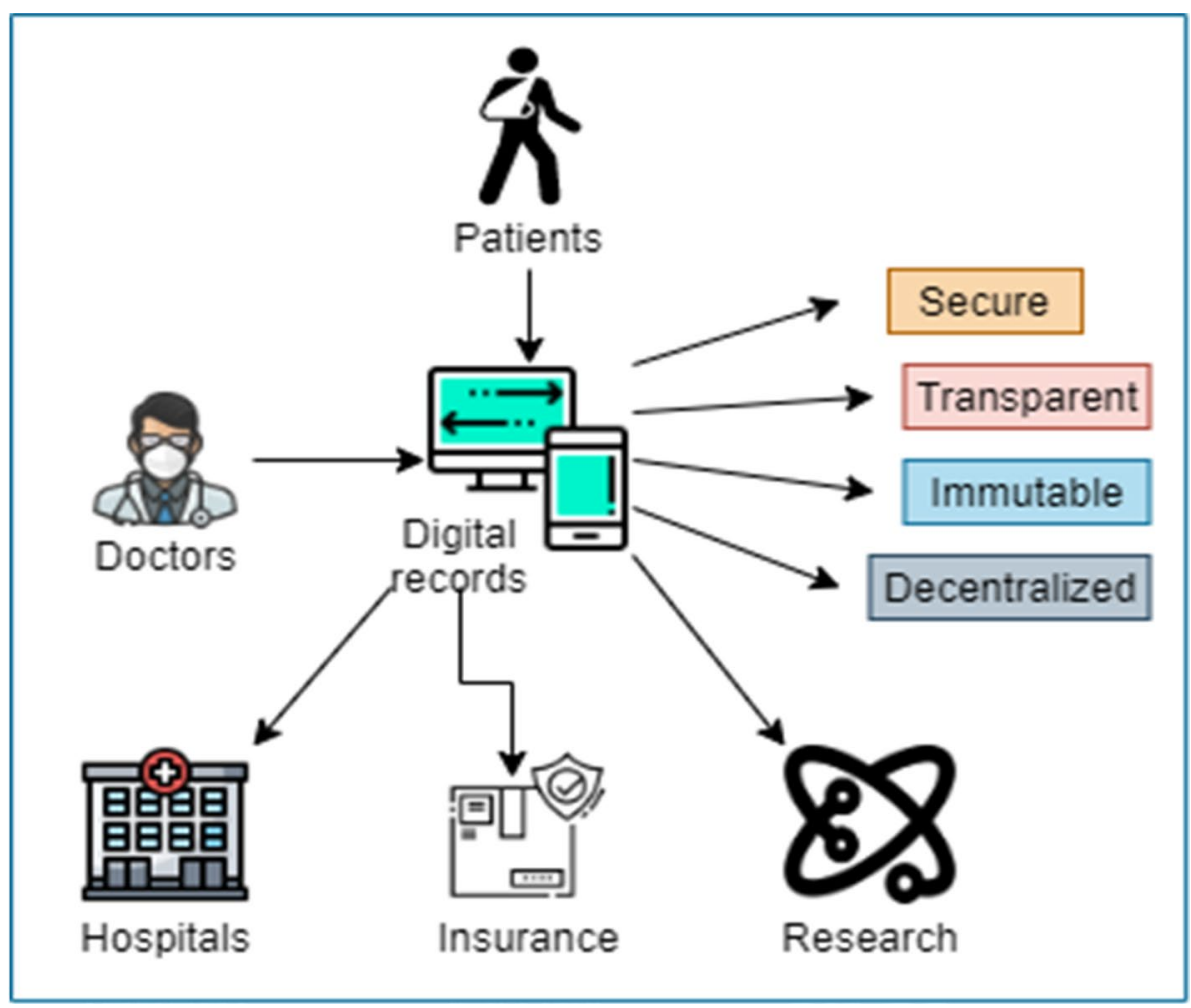




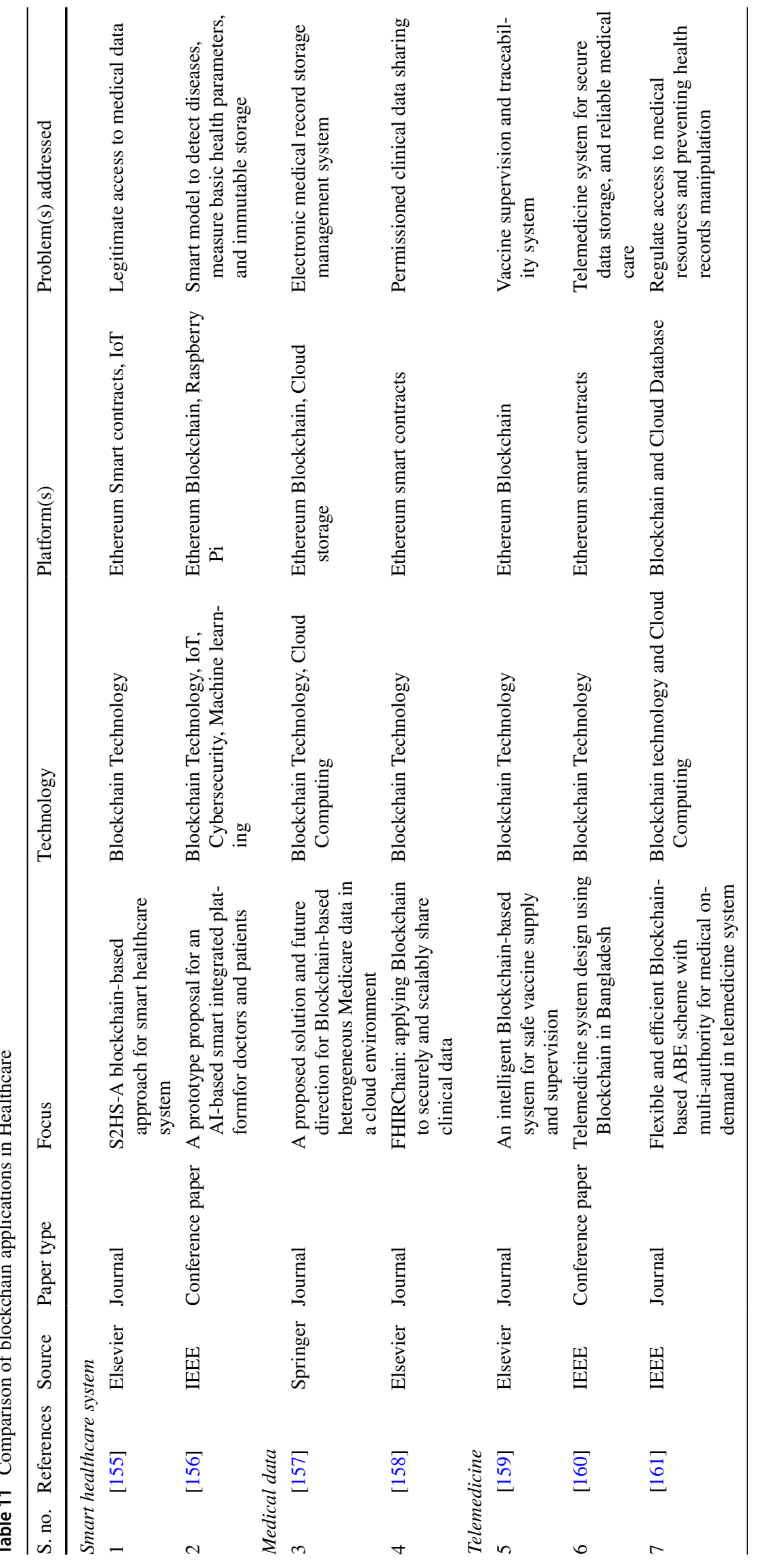


and provide credit scores to each user based on their transaction behavior. Unlike other anonymous blockchain applications, this system requires identity registration. Unlike traditional co-lateral systems, blockchain generates credit history to prohibit manipulation. Lastly, Jaffer et al., [153] proposed a blockchain-based distributed system that is immutable and secures the transaction logs. The self-executing smart contracts were used to automatically execute real-world contracts for auto disbursement of subsidies on meeting specific conditions. This system overcoming traditional cash transfers, and corruption and manipulation related to it can benefit rural or deserving people.

\subsection{Healthcare}

In the healthcare sector, smart healthcare systems, telemedicine, and privacy in medical data sharing to provide security and transparency in the healthcare system between doctors and patients were the commonly addressed areas in related work (Fig. 18). A detailed summary is given in Table 11.

\subsubsection{Medical Data}

Kaur et al., [157] proposed a blockchain-based electronic medical record storage and management system. The proposed model consisted of three main components: Domain experts (doctors, lab technicians, pharmacists, and drug manufacturers), health insurance providers, and patients. To ensure the privacy of medical data which contains most of the private information blockchain distributed data storage for heterogeneous data was proposed having a single source for data storage and access while providing high security and privacy to the users and researchers. Similarly, Zhang et al., [158] proposed secure and scalable clinical data sharing using FHIR Chain, a blockchain-based system meeting ONC (office of the national coordinator for health information technology) requirements. The technical requirements for blockchain-based clinical data sharing were verifying identity and authenticating all participants, Storing and exchanging data securely, consistent Permissioned access to data sources, applying consistent data formats, maintaining modularity. FHIRChain facilitates clinical data exchange while maintaining ownership.

\subsubsection{Telemedicine}

Guo et al., [161] proposed an ABE scheme to achieve dynamic authentication and authorization with higher flexibility and efficiency for the Medical on Demand services in the telemedicine system. The system uses a Consortium Blockchain managed by multiple authorities. Medical examinations are uploaded to the database provided by Cloud Service Provider (CSP). The medical results are downloadable from Cloud only by Medical specialists. All the data is stored in Blocks of Blockchain hence preventing any manipulation in health records. Through this system independence of choice should be provided to the patient whether they want to enroll, leave, or change access policies. Nusrat et al., [160] proposed a model of a telemedicine system for medical care and security of data of rural people by using blockchain technology. The system consisted of stations for primary treatment tests while storing data directly in the blockchain. This system ensured communication and data privacy to doctors and patients while also giving reliable medical care and benefits to underserved (rural) people.

Forbye, Yong et al., [159] have proposed a blockchain and machine learning system for vaccine supply chain traceability. The novel intelligent system based on the blockchain can be used for vaccine supervision in the vaccine supply chain. Additionally, using smart contracts for the vaccine supply chain can provide the following advantages: detection of expired vaccines, vaccine information, and vaccine coin.

\subsubsection{Smart Healthcare System}

Machine Learning holds the power to change the perception of understanding and analyzing data and decision-making in multifarious sectors. Since, the blockchain with its decentralized network focus on secure data sharing, its integration with machine learning would provide a very meticulous outcome. Few of the ways through which blockchain's integration with machine learning and benefit the healthcare system are [162]:

(a) Blockchain ledger with legitimate data collection can feed the machine learning models with highly accurate and dependable data.

(b) Real data can be used to train machine learning models to increase efficiency and precision, therefore, saving cost and time.

(c) Models can be trained to give the same health advice to multiple patients with alike symptoms.

(d) Models can also be trained to give better clinical solutions to doctors based on the patient's symptoms.

(e) Training the models on the patient history and storing them on blockchain ledger can predict outbreaks.

For implementing the integration, Jain et al., [156] proposed an integrated model of blockchain and machine learning to detect diseases. These models can be implemented in a hospital or rural medical camps. The proposed system consisted of IoT, blockchain, cybersecurity, and machine learning. Various components measure basic parameters of the human body such as weight, pulse, blood pressure, and automatically saved the data in the ledger. The system has the potential to expand medical parameters while making it 
Fig. 19 Blockchain applications in Employment

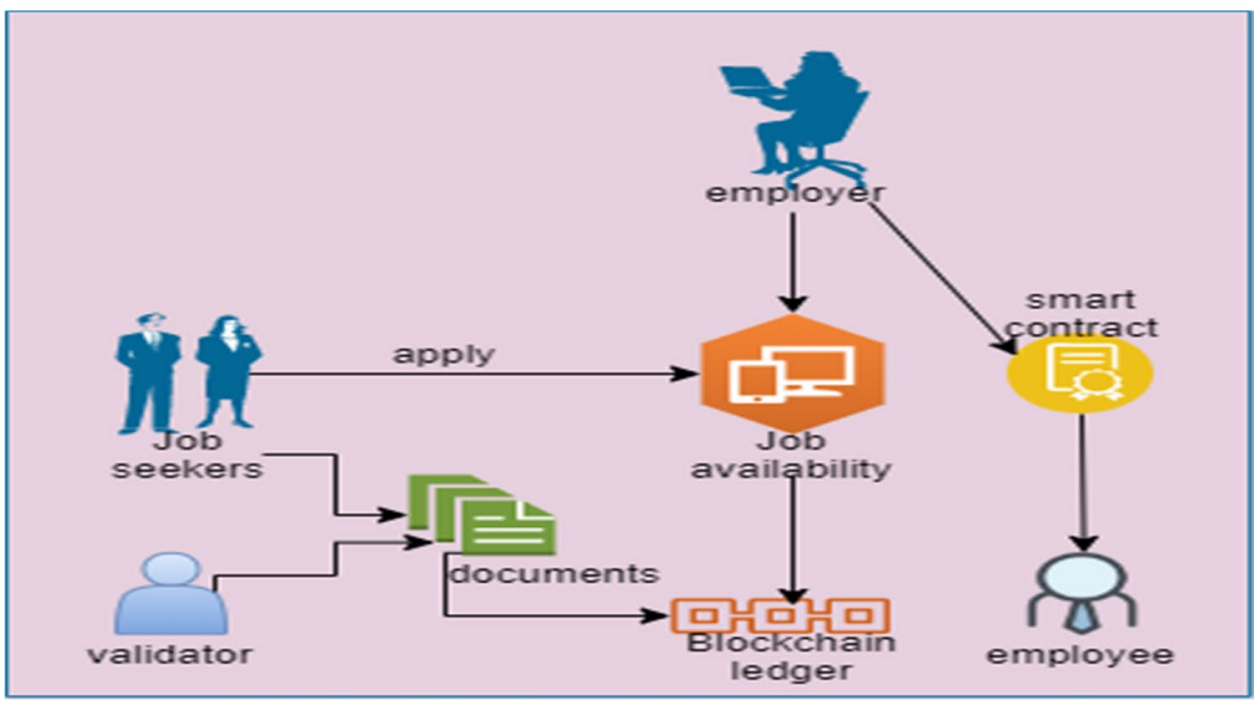

adaptive. The complete system can collect, store, and analyze the data of the patient and benefit the doctors, patients, and medical institutions.

Similarly, Tripathi et al., [155] have proposed a safe and convenient use of medical data and its user through blockchain technology. The proposed work is an improvement on issues and challenges faced regarding security and privacy. The clinical data are recorded in the blockchain ledger with access to legitimate users only. For a doctor to access a patient's data a request has to be made and only when the patient approves the request does the data become visible. The goal of this model is to provide secure and reliable services to insurance companies, drug supply chains, and medical researchers. Lastly.

\subsection{Employment}

This application area mainly focused on employment visibility and temporary employment for rural job security (Fig. 19). Therefore, the following related research articles were identified and a detailed summary is given in Table 12.

\subsubsection{Temporary Employment}

Pinna and Ibba, [163] proposed a decentralized employment system to process employment contracts with a fully automated and fast procedure. The model consists of a new job offer event in which awaiting employers apply for jobs, an application event where a smart contract acquires the application request, a hiring event where the applicant worker meets the employer, a relationship event to enable the workers to check working situation and details, the workday event which describes the maturation of workdays, a payment event where the employee gets paid. The transparent ledger can make sure that the employment contracts were deployed with unchangeable information.

\subsubsection{Employment Visibility}

Similarly, the paper's proposal by M. et al., [164] ensures supply chain visibility to seamlessly connect all stakeholders of the supply chain network who are a part of the Blockchain ecosystem. The paper defined two modules in BC design: the Supply module and the demand module. Supply module to collect worker's data and smart contracts to perform transactions through an application interface and store them on the ledger. Demand module to implement job allocation. The aggregators are given direct access to help track worker's information from the ledger.

\subsection{Existing Systematic Literature Reviews}

A tabular representation of a few major existing works of blockchain in rural development has been done in Table 13. This table communicates the area of literature reviews, and their main contributions in the review regarding blockchain in rural or agriculture.

An extensive literature review was done in this section which portrayed the enormous amount of work done in blockchain technology pertaining to rural development. All the functional areas and sub-areas were compared and discussed in tabular form. Multiple novel ideas and theories were identified during the literature review. At last, a small tabular representation was made for the existing systematic literature reviews and surveys in a similar area to identify the depth of the work done. In the upcoming sections, critical analysis and detailed discussion have been done based on the literature study, followed by the limitations of the survey and conclusion. 


\section{Critical Analysis Existing Technologies and Discussion}

Blockchain Technology possesses much competence and futuristic hold towards rural development. In this review, all possible applications of blockchain that facilitated rural development were found, reviewed, compared, and summarized. With Agriculture being the predominant application of blockchain, various areas under it were analyzed that worked on the relief of agricultural issues in rural areas.

Starting with Supply chain traceability, the study showed integration of blockchain technology with Internet of Things $[51,54,56,58,63,64,69,70,73,76,82,84,85,89,100$, 145], Cloud computing [65, 87], Big Data [87], and Geospatial Technology [100]. Among the papers discussed, this area consisted of papers pertinent to tracing agricultural produce from the beginning of the process till it reached the consumer. The range of traceability options comprised all agricultural products as well as specifically certain products such as soybean [60], grape wine [69], and cocoa beans [62]. Furthermore, blockchain's integration with IoT provided sensing and sharing of private data with blockchain without intermediary support. Additionally, some proposed work used QR codes $[56,60,146]$ for viewing data directly related to the attached product. Articles supporting IoT devices were implemented for tracing agricultural produce, encouraging circular economy, fault-tolerant, and immutable APIs. A few were reviews on agriculture traceability [53, 58, 60, 61] barriers [67], challenges [59, 71, 76] contribution [80], IoT based solutions, and future scopes [78, 96]. Some agricultural prototypes included AgriBlockIoT [70], KHET [83], and FARMAR [68]. A few land record management articles were also discussed that implied security and broker-free methods for land titling and transferring [97, 98]. Most of the platforms used were Ethereum Smart Contracts, Hyperledger, REST, JavaScript (Web3, node, angular), Truffle Framework APIs, and MySQL and MongoDB for cloud storage.

While traceability of agricultural produce is important, the agriculture security system is also a necessity. In this review, the articles for agriculture security systems included prevention of farm data from cyber-attacks using IoT [103] and supervision of agricultural products and food information [102]. In both the works acquired, it used Smart contracts and Ethereum Blockchain respectively, along with IoT-based sensors for farm monitoring.

Organic Farming as a part of agriculture application for sustainable farming and quality food production included two articles for analyzing the effectiveness of supply chain [101], and identifying product quality and transparency of organic food supply chain using decentralized applications and QR codes for tracing product data [104]. 
Table 13 Existing literature reviews

\begin{tabular}{|c|c|c|c|c|}
\hline Reference & Area of Review & Focus & Timeline & Main contribution \\
\hline [165] & Agriculture & $\begin{array}{l}\text { Applications of Information and Communi- } \\
\text { cation Technologies (ICT) and Blockchain } \\
\text { Technologies (BT) in agriculture }\end{array}$ & $2011-2020$ & $\begin{array}{l}\text { Study to explore the contribution of ICT } \\
\text { and BT in the development of precision } \\
\text { agriculture }\end{array}$ \\
\hline [166] & Energy & Blockchain Technology in Energy Sector & $2010-2018$ & $\begin{array}{l}\text { Review of } 140 \text { blockchain innovation projects, } \\
\text { their benefits, and applications in the energy } \\
\text { sector }\end{array}$ \\
\hline [96] & Agri-food Supply chain & $\begin{array}{l}\text { Application of Blockchain Technology, } \\
\text { advanced ICT's, and the Internet of Things } \\
\text { for the agri-food value chain }\end{array}$ & $2008-2018$ & $\begin{array}{l}\text { Review of } 71 \text { publications that identified } \\
\text { future research directions and recent trends } \\
\text { of Blockchain application in agri-food value } \\
\text { chain management }\end{array}$ \\
\hline$[167]$ & Agriculture & $\begin{array}{l}\text { Blockchain Technology and its main contri- } \\
\text { butions in the agricultural sector }\end{array}$ & $2016-2018$ & $\begin{array}{l}\text { Review of } 10 \text { papers relevant in the area of } \\
\text { blockchain development in agriculture with } \\
\text { emphasis on the security of data, food supply } \\
\text { chain, and management and monitoring }\end{array}$ \\
\hline
\end{tabular}

Furthermore, using smart methods to enhance the agricultural process was discusses in the smart agriculture Sect. 3.1.4 where farm controlling, recordkeeping, improved logistics, farm managing and improvising, and monitoring using Blockchain Technology and IoT [106-110] as well as cloud computing [105] and geospatial technology [100] in some articles were covered. Most emphases were given towards improving the quality of farming and its management while providing utmost security to data. Mostly used platforms to implement the proposed work were JavaScript(Node, Ganache, Truffle), Ethereum Smart Contracts, and IoT-based sensors.

Apart from the supply chain in farming, the dairy sector was one of the application areas covered in the review comprising of E-governance in the dairy sector implemented on smart contracts [111], and quality and quantity assurance of milk with a delivery platform [112] using Blockchain Technology. In addition to the dairy sector, blockchain applications in livestock management using Blockchain Technology [114], IoT and Cloud Computing [113, 115, 147] to monitor livestock, observe cattle using RFID tags, storing detailed information on fishes, along with livestock traceability were discussed in the review. Integration with IoT provided real-time monitoring and traceability of livestock and its by-products in the supply chain.

Similarly, to share informative farming data and techniques a review on convenience analysis of the blockchain in agriculture [116], and exploratory data planning and management of agricultural food supply chain for sustainable development [117] was given to explore the work done in E-agriculture using blockchain technology. Since one of the main motives towards implementing blockchain in agriculture is to monitor the faring process and products till it reaches the consumer, therefore, agriculture monitoring section covered farm monitoring system[99], a yield estimation system to share farming plans implemented on smart contracts [119], and an IoT based AG Wallet system to track farm activity implemented using IBM enterprise blockchain platform [118]. Penultimately, the application area was divided into farmer Sect. 3.1.9 where blockchain's reviews to facilitate farmers such as farmer's portal to capture farm activities using HTML and Python [121], farmer's data storage to provide transparency for government scheme using smart contracts [120], and farmer's data accessing using their consent [122] were discussed.

Lastly, an overall blockchain application area covering the use of incentives for numerous activities was discussed in Sect. 3.1.10. The review included a reward-based system in return for solid waste [148], rural waste [128], anonymously reporting an activity [130], reporting an accident [127], storing educational records in ledger [132], green behavior [123, 124], geotagging litters [125], and to safely share medical data [126]. The incentive mechanism works when an activity is performed, therefore in return for good behaviors or activity, cryptocurrency-based tokens are rewarded that can be stored in a blockchain wallet. Most of the platforms used were smart contracts while some of the systems also used ARK Blockchain, Laravel PHP, and JavaScript.

Looking through the applications of blockchain in rural areas, usage of blockchain in reinforcing environmental conditions and changing people's outlook on preserving the environment was the outcome of factors affecting rural people as they were much likely also related to environmental conditions. From this view, the environmental application areas were discovered and discussed to be Water management, Waste management, and Natural hazards.

To begin with, under Sect. 3.2.3 water management, smart measuring and monitoring [137], smart consumption [135], management [139], and control system [136] of water were discussed. These articles provided smart ways of implementing blockchain for efficient use of water in irrigation, distribution, and consumption, preventing 
environmental deterioration while also providing security and digitization.

Secondly, under Sect. 3.2.1 waste management, the reward system in return for waste collection and selling [128, 148], and waste management [133] using Blockchain Technology were discussed. Covered under the integration of Blockchain Technology, Cloud Computing, and IoT, the implementation used smart contracts in the first two proposals and UML, TLA + for the latter.

Lastly, as per the research criteria, only one article contributing to the environment and natural hazards was discovered and reviewed explaining the insurance system for drought-affected farms based on the farm data stored in the blockchain ledger [134]. The model was implemented on NEO virtual machine, smart contracts, and used Oracle server as database.

Similarly, from the challenges faced by rural people acquiring an electric line, energy-efficient methods, to secure, and transparent payments issues were covered and reviewed under the energy section. The blockchain application areas in the energy sector were discovered to be Renewable energy and the Energy grid. With blockchain's integration with renewable energy a smart contract-based energy transfer credibility system of biomass energy grid [143], and a case study of sub-Saharan Africa and its challenges and adoption of renewable energy access were discussed [142]. Whereas in the energy grid section, the blockchain's application in providing peer-to-peer electrification with secure payments, transparent energy usage [144], and the use of smart energy grids for farming and irrigation using Ethereum Blockchain [140] were reviewed.

Besides, from the traditional use of blockchain in Finance, the banking solutions for rural people were discussed in Sect. 3.4. From the banking applications of blockchain, the use of mobile money for semi-offline payments in sub-Saharan Africa without identity proof using a secure, interoperable mobile money system [149], and a delay-tolerant digital payment system based on Ethereum blockchain [150] were discussed. A simpler way of getting a loan with the help of blockchain is by using a hyper ledger fabric-based Loan On Blockchain(LOC) system using smart contracts [151], and a credit scoring system called Bit-score using Ethereum Blockchain [152] were discussed. Finally, a Cash Transfer area where a distributed system for automatic subsidy delivery and fund release using JavaScript and Hyperledger composer [153], and a chit fund system based on smart contracts to provide credit to rural people [154] were reviewed.

Under the Healthcare applications of blockchain, A Smart Healthcare System, Medical Data sharing, and Telemedicine were the areas discovered. Under smart healthcare, the articles reviewed were a smart model to detect diseases and measure basic health parameters using Ethereum blockchain and Raspberry Pi [156] and protected access to medical data using smart contracts [155]. For the recordkeeping of medical data and share it legitimately an electronic medical record storage management system based on ethereum and cloud storage [157], and a permissioned clinical data sharing called FHIRChain using smart contracts [158] was reviewed. Lastly, under Telemedicine, vaccine supervision and traceability for safe vaccine supply [159], secure data storage using telemedicine system based on smart contracts [160], and a telemedicine system to prevent health records manipulation using Blockchain and Cloud Database [161] were the articles reviewed.

Another challenge faced by rural people implemented to recuperate from unemployment using blockchain technology was discussed in Sect. 3.6. Using smart contracts an employment contracts processing, handling, and safe payment system for temporary employment contracts [163], and a blockchain aggregator to perform worker data transactions and employment visibility [164] were the works reviewed in this section.

\subsection{Limitations of Existing Works and Research Gaps}

In this section, the limitations of the existing literature review on blockchain in rural development along with a comparison of existing systematic literature reviews have been discussed. The comparison has been shown in Table 14, and a few research gaps have been mentioned in this section as well.

While Blockchain technology is leading in security and transparency, providing ways of applying its technology in disparate areas its limitations and gaps can still be identified in the proposed and implemented work. While most of the work in agriculture is for ensuring transparency and traceability in the supply chain, there are far more factors in agriculture that affect farmers and crops. Blockchain inevitably uses excessive energy in execution, but its execution in rural areas may become worrisome due to the lack of energy and load in those areas.

Collecting farm data and storing them on the ledger in small farms is easier. However, in the case of big farms, the data collection and integration may consume much time and probably manpower in accumulating and loading it in the ledger. Apart from that, IoT-based services require sensors as well as collecting livestock DNA to trace them and load their information may cost a fortune to small-scale farmers.

Teaching the application usage to laymen, that too uneducated farmers or rural people may become a troubling task. Not only that, the availability of news of the latest technologies is hardly accessible to underdeveloped countries, introducing blockchain-based applications to those areas may toil the deployment and utilization. 


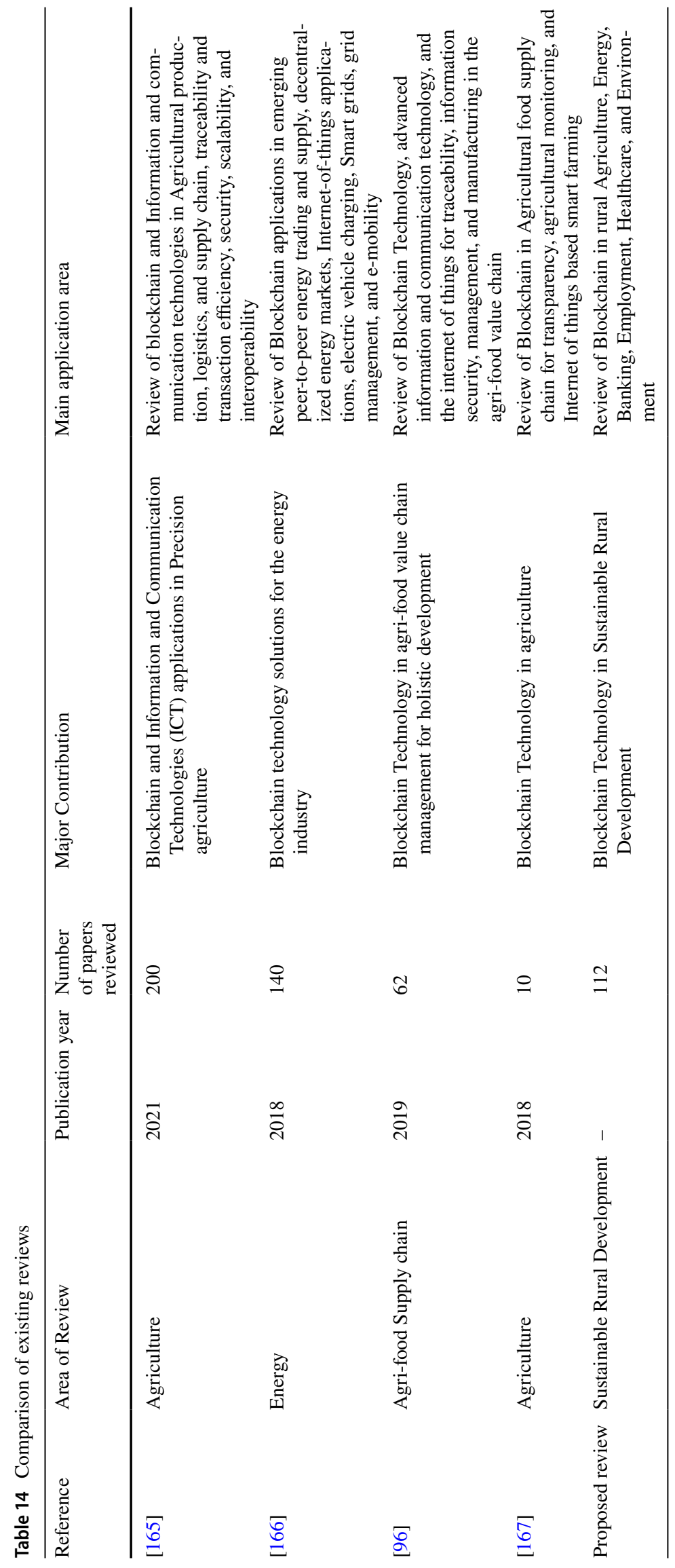




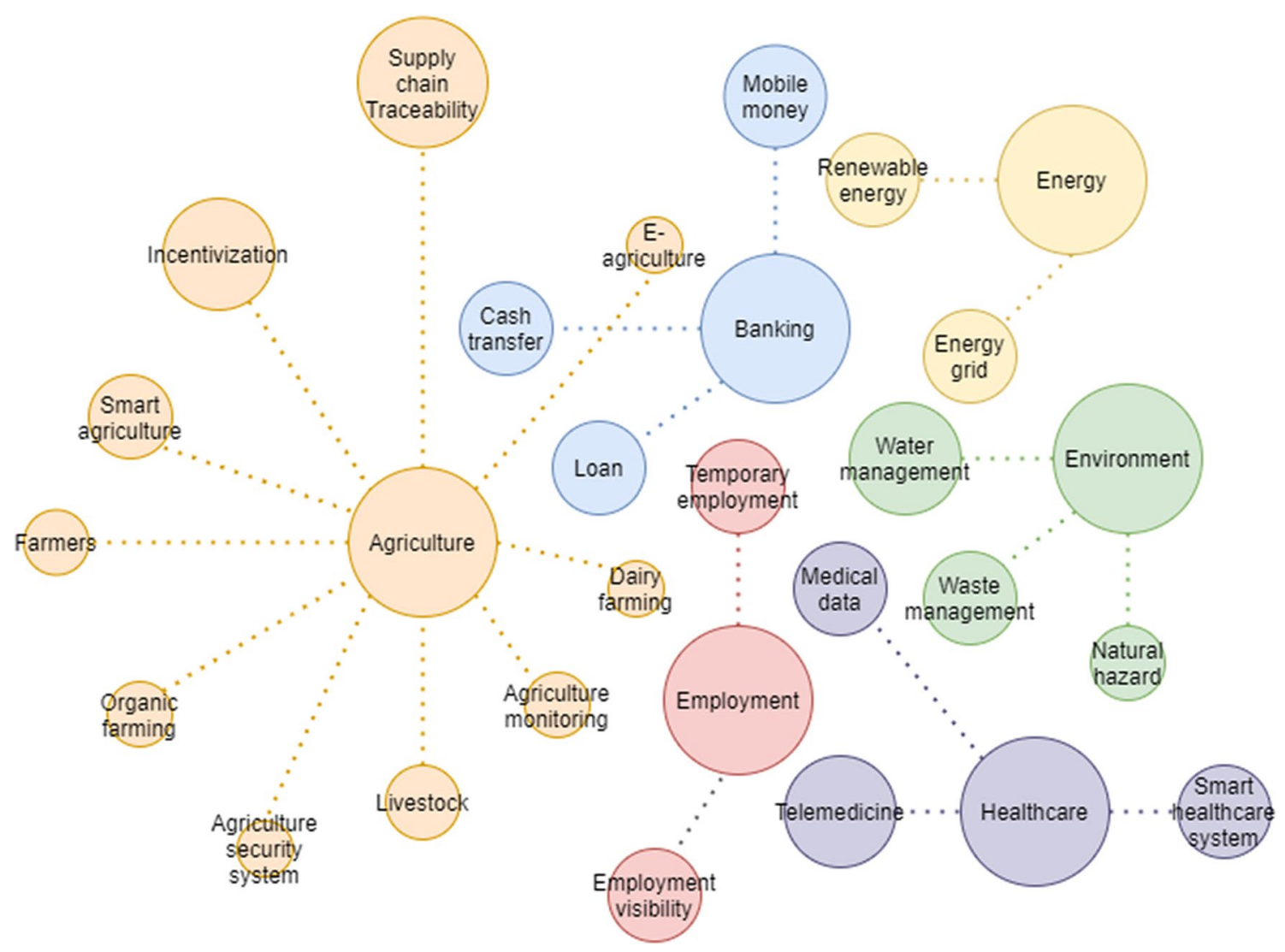

Fig. 20 Blockchain Applications and their Areas in rural development

Mistakes can prove disadvantageous to poor people while making blockchain transactions. A lost private key or a mistakenly added extra digit to the payment can cause irreversible damage.

Thereafter, a data breach of medical data and inappropriate access to medical histories are some issues that may decrease people's trust in the blockchain-based healthcare system for medical data privacy.

Security threat is another limitation that can affect any type of application that requires recordkeeping. Here the blockchain's main characteristics may itself prove faulty to find the intruder as it gives total anonymity to users. With both pros and cons, robust and reliable technology can still be deployed for many usages, making livability easier and people technologically advanced.

\subsection{Discussion}

Multiple issues pertaining to rural areas have been addressed by authors with the help of blockchain. Agriculture is the most economic factor, solutions for blockchain-based supply chain traceability provided secure, transparent, beneficial product delivery. It also ensured timely payments to farmers and quality products to consumers. Banking solutions have also been made easier with blockchain technology, providing remote banking solutions, credit and loan easiness, and easy and transparent banking. Hygiene issues that led to many diseases, generational disabilities have also been given a solution through blockchain which also incentivizes rural people for participating in waste and water management. Rural electrification solutions were also proposed with blockchain for people unable to obtain energy resources, basic electrical amenities, and expensive bills. People who were unable to receive treatments, had to travel long distances for medical assistance, were also provided a blockchain solution with which telemedicine, privacy to medical data usage, and medical-on-demand were made available. Blockchain has also been useful in providing employment solutions to the truly underserved, using a global chain for employment visibility, and secure payment for jobs [168-172].

The Systematic Literature Review's objective is to provide information on the research proposed related to blockchain in rural development to provide new research opportunities, extensive knowledge about each development area, and the possibility for future development in rural areas. After distinctly reviewing every research article variant areas of applications were identified relating to the development of 
rural areas with the help of Blockchain Technology. Overall, 6 disparate applications in rural development were picked out; from which each of these applications has a total of 23 divergent areas combined. These areas contribute to all the research that has been done in the blockchain in the rural development sector and are distributed across 37 countries obtained from 6 journals and 1 web source ranging from the years 2010 to 2020. After searching through journals, applying more than 16 keywords, 112 articles were found in aggregate. From analyzing each article, the primary application of blockchain was identified as agriculture with $67 \%$ of research articles relative to blockchain in agriculture whence $60 \%$ were associated with supply chain traceability. About $55 \%$ of those papers were from the Institute of Electrical and Electronics Engineers (IEEE). Furthermore, in 112 research papers, 8 technologies were implemented with a total of 58 platforms and tools combined.

\subsection{Research Questions Addressed}

From the Research Questions defined (Table 3), the following inference can be made:

RQ1 What are the main applications and areas of implementing Blockchain Technology in Rural Development?

Various extensively researched applications are defined in Tables 5, 6, 7, 8, 9, 10, 11 and 12. These applications define the Blockchain's applications in rural development that impact the rural areas, provide security, opportunities, availability of resources, and a better lifestyle. The areas
Numerous issues in rural areas are explained in Sect. 1.1.1 and the blockchain applications for the eradication of those issues are addressed in Sect. 3.

RQ3 What are the targeted software, platforms, and tools for the implementation of blockchain in rural development?

Throughout the applications, for implementation following (Table 15) technologies' integration, and software and platforms were used:

RQ4. What are the research gaps and future research directions for applying blockchain technology to rural development?

Following the review, in agriculture, most emphases were stated towards supply chain traceability and less or no work in natural resource management, overproduction, yield stagnation, and international trade. In regards to the sociological factor, research on work belonging to blockchain development for rural education, housing, women empowerment, crime reduction, brain drain, and craftsmanship is missing. For the implementation of banking, healthcare, and many other applications the required government and technological assist are still lacking. In some cases, the research proposed could be administered only in the far future, therefore contemporary work was absent. Some more gaps and future research directions are given in Sects. 4.2 and 6.1.

The research questions mentioned in Table 3 are addressed in the following section (Table 16):

Table 15 Blockchain development platforms and tools

Technologies

Software/ Platforms/Tools
Blockchain Technologies, Internet of Things, Cloud Computing, Big Data, Geospatial Technologies, Machine learning, Artificial Intelligence, Cybersecurity

Ethereum Blockchain, Ethereum Smart contracts, Hyperledger Fabric, Application Programming Interface, NodeJS, RFID reader, Arduino Controllers, Cloud Database, IoT sensors(temperature, humidity, Barometer, Grove, Tensiometer, mini-meteo), Cloud Database, Couch DB, WANET, SIGMMA, SPSS19.0 one-way ANOVA, ARK blockchain, RInkeby, Remix IDE, Ganache, Metamask, Laravel, PHP, Javascript, Solidity, Wireless Network Sensor, Geographic Information System, GPS, Hyperledger Sawtooth, Decentralized Applications, Truffle Framework, libCoAP library, Web3API, Bean tracker, Ethereum Virtual Machine, Angular. JS, Python, GO blockchain, NEO blockchain, REST API, Rootnet API, HTML, Hyperledger Composer, Quorum, BigChain DB, MongoDB, Tendermint API, ERC20 API, Java, Satellite Navigation, VS code, GETH, MySQL, CSS, Unified Modeling Language, TLA +, Oracle Server, Fuzzy Logic, Raspberry Pi
(Fig. 20) gave extensive knowledge about the domains of application-defined from several research articles related to it.

RQ2 What are the major issues in Rural Development and how they can be addressed using Blockchain Technology?

\section{Threat to Validity and Limitation of the Survey}

While reviewing the issues in rural areas, blockchain technology, and the applications of blockchain technology in rural development certain limitations can be considered existing. All the articles were selected according to the review process and criteria implied in Sects. 2.1, 2.2, and 
Table 16 Addressed locations of the Research Questions

\begin{tabular}{llll}
\hline & Research questions & Section(s) \\
\hline RQ1 & What are the main applications and areas of implementing Blockchain Technology in Rural Development? & 3 \\
RQ2 & What are the major issues in Rural Development and how they can be addressed using Blockchain Technology? & 1.1 .1 and 3 \\
RQ3 & What are the targeted software, platforms, and tools for the implementation of blockchain in rural development? & 4.2 & 4.1 and 6.1 \\
RQ4 & What are the research gaps and future research directions for applying blockchain technology to rural development? & 4 \\
\hline
\end{tabular}

2.3. During exclusion, some articles were not considered fit for this review, were missed, or were not found. Six applications were considered in this review, there could be more applications that we couldn't figure or that couldn't make the cut of criteria. A total of 23 sub-areas of all the applications were determined. Conclusively, as per our knowledge, there wasn't any systematic review that reviewed all the application areas of blockchain technology in rural and sustainable development nevertheless there could have been a few rural and sustainable development articles that weren't included in this review.

\section{Conclusion and Future Work}

Blockchain Technology has presented a considerable amount of work in the rural sector. While its implementation was few, the ideology is enough to motivate people into changing the lifestyle of rural people leading to the overall country's development. In this systematic literature review, numerous applications of blockchain technology in sustainable rural development were discussed with diverse areas in each application. A comparative study of each application in all the areas pertaining to different approaches has been portrayed with differing attributes elucidating the technology, process, and techniques behind each article. The paper provides extensive literature towards each of the articles sorted after applying the review process consisting of relevant articles and keywords. The primary findings of the systematic literature review were as follows:

(a) From the review, we were able to identify common and exceptional uses of blockchain technology that would help uplift the rural community and lead to sustainable rural development.

(b) Various distinct approaches to implementing blockchain technology for rural welfare were discovered.

(c) Platforms and tools that would facilitate the use of these applications for farmers and uninstructed agrestic people were identified and reviewed.

(d) Blockchain's integration with multiple powerful technologies for rural development was reviewed.

(e) An overall idea for a collaborative approach leading to a smart village framework was constructed.
The gaps determined from reviewing the articles broadly would help researchers explore additional as well as alternative utilization of blockchain technology for sustainable rural development.

\subsection{Future Work}

Blockchain's characteristics are exceptionally conducive to safety, privacy, integrity, traceability, efficiency, and transparency in every area limited by such advantages. While diverse blockchain applications for the welfare of rural community has been discussed nevertheless future work can comprise of facilitating applications in making use of blockchain incentives for a collaborative framework incorporating several services in rural areas namely Smart Village. Blockchain technology in terms of providing incentive mechanisms could lead to a better motivational unit in many areas. Incentivizing rural or urban people for education, data sharing, green farming, green behavior, and environment conservation are real future demands. Apart from emphasizing rural areas, blockchain's integration with networking, cybersecurity, and digital advertising is also a future insistence.

Funding This research did not receive any specific grant from funding agencies in the public, commercial, or not-for-profit sectors.

\section{Declarations}

Conflict of interest None.

\section{References}

1. United Nations, "Implementation of the Third United Nations Decade for the Eradication of Poverty(2018-2027) estimates that 1.3 Billion people worldwide remain in poverty." https://www.un. org/development/desa/socialperspectiveondevelopment/unitednations-decade-for-the-eradication-of-poverty/third.html.

2. Bank TW, "The World Bank- Rural Development Program." https://projects.worldbank.org/en/projects-operations/projectdetail/P089297?lang=en.

3. Li Y, Westlund H, Liu Y (2019) Why some rural areas decline while some others not: an overview of rural evolution in the world. J Rural Stud. https://doi.org/10.1016/j.jrurstud.2019.03. 003 
4. Johnson KM, Lichter DT (2019) Rural depopulation: growth and decline processes over the past century. Rural Sociol. https://doi. org/10.1111/ruso.12266

5. Bird K, Hulme D, Shepherd A, Moore K (2002) Chronic poverty and remote rural areas. Development Economics eJournal

6. Dillman DA, Hobbs DJ (2019) Rural society in the US: Issues for the 1980s. Routledge

7. Kwami CS, Godfrey S, Gavilan H, Lakhanpaul M, Parikh P (2019) Water, sanitation, and hygiene: linkages with stunting in rural Ethiopia. Int J Environ Res Public Health. https://doi.org/ 10.3390/ijerph16203793

8. World Health Organization, "No Title," World health Organization estimated in major gaps in water and sanitation-especially in rural areas. https://www.who.int/mediacentre/news/releases/ 2014/water-sanitation/en/.

9. Deligiannidis KE (2017) Primary care issues in rural populations. Prim Care Clin Off Pract. https://doi.org/10.1016/j.pop.2016.09. 003

10. The Hindu Business Line, "Indian Agriculture Census census estimates more than half of the farmers do not enroll themselves in Government Schemes." https://www.thehindubusinessline. com/economy/agri-business/how-many-farmers-are-there-inindia-government-has-no-clue/article30614882.ece.

11. Yadav VS, Singh AR (2019) Use of blockchain to solve select issues of Indian farmers. In: AIP Conf. Proc., vol. 2148, no. September, https://doi.org/10.1063/1.5123972

12. The World Bank, "The World Bank, World Development Indicators (WDI) and United Nations (1990:2016) reported 939.57 Million people without access to electricity." https://datacatalog. worldbank.org/dataset/world-development-indicators.

13. Global Findex Database, "Global Findex Database: The World Bank (2011:2017) estimates that 1.7 billion people worldwide are still unbanked." https://globalfindex.worldbank.org/.

14. Firpo J (2007) Banking the Unbanked. J Microfinance/ESR Rev 9(1): 3

15. Chun-Wei C, Eber B, Michael A, Saiph S (2019) Designing blockchain technology to transform rural communities. In CHI conference on human factors in computing systems

16. Shuldiner A, Kortuem G (2020) The smart village. IEEE Pervasive Comput 19(1):83-86. https://doi.org/10.1109/MPRV.2020. 2966338

17. Maja PW, Meyer J, Von Solms S (2020) Development of smart rural village indicators in line with industry 4.0. IEEE Access 8(152017):152017-152033. https://doi.org/10.1109/ACCESS. 2020.3017441

18. Commins P (2004) Poverty and social exclusion in rural areas: characteristics, processes and research issues. Sociol Rural 44(1):60-75. https://doi.org/10.1111/j.1467-9523.2004.00262.x

19. United Nations, "Sustainable Development Goals," [Online]. Available: https://sdgs.un.org/goals.

20. IFAD-Investing in rural people., "International Fund for agricultural Development- Projects for rural people.," International Fund for agricultural Development. https://www.ifad.org/en/ web/knowledge.

21. Institute of Electrical and Electronics Engineers, "IEEE Smart Village-Power a Village, Empower Community.” https://smart village.ieee.org/our-projects/.

22. Zinchuk T, Kutsmus N, Kovalchuk O, Charucka O (2018) Challenges of sustainable development of rural economy. Manag Theory Stud Rural Bus Infrastruct Dev 40(4):609-619. https:// doi.org/10.15544/mts.2018.53

23. Burja C, Burja V (2014) Sustainable development of rural areas: a challenge for Romania. Environ Eng Manag J 13(8):18611871. https://doi.org/10.30638/eemj.2014.205

24. Kalantari K, Fami HS, Asadi A, Qasemi I, Chubchian S (2008) Major challenges of iranian rural communities for achieving sustainable development. Am J Agric Biol Sci 3(4):724-728. https://doi.org/10.3844/ajabssp.2008.724.728

25. Nakamoto S (2008) Bitcoin: A Peer-to-Peer Electronic Cash System I Satoshi Nakamoto Institute

26. Drescher D (2017) Blockchain basics: a non-technical introduction in 25 steps.. Apress, Frankfurt-am-Mein. https://doi.org/10. 1007/978-1-4842-2604-9

27. Zheng Z, Xie S, Dai H, Chen X, Wang H (2017) An overview of blockchain technology: architecture, consensus, and future trends. In: Proc. - 2017 IEEE 6th Int. Congr. Big Data, BigData Congr. 2017, no. June, pp 557-564. https://doi.org/10.1109/ BigDataCongress.2017.85

28. Puthal D, Malik N, Mohanty SP, Kougianos E, Das G (2018) Everything you wanted to know about the blockchain: its promise, components, processes, and problems. IEEE Consum Electron Mag. https://doi.org/10.1109/MCE.2018.2816299

29. Buterin V (2014) A next-generation smart contract and decentralized application platform. white pap 3(37)

30. Swan M (2015) Blockchain: Blueprint for a new economy. O'Reilly Media, Inc.

31. TeutschJ, Reitwießner C (2019) A scalable verification solution for blockchains. arXiv

32. Hirai Y (2017) Defining the ethereum virtual machine for interactive theorem provers. In: Lect. Notes Comput. Sci. (including Subser. Lect. Notes Artif. Intell. Lect. Notes Bioinformatics), vol. 10323 LNCS, pp. 520-535. https://doi.org/10.1007/978-3319-70278-0_33.

33. Ethereum, Remix IDE. [Online]. Available: https://remix.ether eum.org/.

34. Cong LW, He Z (2019) Blockchain disruption and smart contracts. Rev Financ Stud 32(5):1754-1797. https://doi.org/10. 1093/rfs/hhz007

35. Solidity, "Solidity." https://docs.soliditylang.org/en/v0.8.7/.

36. Vyper, "Vyper." https://vyper.readthedocs.io/en/stable/.

37. Solidity YUL, "YUL." https://docs.soliditylang.org/en/v0.7.4/ yul.html.

38. Linux Foundation, "Hyperledger." hyperledger.org.

39. Golosova J, Romanovs A (2018) The advantages and disadvantages of the blockchain technology. In 2018 IEEE 6th workshop on advances in information, electronic and electrical engineering (AIEEE) (pp. 1-6). IEEE

40. Kandaswamy R, Furlonger D (2018) Blockchain-based transformation: A gartner trend insight report

41. Bell L, Buchanan WJ, Cameron J, Lo O (2018) Applications of blockchain within healthcare. Blockchain Healthc Today. https:// doi.org/10.30953/bhty.v1.8

42. Gatteschi V, Lamberti F, Demartini C, Pranteda C, Santamaría $\mathrm{V}$ (2018) Blockchain and smart contracts for insurance: is the technology mature enough? Futur Internet 10(2):8-13. https:// doi.org/10.3390/fi10020020

43. Zyskind G, Nathan O, Pentland AS (2015) Decentralizing privacy: using blockchain to protect personal data. In: Proc. - 2015 IEEE Secur. Priv. Work. SPW 2015, pp 180-184. https://doi.org/ 10.1109/SPW.2015.27

44. Wüst K, Gervais A (2017) Do you need a Blockchain?. IACR Cryptol. ePrint Arch., no. i, pp. 375, [Online]. Available: https:// eprint.iacr.org/2017/375.pdf.

45. Alammary A, Alhazmi S, Almasri M, Gillani S (2019) Blockchain-based applications in education: A systematic review. Appl Sci 9(12):2400

46. Nir K (2017) Can blockchain strengthen the internet of things? By: Nir Kshetri Kshetri, Nir (2017). Can blockchain strengthen the internet of things? IEEE IT Prof 19(4):68-72

47. Huh S, Cho S, Kim S (2017) Managing IoT devices using blockchain platform. In: Int. Conf. Adv. Commun. Technol. ICACT, pp 464-467. https://doi.org/10.23919/ICACT.2017.7890132 
48. Kitchenham B, Charters S (2007) Guidelines for performing systematic literature reviews in software engineering

49. Clark AG, Walkinshaw N, Hierons RM (2021) Test case generation for agent-based models: a systematic literature review. Inf Softw Technol 135:1-55. https://doi.org/10.1016/j.infsof.2021. 106567

50. Kaur S, Singh P (2019) How does object-oriented code refactoring influence software quality? Research landscape and challenges. J Syst Softw. https://doi.org/10.1016/j.jss.2019.110394

51. Tian F (2016) An agri-food supply chain traceability system for China based on RFID \& blockchain technology. In: 2016 13th Int. Conf. Serv. Syst. Serv. Manag. ICSSSM 2016. https://doi. org/10.1109/ICSSSM.2016.7538424

52. Enescu FM, Manuel Ionescu V (2020) Using Blockchain in the agri-food sector following SARS-CoV-2 pandemic. In: Proc. 12th Int. Conf. Electron. Comput. Artif. Intell. ECAI 2020. https://doi.org/10.1109/ECAI50035.2020.9223161

53. Shahid A, Almogren A, Javaid N, Al-Zahrani FA, Zuair M, Alam M (2020) Blockchain-based agri-food supply chain: a complete solution. IEEE Access 8:69230-69243. https://doi.org/10.1109/ ACCESS.2020.2986257

54. Kim M, Hilton B, Burks Z, Reyes J (2018) Integrating Blockchain, Smart Contract-Tokens, and IoT to Design a Food Traceability SolutionIn: In: 2018 IEEE 9th Annu. Inf. Technol. Electron. Mob. Commun. Conf., no. Figure 1, pp 335-340

55. Kamble SS, Gunasekaran A, Sharma R (2020) Modeling the blockchain enabled traceability in agriculture supply chain. Int $\mathrm{J}$ Inf Manag 52:1-16. https://doi.org/10.1016/j.ijinfomgt.2019.05. 023

56. Dong X, Zheng X, Lu X, Lin X (2019) A traceability method based on blockchain and internet of things. In: Proc. - 2019 IEEE Intl Conf Parallel Distrib. Process. with Appl. Big Data Cloud Comput. Sustain. Comput. Commun. Soc. Comput. Networking, ISPA/BDCloud/SustainCom/SocialCom 2019, pp 1511-1518. https://doi.org/10.1109/ISPA-BDCloud-SustainCom-Socia 1Com48970.2019.00219

57. Kumarathunga M (2020) Improving farmers' participation in agri supply chains with blockchain and smart contracts. In: 20207 th Int. Conf. Softw. Defin. Syst. SDS 2020, pp 139-144. https://doi. org/10.1109/SDS49854.2020.9143913

58. Casado-Vara R, Prieto J, De La Prieta F, Corchado JM (2018) How blockchain improves the supply chain: case study alimentary supply chain. Procedia Comput Sci 134:393-398. https:// doi.org/10.1016/j.procs.2018.07.193

59. Lin W et al (2020) Blockchain technology in current agricultural systems: from techniques to applications. IEEE Access 8:143920-143937. https://doi.org/10.1109/ACCESS.2020.30145 22

60. Kamilaris A, Fonts A, Prenafeta-Boldó FX (2019) The rise of blockchain technology in agriculture and food supply chains. arXiv, pp 1-33

61. Dutta P, Choi TM, Somani S, Butala R (2020) Blockchain technology in supply chain operations: applications, challenges and research opportunities. Transp Res Part E Logist Transp Rev 142:102067. https://doi.org/10.1016/j.tre.2020.102067

62. Musah S, Medeni TD, Soylu D (2019) Assessment of Role of Innovative Technology through Blockchain Technology in Ghana's Cocoa Beans Food Supply Chains. In: 3rd Int. Symp. Multidiscip. Stud. Innov. Technol. ISMSIT 2019 - Proc. https:// doi.org/10.1109/ISMSIT.2019.8932936

63. Lin J, Zhang A, Shen Z, Chai Y (2018) Blockchain and IoT based food traceability for smart agriculture. In: ACM Int. Conf. Proceeding Ser. pp 1-6, https://doi.org/10.1145/3126973.3126980

64. Thejaswini S, Ranjitha KR (2020) Blockchain in agriculture by using decentralized peer to peer networks. In 2020 fourth international conference on inventive systems and control (ICISC) (pp. 600-606). IEEE

65. Hua J, Wang X, Kang M, Wang H, Wang FY (2018) Blockchain based provenance for agricultural products: a distributed platform with duplicated and shared bookkeeping. In: IEEE Intell. Veh. Symp. Proc., vol. 2018-June, no. Iv, pp 97-101. https://doi. org/10.1109/IVS.2018.8500647

66. Salah K, Nizamuddin N, Jayaraman R, Omar M (2019) Blockchain-based soybean traceability in agricultural supply chain. IEEE Access 7:73295-73305. https://doi.org/10.1109/ACCESS. 2019.2918000

67. Yadav VS, Singh AR, Raut RD, Govindarajan UH (2020) Blockchain technology adoption barriers in the Indian agricultural supply chain: an integrated approach. Resour Conserv Recycl 161:104877. https://doi.org/10.1016/j.resconrec.2020.104877

68. Borah MD, Naik VB, Patgiri R, Bhargav A, Phukan B, Basani SG (2020) Supply chain management in agriculture using blockchain and IoT. In Advanced applications of blockchain technology (pp. 227-242). Springer, Singapore

69. Saurabh S, Dey K (2020) Blockchain technology adoption, architecture, and sustainable agri-food supply chains. J Clean Prod. https://doi.org/10.1016/j.jclepro.2020.124731

70. Caro MP, Ali MS, Vecchio M, Giaffreda R (2018) Blockchainbased traceability in Agri-Food supply chain management: a practical implementation In: 2018 IoT Vert. Top. Summit Agric. - Tuscany, IOT Tuscany 2018, pp 1-4. https://doi.org/10.1109/ IOT-TUSCANY.2018.8373021

71. Mirabelli G, Solina V (2020) Blockchain and agricultural supply chains traceability: research trends and future challenges. Procedia Manuf 42(2019):414-421. https://doi.org/10.1016/j.promfg. 2020.02.054

72. "BC and its potential app infood supply chain.pdf.".

73. Chun-Ting P, Meng-Ju L, Nen-Fu H, Jhong-Ting L, Jia-Jung S (2020) Agriculture blockchain service platform for farm-to-fork traceability with IoT sensors. In: Int. Conf. Inf. Netw., vol. 2020Janua, pp 158-163. https://doi.org/10.1109/ICOIN48656.2020. 9016535

74. Skender HP, Zaninović PA (2020) Perspectives of blockchain technology for sustainable supply chains. In integration of Information flow for greening supply chain management (pp. 77-92). Springer, Cham

75. Baralla G, Ibba S, Marchesi M, Tonelli R, Missineo S (2018) A blockchain based system to ensure transparency and reliability in food supply chain. In European conference on parallel processing (pp. 379-391). Springer, Cham

76. Ferrag MA, Shu L, Yang X, Derhab A, Maglaras L (2020) Security and privacy for green IoT-based agriculture: review, blockchain solutions, and challenges. IEEE Access 8:32031-32053. https://doi.org/10.1109/ACCESS.2020.2973178

77. Shahid A, Sarfraz U, Malik MW, Iftikhar MS, Jamal A, Javaid N (2020) Blockchain-Based Reputation System in Agri-Food Supply Chain. Adv Intell Syst Comput vol. 1151 AISC, no. February, pp 12-21. https://doi.org/10.1007/978-3-030-44041-1_2

78. Galvez JF, Mejuto JC, Simal-Gandara J (2018) Future challenges on the use of blockchain for food traceability analysis. TrAC Trends Anal Chem 107:222-232. https://doi.org/10.1016/j.trac. 2018.08.011

79. Awan SH, Nawaz A, Ahmed S, Khattak HA, Zaman K, Najam Z (2020) Blockchain based Smart Model for Agricultural Food Supply Chain. In: 2020 Int. Conf. UK-China Emerg. Technol. UCET 2020. https://doi.org/10.1109/UCET51115.2020.9205477

80. Xu J, Guo S, Xie D, Yan Y (2020) Blockchain: a new safeguard for agri-foods. Artif Intell Agric 4:153-161. https://doi.org/10. 1016/j.aiia.2020.08.002

81. Hegde B, Ravishankar B, Appaiah M (2020) Agricultural supply chain management using blockchain technology. In: 2020 Int. 
Conf. Mainstreaming Block Chain Implementation, ICOMBI 2020, pp 5-8 https://doi.org/10.23919/ICOMBI48604.2020. 9203259

82. Torky M, Hassanein AE (2020) Integrating blockchain and the internet of things in precision agriculture: analysis, opportunities, and challenges. Comput Electron Agric 178:105476. https://doi. org/10.1016/j.compag.2020.105476

83. Paul S, Joy JI, Sarker S, Shakib AAH, Ahmed S, Das AK (2019) An unorthodox way of farming without intermediaries through blockchain. In: 2019 Int. Conf. Sustain. Technol. Ind. 4.0, STI 2019, vol. 0, pp 24-25. https://doi.org/10.1109/STI47673.2019. 9068007

84. Iqbal R, Butt TA (2020) Safe farming as a service of blockchain-based supply chain management for improved transparency. Cluster Comput 23(3):2139-2150. https://doi.org/10.1007/ s10586-020-03092-4

85. Li J, Wang X (2018) Research on the Application of Blockchain in the Traceability System of Agricultural Products. In: Proc. 2018 2nd IEEE Adv. Inf. Manag. Commun. Electron. Autom. Control Conf. IMCEC 2018, no. Imcec, pp 2637-2640. https:// doi.org/10.1109/IMCEC.2018.8469456

86. Jaiswal A, Chandel S, Muzumdar A, Madhu GM, Modi C, Vyjayanthi C (2019) A conceptual framework for trustworthy and incentivized trading of food grains using distributed ledger and smart contracts. In: 2019 IEEE 16th India Counc. Int. Conf. INDICON 2019 - Symp. Proc., pp 1-4. https://doi.org/10.1109/ INDICON47234.2019.9030290

87. Dakshayini M, Balaji Prabhu BV (2020) An effective big data and blockchain (BD-BC) based decision support model for sustainable agriculture system. In: EAI/Springer Innovations in Communication and Computing

88. Saji AC, Vijayan A, Sundar AJ, Baby Syla L (2020) Permissioned blockchain-based agriculture network in rootnet protocol. https://doi.org/10.1007/978-981-15-0324-5_23

89. Peña M, Llivisaca J, Siguenza-Guzman L (2019) Blockchain and its potential applications in food supply chain management in Ecuador. In The international conference on advances in emerging trends and technologies (pp. 101-112). Springer, Cham

90. Chaudhari A, Vedak J, Vartak R, Sonar M (2020) Supply chain management for selling farm produce using blockchain. In International conference on information and communication technology for intelligent systems (pp. 367-375). Springer, Singapore

91. Xie C, Xiao X (2020) Traceability of agricultural product quality and safety based on blockchain-taking fresh e-commerce as an example. In International conference on applications and techniques in cyber security and intelligence (pp. 288-294). Springer, Cham

92. Li Y, Chu X, Tian D, Feng J, Mu W (2020). A traceability architecture for the fresh food supply chain based on blockchain technology in China. In International conference on artificial intelligence and security (pp. 347-358). Springer, Singapore

93. Flores L, Sanchez Y, Ramos E, Sotelo F, Hamoud N (2020) Blockchain in agribusiness supply chain management: A traceability perspective. In International conference on applied human factors and ergonomics (pp. 465-472). Springer, Cham

94. Fernandez A, Waghmare A, Tripathi S (2020) Agricultural Supply Chain Using Blockchain BT - Proceedings of International Conference on Intelligent Manufacturing and Automation pp 127-134

95. Cortez-Zaga C, Casas-Llamacponcca V, Shiguihara P (2018) Technological model for the exchange of goods in the Peruvian agricultural business sector using the smart contracts and Blockchain. In Brazilian Technology Symposium (pp. 585-593). Springer, Cham

96. Zhao $\mathrm{G}$ et al (2019) Blockchain technology in agri-food value chain management: a synthesis of applications, challenges and future research directions. Comput Ind 109:83-99. https://doi. org/10.1016/j.compind.2019.04.002

97. Bhorshetti H, Ghuge S, Kulkarni A, Bhingarkar S (2020) Land record maintenance using blockchain. In IC-BCT 2019 (pp. 205-214). Springer, Singapore

98. Thakur V, Doja MN, Dwivedi YK, Ahmad T, Khadanga G (2020) Land records on blockchain for implementation of land titling in India. Int J Inf Manag. https://doi.org/10.1016/j.ijinfomgt.2019. 04.013

99. Arshad J et al (2020) A novel remote user authentication scheme by using private blockchain-based secure access control for agriculture monitoring, International conference on engineering and emerging technologies (ICEET), 2020, pp. 1-9. https://doi.org/ 10.1109/ICEET48479.2020.9048218

100. Miloudi L, Rezeg K, Kazar O, Miloudi MK (2020) Smart sustainable farming management using integrated approach of IoT, blockchain \& geospatial technologies. Adv Intell Syst Comput vol. 1103 AISC, pp 340-347. https://doi.org/10.1007/978-3-03036664-3_38

101. Reddy GB, Kumar KR (2020) Quality improvement in organic food supply chain using blockchain technology. In Innovative product design and intelligent manufacturing systems (pp. 887896). Springer, Singapore

102. Tse D, Zhang B, Yang Y, Cheng C, Mu H (2018) Blockchain application in food supply information security. In: IEEE Int. Conf. Ind. Eng. Eng. Manag., vol. 2017-Decem, pp 1357-1361. https://doi.org/10.1109/IEEM.2017.8290114

103. Wu HT, Tsai CW (2019) An intelligent agriculture network security system based on private blockchains. J Commun Network 21(5):503-508

104. Basnayake BMAL, Rajapakse C (2019) A Blockchain-based decentralized system to ensure the transparency of organic food supply chain 103-107

105. Patil AS, Tama BA, Park Y, Rhee KH (2018) A framework for blockchain based secure smart green house farming. Lect Notes Electr Eng 474:1162-1167. https://doi.org/10.1007/978-981-107605-3_185

106. Umamaheswari S, Sreeram S, Kritika N, Prasanth DJ (2019) Biot: blockchain based IoT for agriculture. In 2019 11th International conference on advanced computing (ICoAC) (pp. 324 327). IEEE

107. Voutos Y, Drakopoulos G, Mylonas P (2019) Smart agriculture: An open field for smart contracts. In: 2019 4th South-East Eur. Des. Autom. Comput. Eng. Comput. Networks Soc. Media Conf. SEEDA-CECNSM 2019. https://doi.org/10.1109/SEEDA-CECNSM.2019.8908411

108. Devi MS, Suguna R, Joshi AS (2019) Bagate RA design of IoT blockchain based smart agriculture for enlightening safety and security, vol 985. Springer Singapore, Tamilnadu, India

109. Vangala A, Das AK, Kumar N, Alazab M (2020) Smart secure sensing for IoT-based agriculture: blockchain perspective. IEEE Sens J. https://doi.org/10.1109/jsen.2020.3012294

110. Branco F, Moreira F, Martins J, Au-Yong-Oliveira M, Gonçalves R (2019) Conceptual approach for an extension to a mushroom farm distributed process control system: IoT and blockchain. Adv Intell Syst Comput 930:738-747. https://doi.org/10.1007/978-3030-16181-1_69

111. Misra H, Das RK (2019) Citizen empowerment: block chain supported e-governance in dairy cooperative sector. In: ACM Int. Conf. Proceeding Ser., vol. Part F1481, pp 505-507. https://doi. org/10.1145/3326365.3326442

112. Rambim D, Awuor FM (2020) Blockchain based milk delivery platform for stallholder dairy farmers in Kenya: enforcing transparency and fair payment. In: 2020 IST-Africa Conf. IST-Africa 2020, pp 1-6 
113. Alonso RS, Sittón-Candanedo I, García Ó, Prieto J, RodríguezGonzález S (2020) An intelligent Edge-IoT platform for monitoring livestock and crops in a dairy farming scenario. Ad Hoc Netw. https://doi.org/10.1016/j.adhoc.2019.102047

114. Hang L, Ullah I, Kim DH (2020) A secure fish farm platform based on blockchain for agriculture data integrity. Comput Electron Agric 170:105251. https://doi.org/10.1016/j.compag.2020. 105251

115. Yang L, Liu XY, Kim JS (2020) Cloud-based Livestock Monitoring System Using RFID and Blockchain Technology. In: Proc. - 2020 7th IEEE Int. Conf. Cyber Secur. Cloud Comput. 2020 6th IEEE Int. Conf. Edge Comput. Scalable Cloud, CSCloudEdgeCom 2020, pp 240-245. https://doi.org/10.1109/CSCloudEdgeCom49738.2020.00049

116. Li X, Wang D, Li M (2020) Convenience analysis of sustainable E-agriculture based on blockchain technology. J Clean Prod 271:122503. https://doi.org/10.1016/j.jclepro.2020.122503

117. Song L, Wang X, Merveille N (2020) Research on Blockchain for Sustainable E-Agriculture. In: 2020 IEEE Technol. Eng. Manag. Conf. TEMSCON 2020, vol. 7, pp 14-18. https://doi. org/10.1109/TEMSCON47658.2020.9140121

118. Bore N, et al. (2020) AGWS: Blockchain-enabled Small-scale Farm Digitization. In: IEEE Int. Conf. Blockchain Cryptocurrency, ICBC 2020. https://doi.org/10.1109/ICBC48266.2020. 9169450

119. Osmanoglu M, Tugrul B, Dogantuna T, Bostanci E (2020) An effective yield estimation system based on blockchain technology. IEEE Trans Eng Manag 67(4):1157-1168. https://doi.org/ 10.1109/TEM.2020.2978829

120. Abraham A, Santosh Kumar MB (2020) A study on using private-permissioned blockchain for securely sharing farmers data. In: Proc. - 2020 Adv. Comput. Commun. Technol. High Perform. Appl. ACCTHPA 2020, pp 103-106. https://doi.org/10.1109/ ACCTHPA49271.2020.9213237

121. Talreja R, Chouksey R, Verma S (2020) A Study of Blockchain Technology in Farmer's Portal. In: Proc. 2nd Int. Conf. Inven. Res. Comput. Appl. ICIRCA 2020, pp 828-833. https://doi.org/ 10.1109/ICIRCA48905.2020.9182969

122. Topart L, Genestier P, Picaud Y (2020) Blockchain brings confidence to facilitate the flow of data in the agricultural field. In: 2020 2nd Conf. Blockchain Res. Appl. Innov. Networks Serv. BRAINS 2020, pp 51-52. https://doi.org/10.1109/BRAIN S49436.2020.9223315

123. Giaffreda R, Antonelli F, Spada P (2019) Promoting Sustainable Agricultural Practices Through Incentives. In: 2019 IEEE Int. Work. Metrol. Agric. For. MetroAgriFor 2019 - Proc., pp 242-246. https://doi.org/10.1109/MetroAgriFor.2019.8909281

124. Esmaeilian B, Sarkis J, Lewis K, Behdad S (2020) Blockchain for the future of sustainable supply chain management in Industry 4.0. Resour Conserv Recycl 163:105064. https://doi.org/10. 1016/j.resconrec.2020.105064

125. Lynch S (2018) OpenLitterMap.com—open data on plastic pollution with blockchain rewards (Littercoin). Open Geospatial Data Softw Stand. https://doi.org/10.1186/s40965-018-0050-y

126. Zhu L, Dong H, Shen M, Gai K (2019) An Incentive Mechanism Using Shapley Value for Blockchain-Based Medical Data Sharing. In: Proc. - 5th IEEE Int. Conf. Big Data Secur. Cloud, BigDataSecurity 2019, 5th IEEE Int. Conf. High Perform. Smart Comput. HPSC 2019 4th IEEE Int. Conf. Intell. Data Secur., pp 113-118. https://doi.org/10.1109/BigDataSecurity-HPSC-IDS. 2019.00030

127. Praba Devi GS, Miraclin Joyce Pamila JC (2019) Accident Alert System Application Using a Privacy-Preserving BlockchainBased Incentive Mechanism.In: 2019 5th Int. Conf. Adv. Comput. Commun. Syst. ICACCS 2019, pp 390-394. https://doi.org/ 10.1109/ICACCS.2019.8728507
128. Zhang D (2019) Application of blockchain technology in incentivizing efficient use of rural wastes : study on yitong system. Energy Procedia 158:6707-6714. https://doi.org/10.1016/j.egypro.2019.01.018

129. Verma S (2018) Applying blockchain technology to decentralized," no. April. pp 2-3, [Online]. Available: https://blogs. systweak.com/applying-blockchain-technology-to-waste-manag ement/.

130. Zou S, Xi J, Wang S, Lu Y, Xu G (2019) Reportcoin: a novel blockchain-based incentive anonymous reporting system. IEEE Access 7:65544-65559. https://doi.org/10.1109/ACCESS.2019. 2915956

131. Sharples M, Dominigue J (2016) The Blockchain and Kudos: a distributed system for educational record, reputation and reward. Springer, vol. 2, p 7. https://doi.org/10.1007/978-3-319-45153-4

132. Turkanović M, Hölbl M, Košič K, Heričko M, Kamišalić A (2018) EduCTX: a blockchain-based higher education credit platform. IEEE Access 6:5112-5127. https://doi.org/10.1109/ ACCESS.2018.2789929

133. Latif S, Rehman A, Zafar NA (2019) Blockchain and IoT based formal model of smart waste management system using TLA+. In: Proc. - 2019 Int. Conf. Front. Inf. Technol. FIT 2019, pp 304-309. https://doi.org/10.1109/FIT47737.2019.00064

134. Nguyen TQ, Das AK, Tran LT 2019) NEO Smart Contract for Drought-Based Insurance. In: 2019 IEEE Can. Conf. Electr. Comput. Eng. CCECE 2019. https://doi.org/10.1109/CCECE. 2019.8861573

135. Munir MS, Bajwa IS, Cheema SM (2019) An intelligent and secure smart watering system using fuzzy logic and blockchain. Comput Electr Eng, Elsevier, 77:109-119. https://doi.org/10. 1016/j.compeleceng.2019.05.006

136. Bordel B, Martin D, Alcarria R, Robles T A Blockchain-based Water Control System for the Automatic Management of Irrigation Communities. In: 2019 IEEE Int. Conf. Consum. Electron., pp 1-2

137. Dogo EM, Salami AF, Nwulu NI, Aigbavboa CO (2019) Blockchain and internet of things-based technologies for intelligent water management system. pp 129-150. https://doi.org/10.1007/ 978-3-030-04110-6 7

138. Hassija V, Saxena V, Chamola V (2020) A blockchain-based framework for drone-mounted base stations in tactile internet environment. In: IEEE INFOCOM 2020 - IEEE Conf. Comput. Commun. Work. INFOCOM WKSHPS 2020, pp 261-266. https://doi.org/10.1109/INFOCOMWKSHPS50562.2020.91629 91

139. Pincheira M, Vecchio M, Giaffreda R, Kanhere SS (2020) Exploiting constrained IoT devices in a trustless blockchainbased water management system. In: IEEE Int. Conf. Blockchain Cryptocurrency, ICBC 2020. https://doi.org/10.1109/ICBC4 8266.2020.9169404

140. Enescu FM, Bizon N, Stirbu C (2019) Smart Energy Grids used in irrigation systems using the blockchain applications. In: Proc. 11th Int. Conf. Electron. Comput. Artif. Intell. ECAI 2019, no. 4. https://doi.org/10.1109/ECAI46879.2019.9042044

141. Kulkarni V, Kulkarni K (2020) A blockchain-based smart grid model for rural electrification in India. In 2020 8th International conference on smart grid (icSmartGrid) (pp. 133-139). IEEE.

142. Levi-Oguike J, Sandoval D, Ntagwirumugara E (2019) Blockchain Technology and Renewable Energy Access: A Case for sub-Saharan Africa. In: 2019 IEEE 5th Int. Conf. Converg. Technol. I2CT 2019, pp 1-6. https://doi.org/10.1109/I2CT45611. 2019.9033952

143. Krajnakova E, Svazas M, Navickas V (2019) Biomass blockchain as a factor of energetical sustainability development. Entrep Sustain Issues 6(3):1456-1467. https://doi.org/10.9770/jesi.2019.6. $3(28)$ 
144. Kulkarni V, Kulkarni K (2020) A Blockchain-based Smart Grid Model for Rural Electrification in India. In: 8th Int. Conf. Smart Grid, icSmartGrid 2020, pp 133-139. https://doi.org/10.1109/ icSmartGrid49881.2020.9144898

145. Madumidha S, Ranjani PS, Vandhana U, Venmuhilan B (2019) A theoretical implementation: Agriculture-food supply chain management using blockchain technology. In 2019 TEQIP III Sponsored International Conference on Microwave Integrated Circuits, Photonics and Wireless Networks (IMICPW) (pp. 174-178). IEEE.

146. Baralla G, Pinna A, Corrias G (2019) Ensure traceability in european food supply chain by using a blockchain system. In: Proc. - 2019 IEEE/ACM 2nd Int. Work. Emerg. Trends Softw. Eng. Blockchain, WETSEB 2019, pp 40-47. https://doi.org/10.1109/ WETSEB.2019.00012

147. Leme L, Medeiros A, Srivastava G, Crichigno J, Filho R (2020) Secure cattle stock infrastructure for the internet of things using blockchain. In: 2020 43rd Int. Conf. Telecommun. Signal Process. TSP 2020, pp 337-341. https://doi.org/10.1109/TSP49548. 2020.9163494

148. França ASL, Amato Neto J, Gonçalves RF, Almeida CMVB (2020) Proposing the use of blockchain to improve the solid waste management in small municipalities. J Clean Prod. https:// doi.org/10.1016/j.jclepro.2019.118529

149. Ghatpande S, Ouattara H, Ahmat D, Sawadogo Z, Bissyandé TF (2018) Secure, transparent and uniform mobile money for internet-underserved areas using sporadically-synchronized blockchain. In International conference on e-Infrastructure and e-Services for developing countries (pp. 120-130). Springer, Cham

150. Hu Y, Manzoor A, Ekparinya P, Liyanage M, Thilakarathna K, Jourjon G, Seneviratne A (2019) Adelay-tolerant payment scheme based on the ethereum blockchain. IEEE Access, 7, 33159-33172

151. Guo C, Ma S, Wang H (2018) LOC: Poverty Alleviation Loan Management System based on Smart Contracts, pp 1527-1532. https://doi.org/10.1109/Cybermatics

152. Jain N, Agrawal T, Goyal P, Hassija V (2019) A BlockchainBased distributed network for Secure Credit Scoring, pp 306-312

153. Jaffer SA, Pandey S, Mehta R, Bhavathankar P (2020) Blockchain based direct benefit transfer system for subsidy delivery. In: 2020 Int. Conf. Emerg. Technol. INCET 2020, pp 1-6. https:// doi.org/10.1109/INCET49848.2020.9154178

154. Kumar P, Sangal AL (2020) Blockchain-Based Chit Fund System: A Financial Inclusion Tool. In: Proc. - Int. Conf. Smart Electron. Commun. ICOSEC 2020, no. Icosec, pp 658-666. https://doi.org/10.1109/ICOSEC49089.2020.9215352

155. Tripathi G, Ahad MA, Paiva S (2020) S2HS- A blockchain based approach for smart healthcare system. Healthcare 8(1):100391. https://doi.org/10.1016/j.hjdsi.2019.100391

156. Jain P, Anand A, Saria M, Kumari R, Bothra P, Sultana M (2020) A Prototype Proposal for AI based Smart Integrated Platform for Doctors and Patients. In: ICRITO 2020 - IEEE 8th Int. Conf. Reliab. Infocom Technol. Optim. (Trends Futur. Dir., pp 9981003. https://doi.org/10.1109/ICRITO48877.2020.9197871

157. Kaur H, Alam MA, Jameel R, Mourya AK, Chang V (2018) A proposed solution and future direction for blockchain-based heterogeneous medicare data in cloud environment. J Med Syst 42(8):1-14. https://doi.org/10.1007/s10916-018-1007-5

158. Zhang P, White J, Schmidt DC, Lenz G, Rosenbloom ST (2018) FHIRChain: applying blockchain to securely and scalably share clinical data. Comput Struct Biotechnol J 16:267-278. https:// doi.org/10.1016/j.csbj.2018.07.004

159. Yong B, Shen J, Liu X, Li F, Chen H, Zhou Q (2020) An intelligent blockchain-based system for safe vaccine supply and supervision. Int J Inf Manag. https://doi.org/10.1016/j.ijinfomgt. 2019.10.009

160. Nusrat SA, Ferdous J, Ajmat SB, Ali A, Sorwar G (2019) Telemedicine System Design using Blockchain in Bangladesh. In: 2019 IEEE Asia-Pacific Conf. Comput. Sci. Data Eng. CSDE 2019. https://doi.org/10.1109/CSDE48274.2019.9162401

161. Guo R, Shi H, Zheng D, Jing C, Zhuang C, Wang Z (2019) Flexible and efficient blockchain-based ABE scheme with multiauthority for medical on demand in telemedicine system. IEEE Access 7:88012-88025. https://doi.org/10.1109/ACCESS.2019. 2925625

162. Vyas S, Gupta M, Yadav R (2019) Converging Blockchain and Machine Learning for Healthcare. In: Proc. - 2019 Amity Int. Conf. Artif. Intell. AICAI 2019, pp 709-711. https://doi.org/10. 1109/AICAI.2019.8701230

163. Pinna A, Ibba S (2018) A blockchain-based decentralized system for proper handling of temporary employment contracts. In Science and information conference (pp. 1231-1243). Springer, Cham

164. Hrishikesh M, Mayur S, Sidnag HL, Ravishankar B, Shailaja VN (2020) Design of blockchain aggregator for benefit of rural workers using IE techniques. In 2020 International conference on mainstreaming block chain implementation (ICOMBI) (pp. 1-7). IEEE

165. Liu W, Shao XF, Wu CH, Qiao P (2021) A systematic literature review on applications of information and communication technologies and blockchain technologies for precision agriculture development. J Clean Prod. https://doi.org/10.1016/j.jclepro. 2021.126763

166. Andoni $\mathrm{M}$ et al (2019) Blockchain technology in the energy sector: a systematic review of challenges and opportunities. Renew Sustain Energy Rev 100:143-174. https://doi.org/10.1016/j.rser. 2018.10.014

167. Bermeo-Almeida O, Cardenas-Rodriguez M, Samaniego-Cobo T, Ferruzola-Gómez E, Cabezas-Cabezas R, Bazán-Vera W (2018) Blockchain in agriculture: A systematic literature review. In International Conference on Technologies and Innovation (pp. 44-56). Springer, Cham

168. Bodkhe U et al (2020) Blockchain for industry 4.0: a comprehensive review. IEEE Access 8:79764-79800. https://doi.org/10. 1109/ACCESS.2020.2988579

169. Alladi T, Chamola V, Parizi RM, Choo KKR (2019) Blockchain applications for industry 4.0 and industrial IoT: a review. IEEE Access 7:176935-176951. https://doi.org/10.1109/ACCESS. 2019.2956748

170. Bermeo-Almeida O, Cardenas-Rodriguez M, Samaniego-Cobo T, Ferruzola-Gómez E, Cabezas-Cabezas R, Bazán-Vera W (2018) Blockchain in agriculture: a systematic literature review. Commun Comput Inf Sci 883:44-56. https://doi.org/10.1007/ 978-3-030-00940-3_4

171. Chinnaiyan R, Balachandar S (2020) Reliable administration framework of drones and IoT sensors in agriculture farmstead using blockchain and smart contracts. In Proceedings of the 2020 2nd International conference on big data engineering and technology (pp. 106-111)

172. Zhang S, Wang L, Wang L (2020) Research on crowdsourcing mode of internet+ rural logistics based on blockchain. In Proceedings of the 4 th international conference on computer science and application engineering (pp. 1-5)

Publisher's Note Springer Nature remains neutral with regard to jurisdictional claims in published maps and institutional affiliations. 